ASSESSMENT OF THE MICROBIOME ASSOCIATED

WITH ENDANGERED ORCHIDS

\author{
A Dissertation \\ presented to \\ the Faculty of the Graduate School \\ at the University of Missouri-Columbia
}

In Partial Fulfillment

of the Requirements for the Degree

Doctor of Philosophy

by

ANDREA RAVELO

Dr. J. Chris Pires, Dissertation Supervisor

JULY 2018 
The undersigned, appointed by the dean of the Graduate School, have examined the dissertation entitled

\section{ASSESSMENT OF THE MICROBIOME ASSOCIATED WITH ENDANGERED ORCHIDS}

presented by Andrea Ravelo, a candidate for the degree of doctor of philosophy, and hereby certify that, in their opinion, it is worthy of acceptance.

Professor Chris Pires

Professor Lori Eggert

Professor Pam Brown

Professor Gavin Conant 


\section{ACKNOWLEDGEMENTS}

I would like to thank my advisor, Dr. J. Chris Pires, for his encouragement and willingness to allow me to approach a research topic that I found interesting despite it being outside the traditional topics of the lab.

I would also like to thank my committee members, Dr. Gavin Conant, Dr. Pamela Brown

and Dr. Lori Eggert for their unwavering support and thoughtful revisions to this dissertation. Finally, all of the members of the Pires lab were fundamental in providing ongoing feedback and camaraderie. My time at Mizzou would not have been nearly as wonderful without them. 


\section{TABLE OF CONTENTS}

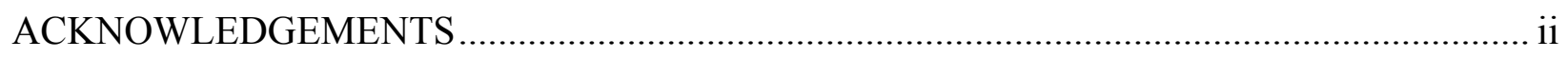

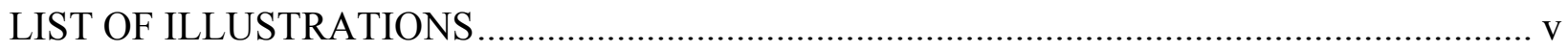

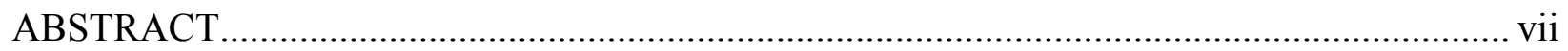

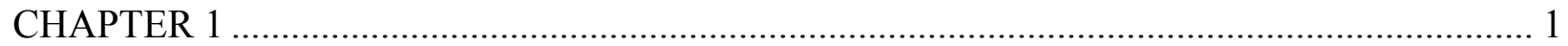

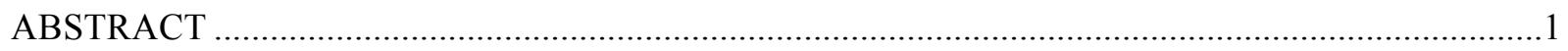

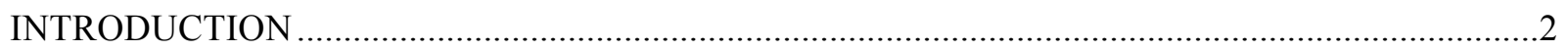

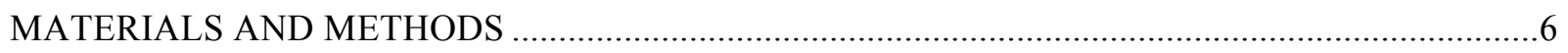

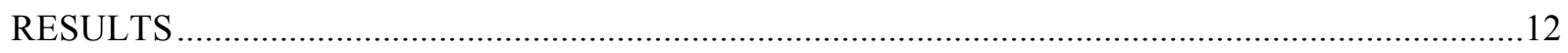

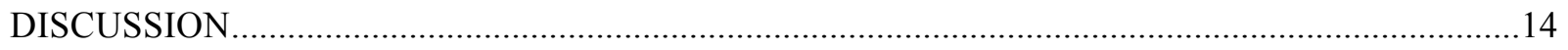

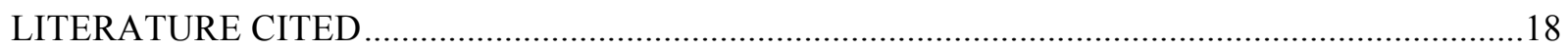

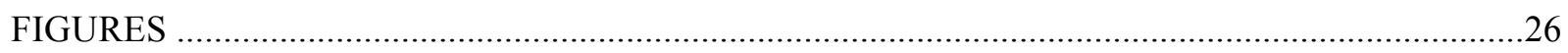

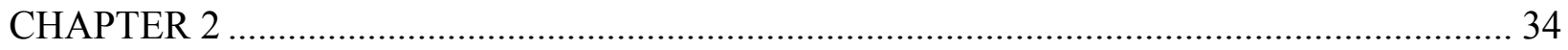

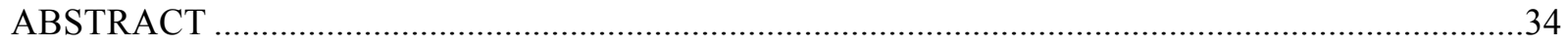

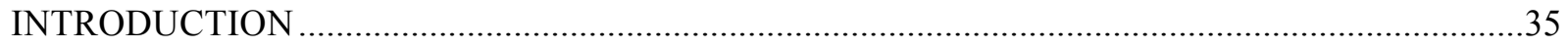

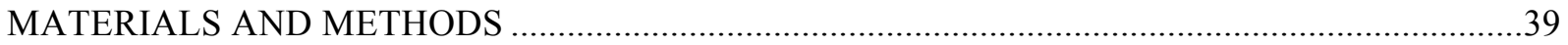

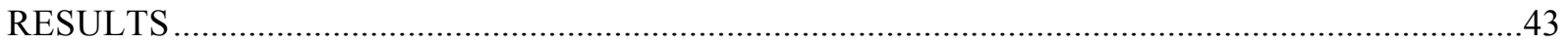

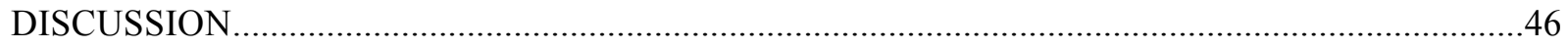

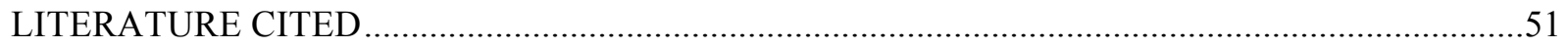

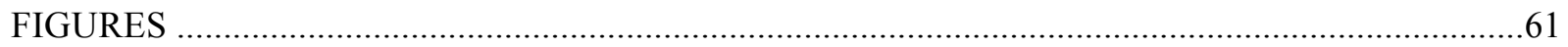

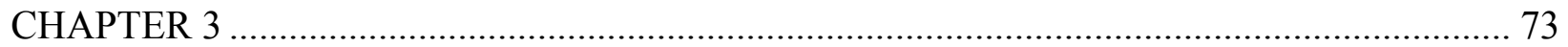

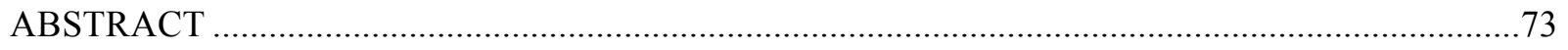

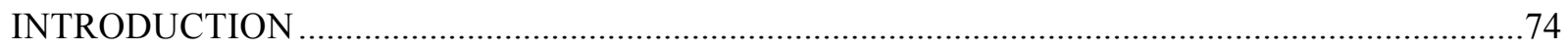


MATERIALS AND METHODS

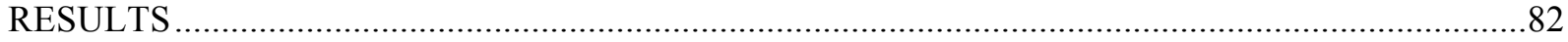

DISCUSSION

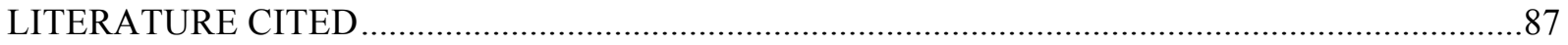

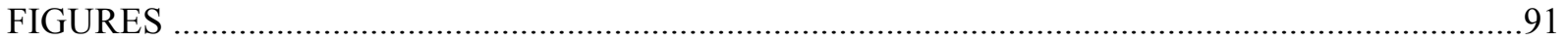

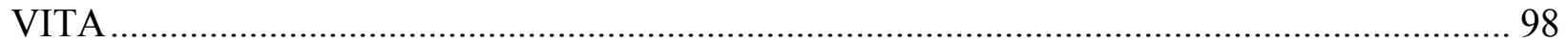




\section{LIST OF ILLUSTRATIONS}

FIGURE

1. Map of Area of Study in Northwest Missouri 26

2. Taxonomic Composition at Phylum Level 27

3. Alpha Diversity Metrics 28

4. Pairwise Comparison of Alpha Diversity Metrics 29

5. PCoA of Sampling Locations 30

6. PCoA of Sampling Distances 31

7. Venn Diagram of OTUs in Core Microbiome 32

8. Linear Discriminant Analysis using LefSe Algorithm 33

9. Taxonomic Composition of Samples at Domain Level 61

10. Taxonomic Composition of Samples by Phylum (Bacteria) 62

11. Taxonomic Composition of Samples by Phylum (Eukaryota) 63

12. Taxonomic Composition of Samples by Class (Basidiomycota) 64

13. Taxonomic Composition of Samples by Order (Agaricomycetes) 65

14. Comparison of Bacteria Families between Site "P" and All Others 66

15. Bacteria Genera Comparison between Sites "S" and "LT" 67

16. Comparison of Functional Profiles between Site "P" and All Others 68

17. Comparison of Functional Profiles between Sites "S" and "LT" 69

18. Sequencing Information for 15 Metagenomes $\quad 70$

19. Comparison of Low Reads 71

20. Non-normalized Taxonomic Composition 71

21. Alpha Rarefaction Curves $\quad 72$ 


\section{LIST OF ILLUSTRATIONS}

FIGURE

PAGE

22. Platanthera ciliaris Plants and Stereoscope Image of Seeds

91

23. Seed Germination and Protocorm Stages

92

24. Means of Germination Stages at 30 Days

93

25. Means of Germination Stages at 45 Days

94

26. Normalized Mean of Germination Stages by Seed Batch

95

27. One-Way ANOVA by Bacteria Culture

96

28. One-Way ANOVA by Seed Batch

97 


\title{
ASSESSMENT OF THE MICROBIOME ASSOCIATED WITH ENDANGERED ORCHIDS
}

\author{
Andrea Ravelo
}

Dr. J. Chris Pires, Dissertation Supervisor

\begin{abstract}
The Orchidaceae (orchid family) is perhaps the most speciose group of flowering plants with approximately 25,000 described species and many thousands of hybrids. All orchids share a dependency on fungal symbionts to facilitate seed germination. Orchid mycorrhizal fungi invade the embryo in the seed and form a mass of orchid and fungal tissue called a protocorm. While they impact a fundamental aspect of the orchid life cycle, orchid mycorrhizae form just part of a microbial community that interacts with the plant. Considering the importance of the relationship between mycorrhizal fungi and orchids, it is relevant to obtain a broader picture of the microbiome that is also associated with these plants and of which very little is known. We studied the soil microbiome associated with two species of endangered prairie orchids, Platanthera praeclara and P. leucophaea. A major motivation for our work is the concern that the gaps in our understanding of orchid microbiomes might have important consequences when decisions are made in the management of species of conservation concern.
\end{abstract}




\title{
CHAPTER 1
}

\section{Assessment of the Bacterial Community Associated with Two Endangered Orchids}

\begin{abstract}
The Orchidaceae (orchid family) is perhaps the most speciose group of flowering plants with approximately 25,000 described species and many thousands of hybrids. While certain mycorrhizal fungi are required for orchids to germinate, these mycorrhizae form just part of a microbial community that interacts with the plant. In this study, we sought a broader picture of the microbiome associated with these plants. A major motivation for our work is the concern that the gaps in our understanding of orchid microbiomes might have important consequences when decisions are made in the management of species of conservation concern. Because of the complexity of their symbiotic interactions, orchids are particularly at risk when faced with habitat loss or the potential effects of climate change. We studied two species of endangered terrestrial orchids in Missouri and, using DNA collected from soil and high throughput sequencing, evaluated the bacterial microbiome associated with these two orchid species.
\end{abstract}




\section{INTRODUCTION}

The impact that microbial communities have on plants has been studied extensively in various contexts ranging from the cellular (Delaux, Séjalon-Delmas, Bécard, \& Ané, 2013; Genre, Chabaud, Timmers, Bonfante, \& Barker, 2005; Glick, 2012) to the ecological (Barea, Pozo, Azcón, \& Azcón-Aguilar, 2013; Fierer et al., 2013; Redford, Bowers, Knight, Linhart, \& Fierer, 2010). The importance of their influence for plant development, growth and population establishment is no longer in question. The details regarding the nature of these interactions are still unclear in many cases; however, the advent of various new technologies allows us to address many previously unanswered questions (Jones, 2013; Knief, 2014).

In regards to the community aspect of microbial influence, technologies such as high throughput sequencing and advances in metagenomic pipelines have opened up new avenues to explore the relationships between these communities and plants (Di Bella, Bao, Gloor, Burton, \& Reid, 2013). We are now able to find and identify so many more types of bacteria and fungi that a major limiting factor is the requirement for improved databases incorporating all of the newly discovered taxa (McDonald et al., 2012;

Santamaria et al., 2012).

Just as microorganisms are known for their diversity of forms and functions, in similar fashion, plants are also known to be a diverse and complex group. Their interactions with the surrounding microbiota will vary and can be species-specific (Andreote, Gumiere, \& Durrer, 2014; Hassani, Durán, \& Hacquard, 2018; Schlaeppi \& Bulgarelli, 2015). Taking into consideration the specific characteristics of a plant taxon and its microbial entourage can help establish patterns of association and impact. Therefore, in this study, we are 
interested in the particular relationships that exist between orchids and associated microorganisms(Harris, 2009; Lebeis, 2014; Zarraonaindia et al., 2015).

The Orchidaceae (orchid family) is perhaps the most speciose group of flowering plants with approximately 25,000 described species and many thousands of hybrids (Givnish et al., 2015; Swarts \& Dixon, 2009). This diversity is mirrored in their ability to live in a wide variety of environments, as their habitats can range from the tropics to extreme northern and southern latitudes and the plants can adopt terrestrial, epiphytic or even lithophytic life habits (Fay, 2010).

All orchids share a dependency on fungal symbionts to facilitate seed germination (Dearnaley, 2007) (Smith \& Read, 2008). As the orchid further develops and is able to photosynthesize, the extent and characteristics of the association between the plant and the various fungi it associates with becomes less clear and is a topic of ongoing study (Cameron, Leake, \& Read, 2006; Rasmussen, Dixon, Jersáková, \& Těšitelová, 2015; Stöckel, Těšitelová, Jersáková, Bidartondo, \& Gebauer, 2014)

The presence of these fungi is therefore a fundamental necessity for orchids to complete their life cycle. Several studies have posited that the distribution and abundance of orchids is connected to the presence or absence of their mycorrhizal symbiont (Bailarote, Lievens, \& Jacquemyn, 2012; Jacquemyn, Brys, Lievens, \& Wiegand, 2012; Phillips, Barrett, Dixon, \& Hopper, 2011). Orchids have shown varying levels of specificity in the selection of their mycorrhizal partner, with some associating with only a few species of fungi while others are less selective (Jacquemyn et al., 2014; Pandey, Sharma, Taylor, \& Yadon, 2013). There is no definitive answer as to how much influence the fungal partner ultimately has on an orchid population (Bonnardeaux et al., 2007; Dearnaley, 2007); 
however, the importance of the presence of the requisite symbiont is clear.

Although mycorrhizae are fundamental in the life cycle of orchids, they are not the only relationship in which the orchids participate. Instead, they form part of a microbial community that interacts with the plants and also with other microbes. This network of interactions can affect different biological processes and needs to be taken into consideration in the same way that abiotic factors, such as precipitation and temperature, are known to influence plant growth and development (Andreote et al., 2014; Philippot, Raaijmakers, Lemanceau, \& van der Putten, 2013).

A relevant example of the interaction of myccorhizae and bacteria is the presence of Mycorrhizal Helper Bacteria (MHB), which facilitate the establishment of mycorrhizae on plant roots (Garbaye, 1994). This association is widespread and may have crucial implications in the proper functioning of entire ecosystems (Artursson, Finlay, \& Jansson, 2006; De Boer, Folman, Summerbell, \& Boddy, 2005; Frey-Klett, Garbaye, \& Tarkka, 2007). This new outlook on the dynamics of plant- mycorhizae- bacteria interactions has led to considering these associations as true tripartite relationships (Bonfante \& Anca, 2009; Deveau \& Labbé, 2016). It is also known that not only do plants interact with the microbiota of their immediate surroundings but these microorganisms also affect each other, forming a complex web of interactions and feedback loops (Andreote et al., 2014; Bakker, Schlatter, Otto-Hanson, \& Kinkel, 2014; Lou et al., 2014).

Considering the importance of the relationship between mycorrhizal fungi and orchids, it is relevant to obtain a broader picture of the microbiome that is also associated with these plants and of which very little is known (Tsavkelova, Cherdyntseva, Lobakova, 
Kolomeitseva, \& Netrusov, 2001.). This gap in understanding might have important consequences when decisions are made in the management of species of conservation concern. Furthermore, because of the complexity of their symbiotic interactions, orchids are particularly at risk when faced with habitat loss or the potential effects of climate change (Bailarote et al., 2012; Swarts, Sinclair, Francis, \& Dixon, 2010) as these could have a compound effect if they differentially impact each symbiont. For this study, we considered the following questions: Is there a specific assemblage of bacterial species that appears to associate with orchids and the locations where they are found? Does the proximity of an orchid modify the bacterial microbiome? Can bacterial community composition be used as an indicator of orchid habitat quality? To answer these questions, we combined the high resolution provided by direct DNA collection methods and current sequencing technologies with traditional ecological sampling and observations.

One pair of sister species of orchids in the Platanthera genus, P. leucophaea (eastern prairie fringed orchid) and P. praeclara (western prairie fringed orchid), has suffered a great reduction in available habitat with the conversion of the North American prairie to farmland. Historically found throughout a great portion of the continent, their populations are now often confined to small remnants of pristine grassland (Hapeman \& Inoue, 1997; C. J. Sheviak \& Bowles, 1986). Efforts have been made to protect the remaining populations by placing them on state and federal lists of threatened species (U.S. Fish and Wildlife Service, 1996, 2001). Several studies have focused on elucidating the environmental factors that most impact their survival and determining their potential 
fungal symbionts (Bowles, Zettler, Bell, \& Kelsey, 2005; Knudson, VanLooy, \& Hill, 2015; Sieg \& King, 1995).

A primary goal of this study was to characterize the bacterial components of the soil microbial community associated with $P$. leucophaea and $P$. praeclara. We aimed to describe the bacterial microbiome at different positions of proximity to individuals of these two species. We also sought to assess the microbial communities present at the different locations across the northern part of Missouri within their native range to help establish a baseline understanding of the soil microbiota of these grasslands and prairies. An ancillary objective of this study was to compare the sites with established orchid populations with a site that contains high-quality prairie that has all the characteristics of a potential habitat but, despite close monitoring, has never been known to have populations of these orchids.

\section{MATERIALS AND METHODS}

\section{Study species}

The Platanthera genus is primarily found in the northern hemisphere with the majority of its 200 species located in North America and East Asia. They are terrestrial orchids predominantly found in temperate region and grow in a great diversity of habitats, from forest to prairie and bogs to savannas (Hapeman \& Inoue, 1997).

The sister species Platanthera praeclara and P. leucophaea were historically found throughout the prairies of North America (C. J. Sheviak \& Bowles, 1986; Wallace, 2003). With the cultivation and fragmentation of the tallgrass prairies, their populations have 
declined and both species are currently federally listed as threatened (U.S. Fish and Wildlife Service, 1996, 2001, 2009).

There are a few remaining large populations for each species, such as those in the Sheyenne National Grassland in North Dakota (P. praeclara) and southeast counties of Wisconsin (P. leucophaea). Most other populations are small (fewer than 100 individuals) (U.S. Fish and Wildlife Service, 2001) and only a portion exist on protected lands.

\section{Study area}

In the northwest portion of the state of Missouri, there are three known populations of $P$. praeclara (sample sites "LT", "T" and "H”) (Figure 1). The Missouri Department of Conservation (MDC) has been surveying the Missouri populations of $P$. praeclara for nearly 20 years. During this time, they have recorded the total number of individuals, total number of flowering individuals and other metrics. For some of those years, they also obtained locality data for the individuals they found. More recently, they started to monitor a population of $P$. leucophaea (sample sites "S" and "NE") that was discovered in 2009 (McKenzie, 2012) (Figure 1). This species had not been observed in the state since 1951.

\section{Sampling}

Sampling took place in 2014 during the flowering season of the orchids (July) to facilitate finding individuals in the tall vegetation of the prairies. The soil collection strategy included obtaining one composite soil sample close to an orchid $(0.25 \mathrm{~m})$ at 4 different sites ("NE", "S", "T" and "LT"); 3 samples at a distance of at least $5 \mathrm{~m}$ or more away from the orchid for two of those sites ("NE" and "LT"). These were chosen at random 
using a grid and random number generator. We selected one orchid site ("NE") to do a more intensive sampling effort with soil taken at $0.25 \mathrm{~m}$ intervals from the orchid until $1 \mathrm{~m}$ and then again at $2 \mathrm{~m}$.

Soil cores were collected using a soil probe to $15 \mathrm{~cm}$ deep, forming a circle around the plant. A total of 5 to 8 cores were taken for each sample and then combined into one composite sample. The probes were cleaned with distilled water and then sanitized with $75 \%$ EtOH between samples. These samples were placed in a cooler with ice while in the field and then frozen that same day. Long-term storage was at -20C.

A total of 24 samples were collected: 4 samples at $0.25 \mathrm{~cm}$ away from different orchids (one for each site: "S", "NE", “T” and "LT") which were labeled "near" for comparative analyses; 8 samples at distances of $5 \mathrm{~m}$ or more from an orchid ( 3 for site "NE", 3 for site "LT" and 1 each for sites "T" and "S") which were labeled "far"; 4 samples at successively longer distances from the orchid at site "NE" $(0.5,0.75,1$ and $2 \mathrm{~m})$ which were labeled "intermediate"; 2 samples at $1 \mathrm{~m}$ (1 for site "LT" and 1 for "T") also labeled "intermediate"; 3 from a site that historically had orchids but where none were visible that season (site "H") labeled "no orchids" and finally, 3 from a high-quality prairie that has never had any populations of the orchids (site "P") labeled "no orchids ever".

\section{DNA extraction}

Processing for DNA extraction included homogenization and subsampling by way of a $2 \mathrm{~mm}$ sieve. The subsample of each bag was placed in a sterile $30-\mathrm{ml}$ falcon tube for longterm storage, after which we used the Powerlyzer Powersoil DNA extraction kit (MoBio, Carlsbad, CA) following the manufacturer's protocol for the actual extraction. This 
treatment included a bead-beating step with speeds ranging from $4.85 \mathrm{~m} / \mathrm{s}$ to $6.45 \mathrm{~m} / \mathrm{s}$ depending on the clay content of the soil.

\section{PCR and Sequencing}

Libraries for amplicon sequencing were prepared by the University of Missouri's DNA core. The V4 hypervariable region of the bacterial 16S rRNA gene was amplified using Illumina primers specific to this region (J Gregory Caporaso et al., 2011). This primer choice was used to target bacteria and archaea. The samples were then multiplexed and run on one lane of an Illumina MiSeq, resulting in 2x250 base pair, paired reads generating $\sim 15 \mathrm{M}$ reads with $91 \%$ passing filter.

\section{Bioinformatic processing}

Paired ends were merged using Pandaseq (Masella, Bartram, Truszkowski, Brown, \& Neufeld, 2012) and the QIIME software package v.1.8.0 (J Gregory Caporaso et al., 2010) was used to analyze the diversity of the microbial communities. Sequences were clustered into OTUs (Operational Taxonomic Units) using CD-HIT (Fu, Niu, Zhu, Wu, \& $\mathrm{Li}, 2012$ ) at a $97 \%$ sequence identity level. Representative sequences were selected using the default method of picking the first sequence of each OTU cluster. These sequences were then aligned to the Greengenes 13_5 database using PyNAST (J. G. Caporaso et al., 2010; DeSantis et al., 2006). The resulting aligned OTU sequences were then used to produce a phylogenetic tree with FastTree (Price, Dehal, \& Arkin, 2009). After OTU assignment, those reads that returned "no blast hits" were filtered and removed. Subsampling was conducted to ensure even sequencing depths across samples, selecting the minimum number of sequences in a sample as our subsampling depth, which was 54,631 sequence read pairs. 
An OTU table was created in QIIME and then used to graph the relative abundances of taxa for each sample. We determined the five most abundant taxa at the phylum level for each sample, and these were compared across all samples.

\section{Alpha Diversity}

To analyze the alpha diversity of the samples, the following metrics were calculated with QIIME: chao1, observed species (OTU number), and the Shannon Index. These metrics represent different estimates of species richness and evenness regarding diversity across samples. The chaol alpha diversity metric takes into account the number of rare (singleton) OTUs and then estimates the true species richness for a sample. This value is typically larger than that of observed OTUs. The "Observed OTUs" metric indicates the number of unique taxonomic units identified using, in this case, a 97\% identity cutoff for OTU membership. The Shannon Diversity Index accounts for both richness and evenness with values that range from 0 to infinity. The closer the index is to 0 , it indicates less diversity as well as less evenness (a value of 0 signifies that only one taxon is present). With the Shannon Index, the larger the value, the greater the diversity of the sample.

\section{Beta diversity}

Measures of beta diversity compare the communities among different samples. Communities were compared based on their location (site) as well as their distance from an orchid (if applicable). First, we compared estimates for chao1, observed OTU abundance, and Shannon Diversity Index values between each pairwise set of sampling locations using one-way ANOVA followed by a post-hoc Tukey test in package multcomp R v. 3.3.1 (R Development Core Team 2016)(Hothorn, Bretz, \& Westfall, 2008) (Table 1). We then calculated Bray-Curtis dissimilarity matrices for all OTU 
abundances to perform a Principal Coordinate Analysis ( $\mathrm{PCoA})$ in $\mathrm{R}$ with package vegan (Oksanen et al., 2013).

To test for statistical differences between our covariates of interest resulting from PCoA (Figures 4 and 5) Permutational Multivariate Analysis of Variance (PERMANOVA) (Anderson, 2001) and Analysis of Similarity (ANOSIM) (CLARKE, 1993) were conducted at 9999 permutations based on Bray-Curtis distances and p-values were assessed among sampling location as well as proximity of sample to its host orchid. PERMANOVA and ANOSIM are slightly different in their inference; while PERMANOVA more strictly assesses the statistical difference between the centroids of separate groups, ANOSIM evaluates the degree to which different groups cluster tightly together with respect to all other groups. However, both methods are known to be robust for analyzing community composition with balanced sampling designs (Anderson \& Walsh, 2013).

\section{Core Microbiome}

To understand the similarity and differences of OTUs across locations and distances to the orchids, the core microbiome was calculated by selecting only the OTUs that were present in majority of the samples. This subset of OTUs comprises the core microbiome of all the samples collected. To determine the core bacterial microbiome for all the samples, we ran the compute_core_microbiome.py script in QIIME and determined a threshold of OTUs that were present in $90 \%$ of samples as the core microbiome. A Venn diagram was used compare the specific OTUs present at distances both near and far from an orchid as well as those that are unique to a specific distance, either near or far to the orchids. 
The linear discriminant analysis effect size (LEfSe) algorithm (Segata et al., 2011) was used to test for significant differences in core OTU relative abundance across samples based on location as well as distance to orchids. LEfSe determines the features, be it organisms, OTUs or genes, most likely to explain differences between classes. A linear discriminant analysis (LDA) score was calculated for OTUs that were found to be differentially abundant for each location and therefore can be considered biomarkers for that specific location.

\section{RESULTS}

\section{Taxonomic composition of bacterial communities at orchid sites}

The taxonomic composition of the bacterial communities is shown in Figure 2. In the figure we highlight samples from sites that have had orchids present during the sampling season or in the past (sites "LT", "NE", "T", "S", "H") versus the site that has never had these species of orchids ("P"). We also distinguish between samples taken close to the plant (Near) versus those from $5 \mathrm{~m}$ or more (Far).

The bacterial phyla that showed the highest relative abundance across all sites were: Verrucomicrobia (29.9\%), Proteobacteria (27.9\%), Actinobacteria (15.2\%) Acidobacteria (10.3\%), Chloroflexi (4.8\%) and Planctomycetes (3.8\%). The remaining 56 phyla of Bacteria and Archaea found in the samples had total relative values of $1.8 \%$ or less each. One site ("S") showed substantially less relative abundance of Verrucomicrobia (7.1\%) than all of the other sites.

Analyzing differences between sites at lower taxonomic levels, one site which has orchids present ("T") showed to have a much higher proportion of the order Bacillales (phylum Firmicutes) with relative abundances ranging from $4.1 \%$ to $10.3 \%$ across its 
samples versus the average abundance across all sites of $1.5 \%$. Further analysis using the LEfSe algorithm shows this taxa to be a significant biomarker for this site (Figure 6).

\section{Alpha diversity metrics}

Diversity metrics that considered the richness (Observed OTUs and Chao1) as well as evenness (Shannon Index) of each site are found in Figure 3. The site with the highest richness is the location where these two orchid species have never been observed (site "P”). When considering evenness, one site ("S") stood out as having a much more even diversity than any of the other sites in the study. The other locations had comparable metrics; however, one of the sites ("T") had both lower richness and evenness metrics than any of the other sites.

To test for statistical significance across sites, we used a one-way ANOVA with its

results shown in Table 1. Site comparisons that did not have any significant differences were omitted from the table. Two of the pairwise comparisons between sites were statistically significant across all three metrics ("T" vs. "NE" and "T" vs. "P"). Of all the diversity metrics, the Shannon Index showed the greatest variation across sites with eight out of the fifteen comparisons being significant.

\section{Beta Diversity}

To analyze the differences across sites and between samples taken at varying distances to the orchids, we conducted a Principal Coordinates Analysis (PCoA) (Figures 4 and 5). We found that location of sample sites was a statistically significant factor, however no statistical differences were found when considering the distances to the orchids at the same site. 


\section{Core Microbiome}

The Venn diagram (Figure 6) derived from our core microbiome OTU table depicts the overlap in OTUs from the core microbiome when comparing samples taken close to the orchids versus samples taken at $5 \mathrm{~m}$ or more.

To test for significant differences within the core microbiome, we ran a Linear Discriminant Analysis (LDA) using the LEfSe algorithm. The results of this analysis indicate significant biomarkers across locations. These are OTUs that were found to be differentially abundant in those sites (Figure 7).

\section{DISCUSSION}

Our understanding of the complex association between orchids and their microbial symbionts is still mostly limited to their mycorrhizal partners. The potential impact of other members of the microbial community, such as bacteria, is largely unknown for the Orchidaceae. However, studies of species of economic importance, such as rice or Brassica cultivars, often reveal a significant impact on growth and development (Edwards et al., 2015; Khan, Jilani, Akhtar, Saqlan, \& Rasheed, 2009; Panke-Buisse, Poole, Goodrich, Ley, \& Kao-Kniffin, 2015). Due to the conservation status of our two study species, we were interested in addressing this gap in the literature in hopes of obtaining insights that could later be used to inform management and conservation practices. By applying high-throughput sequencing technology to our samples, we were able to obtain a detailed snapshot of the bacterial communities present in the different locations. One of our main interests was to determine how similar the soil bacterial diversity was for the different populations of orchids present in Missouri. Identifying a common denominator could potentially provide a guide for choosing suitable locations for 
population reintroduction efforts by management agencies such as the Missouri Department of Conservation. Results from several of our analyses give no evidence that there is specific assemblage of bacterial taxa that is necessarily associated with our orchid species. On the contrary, the taxonomic composition of communities from sites with orchids was not significantly different to that of a site that did not have orchid populations (Figure 2). Furthermore, the highest number of observed OTUs was actually for our non-orchid site $(\mathrm{P})$, which implies that the presence of orchids is not necessarily due to the bacterial community of the site surpassing a minimum threshold of microbial diversity (Figure 3). Likewise, in Table 1, we see several pair-wise comparisons amongst sites that show significant differences, especially when comparing the Shannon Index. These differences are not limited to a "sites with orchids" versus a "site without orchids" dichotomy.

When considering the relative abundances of the bacterial taxa present across all sites (Figure 2), the same six phyla (Verrucomicrobia, Proteobacteria, Actinobacteria, Acidobacteria, Chloroflexi and Planctomycetes) were present in similar proportions. The greatest difference in these abundances was for one site ("S") that presented a much lower abundance of Verrucomicrobia. This site was only recently found to have an orchid population and as it is a privately-owned plot, there are cattle present and it does not have the same management practices of the other locations. Based on this substantial difference in abundance for the phyla, we can surmise that, although the Verrucomicrobia are prevalent in prairie soils and normally quite abundant (Bergmann et al., 2011), they are not a fundamental requisite for the establishment of these orchid species. 
Another taxonomic group of interest due to a significant difference in relative abundance when compared to most sample locations is the bacterial order Bacillales (phylum Firmicutes). This order and even its corresponding phylum, were mostly found in very low quantities with an average across all sites of $1.5 \%$ for the order. The exception to this trend was one location ("T"), which had a substantially higher presence of these bacteria, with relative abundances ranging from $4.1 \%$ to $10.3 \%$ depending on the sample. This phylum has been shown to be more relatively abundant in arid soils when comparing natural and agriculturally modified land plots (Trivedi, Delgado-Baquerizo, Anderson, \& Singh, 2016). This difference could be used to determine if a site presents drier soil conditions and therefore evaluate the impact this difference could have on the orchid populations.

The LDA scores obtained from applying the LEfSe algorithm (Figure 7) showed just 6 taxa that were determined to be biomarkers and differentially abundant in their respective sites. Considering the normally high bacterial diversity of prairie soils (Barberán et al., 2014; Delgado-Baquerizo et al., 2018), such a small number of differentially abundant OTUs would indicate that the sites considered here share the great majority of species from their core microbiomes.

Despite many shared characteristics in terms of taxa present and their relative abundances across locations, our PCoA (Figure 4) did show that the sites where these populations are found were statistically different and that the data points tended to cluster based on geographic location. There isn't a clear trend based on either a latitudinal gradient or along an East-West axis. It's encouraging to find that these orchids are able to establish 
populations in locations that are different in terms of bacterial diversity, which implies some plasticity in their ability to survive in different microbial communities.

No differences in the bacterial microbiome were found based on proximity to the orchid itself (Figure 5). Therefore, we surmise that that the presence of the orchid plant does not induce changes in the microbial community nor does it establish itself only in sites that have a particular bacterial taxonomic composition. However, the core microbiome that was unique to samples taken close to the orchid had a much higher number of OTUs (653) compared to those that were only found further away from the plants (173) (Figure 6). This would indicate that many OTUs were consistently only found in proximity to an orchid. It would be interesting to further investigate the potential impact this result might have on the population dynamics of these species especially considering that most orchid studies evaluate population recruitment solely as a function of the presence of their mycorrhizal symbionts (McCormick \& Jacquemyn, 2014; McCormick, Taylor, Whigham, \& Burnett, 2016; Rasmussen et al., 2015).

In summary, when considering the bacterial communities that characterize the sites where these endangered orchids are found, we found broad similarities in terms of taxonomic composition but also some location-dependent differences as well. This shows that, at least at the bacterial level, there isn't a highly specific community required for the establishment of these orchid populations. This insight can be used in the decisionmaking process when determining best practices for management of these species of conservation concern by organizations and government agencies. 


\section{LITERATURE CITED}

Anderson, M. J. (2001). A new method for non-parametric multivariate analysis of variance. Austral Ecology, 26(1), 32-46. https://doi.org/10.1111/j.14429993.2001.01070.pp.x

Anderson, M. J., \& Walsh, D. C. I. (2013). PERMANOVA, ANOSIM, and the Mantel test in the face of heterogeneous dispersions: What null hypothesis are you testing? Ecological Monographs, 83(4), 557-574. https://doi.org/10.1890/12-2010.1

Andreote, F. D., Gumiere, T., \& Durrer, A. (2014). Exploring interactions of plant microbiomes. Scientia Agricola, 71(6), 528-539. https://doi.org/10.1590/0103-90162014-0195

Artursson, V., Finlay, R. D., \& Jansson, J. K. (2006). Interactions between arbuscular mycorrhizal fungi and bacteria and their potential for stimulating plant growth. Environmental Microbiology. https://doi.org/10.1111/j.1462-2920.2005.00942.x

Bailarote, B. C., Lievens, B., \& Jacquemyn, H. (2012). Does mycorrhizal specificity affect orchid decline and rarity? American Journal of Botany, 99(10), 1655-1665. https://doi.org/10.3732/ajb.1200117

Bakker, M. G., Schlatter, D. C., Otto-Hanson, L., \& Kinkel, L. L. (2014). Diffuse symbioses: roles of plant-plant, plant-microbe and microbe-microbe interactions in structuring the soil microbiome. Molecular Ecology, 23(6), 1571-83. https://doi.org/10.1111/mec.12571

Barberán, A., Ramirez, K. S., Leff, J. W., Bradford, M. A., Wall, D. H., \& Fierer, N. (2014). Why are some microbes more ubiquitous than others? Predicting the habitat breadth of soil bacteria. Ecology Letters. https://doi.org/10.1111/ele.12282

Barea, J.-M., Pozo, M.-J., Azcón, R., \& Azcón-Aguilar, C. (2013). Microbial Interactions in the Rhizosphere. In Molecular Microbial Ecology of the Rhizosphere (pp. 29-44). John Wiley \& Sons, Inc. https://doi.org/10.1002/9781118297674.ch4

Bergmann, G. T., Bates, S. T., Eilers, K. G., Lauber, C. L., Caporaso, J. G., Walters, W. A., ... Fierer, N. (2011). The under-recognized dominance of Verrucomicrobia in soil bacterial communities. Soil Biology \& Biochemistry, 43(7), 1450-1455. https://doi.org/10.1016/j.soilbio.2011.03.012 
Bonfante, P., \& Anca, I.-A. (2009). Plants, mycorrhizal fungi, and bacteria: a network of interactions. Annual Review of Microbiology, 63, 363-83. https://doi.org/10.1146/annurev.micro.091208.073504

Bonnardeaux, Y., Brundrett, M., Batty, A., Dixon, K., Koch, J., \& Sivasithamparam, K. (2007). Diversity of mycorrhizal fungi of terrestrial orchids: compatibility webs, brief encounters, lasting relationships and alien invasions. Mycological Research, 111 (1), 51-61. https://doi.org/10.1016/j.mycres.2006.11.006

Bowles, M., Zettler, L. W., Bell, T., \& Kelsey, P. (2005). Relationships between soil characteristics, distribution and restoration potential of the federal threatened eastern prairie fringed orchid, Platanthera leucophaea (Nutt.) Lindl. American Midland Naturalist, 154(2), 273-285. Retrieved from https://www-jstororg.proxy.mul.missouri.edu/action/exportSingleCitation?singleCitation=true $\&$ doi=1 $0.2307 / 3566690$

Cameron, D. D., Leake, J. R., \& Read, D. J. (2006). Mutualistic mycorrhiza in orchids: evidence from plant-fungus carbon and nitrogen transfers in the green-leaved terrestrial orchid Goodyera repens. The New Phytologist, 171(2), 405-16. https://doi.org/10.1111/j.1469-8137.2006.01767.x

Caporaso, J. G., Bittinger, K., Bushman, F. D., DeSantis, T. Z., Andersen, G. L., \& Knight, R. (2010). PyNAST: a flexible tool for aligning sequences to a template alignment. Bioinformatics, 26(2), 266-267. https://doi.org/10.1093/bioinformatics/btp636

Caporaso, J. G., Kuczynski, J., Stombaugh, J., Bittinger, K., Bushman, F. D., Costello, E. K., ... Knight, R. (2010). QIIME allows analysis of high-throughput community sequencing data. Nature Methods, 7(5), 335-6. https://doi.org/10.1038/nmeth.f.303

Caporaso, J. G., Lauber, C. L., Walters, W. A., Berg-Lyons, D., Lozupone, C. A., Turnbaugh, P. J., ... Knight, R. (2011). Global patterns of 16S rRNA diversity at a depth of millions of sequences per sample. Proceedings of the National Academy of Sciences of the United States of America, 108 Suppl, 4516-4522. https://doi.org/10.1073/pnas.1000080107

Clarke, K. R. (1993). Non-parametric multivariate analyses of changes in community structure. Austral Ecology, 18(1), 117-143. https://doi.org/10.1111/j.1442- 
9993.1993.tb00438.x

De Boer, W., Folman, L. B., Summerbell, R. C., \& Boddy, L. (2005). Living in a fungal world: Impact of fungi on soil bacterial niche development. FEMS Microbiology Reviews. https://doi.org/10.1016/j.femsre.2004.11.005

Dearnaley, J. D. W. (2007). Further advances in orchid mycorrhizal research. Mycorrhiza, 17(6), 475-486. https://doi.org/10.1007/s00572-007-0138-1

Delaux, P.-M., Séjalon-Delmas, N., Bécard, G., \& Ané, J.-M. (2013). Evolution of the plant-microbe symbiotic "toolkit". Trends in Plant Science, 18(6), 298-304. https://doi.org/10.1016/j.tplants.2013.01.008

Delgado-Baquerizo, M., Oliverio, A. M., Brewer, T. E., Benavent-González, A., Eldridge, D. J., Bardgett, R. D., ... Fierer, N. (2018). A global atlas of the dominant bacteria found in soil. Science, 359(6373). https://doi.org/10.1126/science.aap9516

DeSantis, T. Z., Hugenholtz, P., Larsen, N., Rojas, M., Brodie, E. L., Keller, K., ... Andersen, G. L. (2006). Greengenes, a chimera-checked 16S rRNA gene database and workbench compatible with ARB. Applied and Environmental Microbiology, 72(7), 5069-72. https://doi.org/10.1128/AEM.03006-05

Deveau, A., \& Labbé, J. (2016). Mycorrhiza helper bacteria. In Molecular Mycorrhizal Symbiosis (pp. 437-450). https://doi.org/10.1002/9781118951446.ch24

Di Bella, J. M., Bao, Y., Gloor, G. B., Burton, J. P., \& Reid, G. (2013). High throughput sequencing methods and analysis for microbiome research. Journal of Microbiological Methods, 95(3), 401-14. https://doi.org/10.1016/j.mimet.2013.08.011

Edwards, J., Johnson, C., Santos-Medellín, C., Lurie, E., Podishetty, N. K., Bhatnagar, S., ... Sundaresan, V. (2015). Structure, variation, and assembly of the root-associated microbiomes of rice. Proceedings of the National Academy of Sciences. https://doi.org/10.1073/pnas.1414592112

Fay, M. F. (2010). Celebrating orchids in the International Year of Biodiversity. Botanical Journal of the Linnean Society, 163(2), 107-110. https://doi.org/10.1111/j.1095-8339.2010.01056.x

Fierer, N., Ladau, J., Clemente, J. C., Leff, J. W., Owens, S. M., Pollard, K. S., ... McCulley, R. L. (2013). Reconstructing the Microbial Diversity and Function of 
Pre-Agricultural Tallgrass Prairie Soils in the United States. Science (AAAS), 342(6158), 621-624. https://doi.org/10.1126/science.1243768

Frey-Klett, P., Garbaye, J., \& Tarkka, M. (2007). The mycorrhiza helper bacteria revisited. The New Phytologist, 176(1), 22-36. https://doi.org/10.1111/j.14698137.2007.02191.x

Fu, L., Niu, B., Zhu, Z., Wu, S., \& Li, W. (2012). CD-HIT: accelerated for clustering the next-generation sequencing data. Bioinformatics, 28(23), 3150-3152. https://doi.org/10.1093/bioinformatics/bts565

Garbaye, J. (1994). Tansley review No.76 Helper bacteria: A new dimension to the mycorrhizal symbiosis. New Phytologist, 128(2), 197-210. https://doi.org/10.1111/j.1469-8137.1994.tb04003.x

Genre, A., Chabaud, M., Timmers, T., Bonfante, P., \& Barker, D. G. (2005). Arbuscular mycorrhizal fungi elicit a novel intracellular apparatus in Medicago truncatula root epidermal cells before infection. Plant Cell, 17(12), 3489-3499.

https://doi.org/10.1105/tpc.105.035410.1

Givnish, T. J., Spalink, D., Ames, M., Lyon, S. P., Hunter, S. J., Zuluaga, A., ... Cameron, K. M. (2015). Orchid phylogenomics and multiple drivers of their extraordinary diversification. Proceedings. Biological Sciences / The Royal Society, 282(1814). https://doi.org/10.1098/rspb.2015.1553

Glick, B. R. (2012). Plant Growth-Promoting Bacteria: Mechanisms and Applications. Scientifica, 2012, 1-15. https://doi.org/10.6064/2012/963401

Hapeman, J. R., \& Inoue, K. (1997). Plant-pollinator interactions and floral radiation in Platanthera (Orchidaceae). In T. Givnish \& K. Sytsma (Eds.), Molecular evolution and adaptive radiation (pp. 433-454). Cambridge: Cambridge University Press.

Harris, J. (2009). Soil Microbial Communities and Restoration Ecology: Facilitators or Followers? Science (AAAS), 325(5940), 573-574. https://doi.org/10.1126/science. 1172975

Hassani, M. A., Durán, P., \& Hacquard, S. (2018). Microbial interactions within the plant holobiont. Microbiome. https://doi.org/10.1186/s40168-018-0445-0

Hothorn, T., Bretz, F., \& Westfall, P. (2008). Simultaneous Inference in General Parametric Models. Biometrical Journal, 50(3), 346-363. 
https://doi.org/10.1002/bimj.200810425

Jacquemyn, H., Brys, R., Lievens, B., \& Wiegand, T. (2012). Spatial variation in belowground seed germination and divergent mycorrhizal associations correlate with spatial segregation of three co-occurring orchid species. Journal of Ecology, 100(6), 1328-1337. https://doi.org/10.1111/j.1365-2745.2012.01998.x

Jacquemyn, H., Brys, R., Merckx, V. S. F. T., Waud, M., Lievens, B., \& Wiegand, T. (2014). Coexisting orchid species have distinct mycorrhizal communities and display strong spatial segregation. New Phytologist, 202(2), 616-627. https://doi.org/10.1111/nph.12640

Jones, S. (2013). Trends in microbiome research. Nature Biotechnology, 31(4), 277-277. https://doi.org/10.1038/nbt.2546

Khan, A. A., Jilani, G., Akhtar, M. S., Saqlan, S. M., \& Rasheed, M. (2009). Phosphorus Solubilizing Bacteria: Occurrence, Mechanisms and their Role in Crop Production. Journal of Agriculture and Biological Sciences, 1(1), 48-58. https://doi.org/10.5923/j.re.20120201.10

Knief, C. (2014). Analysis of plant microbe interactions in the era of next generation sequencing technologies. Frontiers in Plant Science, 5, 216. https://doi.org/10.3389/fpls.2014.00216

Knudson, M. D., VanLooy, J. A., \& Hill, M. J. (2015). A Habitat Suitability Index (HSI) for the Western Prairie Fringed Orchid (Platanthera praeclara) on the Sheyenne National Grassland, North Dakota, USA. Ecological Indicators, 57, 536-545. https://doi.org/10.1016/j.ecolind.2015.05.011

Lebeis, S. L. (2014). The potential for give and take in plant-microbiome relationships. Frontiers in Plant Science, 5, 287. https://doi.org/10.3389/fpls.2014.00287

Lou, Y., Clay, S. A., Davis, A. S., Dille, A., Felix, J., Ramirez, A. H. M., ... Yannarell, A. C. (2014). An affinity-effect relationship for microbial communities in plant-soil feedback loops. Microbial Ecology, 67(4), 866-76. https://doi.org/10.1007/s00248013-0349-2

Masella, A. P., Bartram, A. K., Truszkowski, J. M., Brown, D. G., \& Neufeld, J. D. (2012). PANDAseq: paired-end assembler for illumina sequences. $B M C$ Bioinformatics, 13(1), 31. https://doi.org/10.1186/1471-2105-13-31 
McCormick, M. K., \& Jacquemyn, H. (2014). What constrains the distribution of orchid populations? New Phytologist, 202(2), 392-400. https://doi.org/10.1111/nph.12639

McCormick, M. K., Taylor, D. L., Whigham, D. F., \& Burnett, R. K. (2016).

Germination patterns in three terrestrial orchids relate to abundance of mycorrhizal fungi. Journal of Ecology. https://doi.org/10.1111/1365-2745.12556

McDonald, D., Price, M. N., Goodrich, J., Nawrocki, E. P., DeSantis, T. Z., Probst, A., ... Hugenholtz, P. (2012). An improved Greengenes taxonomy with explicit ranks for ecological and evolutionary analyses of bacteria and archaea. The ISME Journal, 6(3), 610-8. https://doi.org/10.1038/ismej.2011.139

Oksanen, J., Blanchet, F. G., Kindt, R., Legendre, P., Minchin, P. R., O’Hara, R. B., ... Wagner, H. (2013). Package "vegan.” R Package Ver. 2.0-8. https://doi.org/10.4135/9781412971874.n145

Pandey, M., Sharma, J., Taylor, D. L., \& Yadon, V. L. (2013). A narrowly endemic photosynthetic orchid is non-specific in its mycorrhizal associations. Molecular Ecology, 22(8), 2341-2354. https://doi.org/10.1111/mec.12249

Panke-Buisse, K., Poole, A. C., Goodrich, J. K., Ley, R. E., \& Kao-Kniffin, J. (2015). Selection on soil microbiomes reveals reproducible impacts on plant function. ISME Journal, 9. https://doi.org/10.1038/ismej.2014.196

Philippot, L., Raaijmakers, J. M., Lemanceau, P., \& van der Putten, W. H. (2013). Going back to the roots: the microbial ecology of the rhizosphere. Nature Reviews. Microbiology, 11(11), 789-99. https://doi.org/10.1038/nrmicro3109

Phillips, R. D., Barrett, M. D., Dixon, K. W., \& Hopper, S. D. (2011). Do mycorrhizal symbioses cause rarity in orchids? Journal of Ecology, 99(3), 858-869. https://doi.org/10.1111/j.1365-2745.2011.01797.x

Price, M. N., Dehal, P. S., \& Arkin, A. P. (2009). FastTree: computing large minimum evolution trees with profiles instead of a distance matrix. Molecular Biology and Evolution, 26(7), 1641-50. https://doi.org/10.1093/molbev/msp077

Rasmussen, H. N., Dixon, K. W., Jersáková, J., \& Těšitelová, T. (2015). Germination and seedling establishment in orchids: a complex of requirements. Annals of Botany, mcv087-. https://doi.org/10.1093/aob/mcv087

Redford, A. J., Bowers, R. M., Knight, R., Linhart, Y., \& Fierer, N. (2010). The ecology 
of the phyllosphere: geographic and phylogenetic variability in the distribution of bacteria on tree leaves. Environmental Microbiology, 12(11), 2885-93. https://doi.org/10.1111/j.1462-2920.2010.02258.x

Santamaria, M., Fosso, B., Consiglio, A., De Caro, G., Grillo, G., Licciulli, F., Pesole, G. (2012). Reference databases for taxonomic assignment in metagenomics. Briefings in Bioinformatics, 13(6), 682-95. https://doi.org/10.1093/bib/bbs036

Schlaeppi, K., \& Bulgarelli, D. (2015). The Plant Microbiome at Work. Molecular PlantMicrobe Interactions. https://doi.org/10.1094/MPMI-10-14-0334-FI

Segata, N., Izard, J., Waldron, L., Gevers, D., Miropolsky, L., Garrett, W. S., \& Huttenhower, C. (2011). Metagenomic biomarker discovery and explanation. Genome Biology. https://doi.org/10.1186/gb-2011-12-6-r60

Sheviak, C. (2002). Platanthera. In F. of N. A. E. C. Eds. (Ed.), Flora of North America North of Mexico vol. 26 (pp. 551-571). Oxford: Oxford University Press.

Sheviak, C. J., \& Bowles, M. L. (1986). The prairie fringed orchids: a pollinator-isolated species pair. Rhodora, 88, 267-290.

Sieg, C. H., \& King, R. M. (1995). Influence of Environmental Factors and Preliminary Demographic Analyses of a Threatened Orchid, Platanthera praeclara. American Midland Naturalist, 134(2), 307-323. https://doi.org/10.2307/2426300

Smith, S. E., \& Read, D. (2008). Mycorrhizal Symbiosis. Mycorrhizal Symbiosis. https://doi.org/10.1016/B978-012370526-6.50015-5

Stöckel, M., Těšitelová, T., Jersáková, J., Bidartondo, M. I., \& Gebauer, G. (2014). Carbon and nitrogen gain during the growth of orchid seedlings in nature. $\mathrm{New}$ Phytologist, 202(2), 606-15. https://doi.org/10.1111/nph.12688

Swarts, N. D., \& Dixon, K. W. (2009). Terrestrial orchid conservation in the age of extinction. Annals of Botany, 104(3), 543-56. https://doi.org/10.1093/aob/mcp025

Swarts, N. D., Sinclair, E. A., Francis, A., \& Dixon, K. W. (2010). Ecological specialization in mycorrhizal symbiosis leads to rarity in an endangered orchid. Molecular Ecology, 19(15), 3226-3242. https://doi.org/10.1111/j.1365294X.2010.04736.x

Trivedi, P., Delgado-Baquerizo, M., Anderson, I. C., \& Singh, B. K. (2016). Response of Soil Properties and Microbial Communities to Agriculture: Implications for Primary 
Productivity and Soil Health Indicators. Frontiers in Plant Science, 7, 990. https://doi.org/10.3389/fpls.2016.00990

Tsavkelova, E. A., Cherdyntseva, T. A., Lobakova, E. S., Kolomeitseva, G. L., \& Netrusov, A. I. (n.d.). Microbiota of the Orchid Rhizoplane. Microbiology, 70(4), 492-497. https://doi.org/10.1023/A:1010402715376

U.S. Fish and Wildlife Service. (1996). Platanthera praeclara (western prairie fringed orchid) recovery plan. Ft. Snelling, MN.

U.S. Fish and Wildlife Service. (2001). Eastern prairie fringed orchid, Platanthera leucophaea (Nuttall) Lindley recovery plan. Fort Snelling, Minnesota.

U.S. Fish and Wildlife Service. (2009). Western Prairie Fringed Orchid (Platanthera praeclara) 5-year Review: Summary and Evaluation. Bloomington, Minnesota.

Wallace, L. E. (2003). The cost of inbreeding in Platanthera leucophaea (Orchidaceae). American Journal of Botany, 90(2), 235-242. https://doi.org/10.3732/ajb.90.2.235

Zarraonaindia, I., Owens, S. M., Weisenhorn, P., West, K., Hampton-Marcell, J., Lax, S., Gilbert, J. A. (2015). The soil microbiome influences grapevine-associated microbiota. mBio, 6(2). https://doi.org/10.1128/mBio.02527-14 
FIGURES

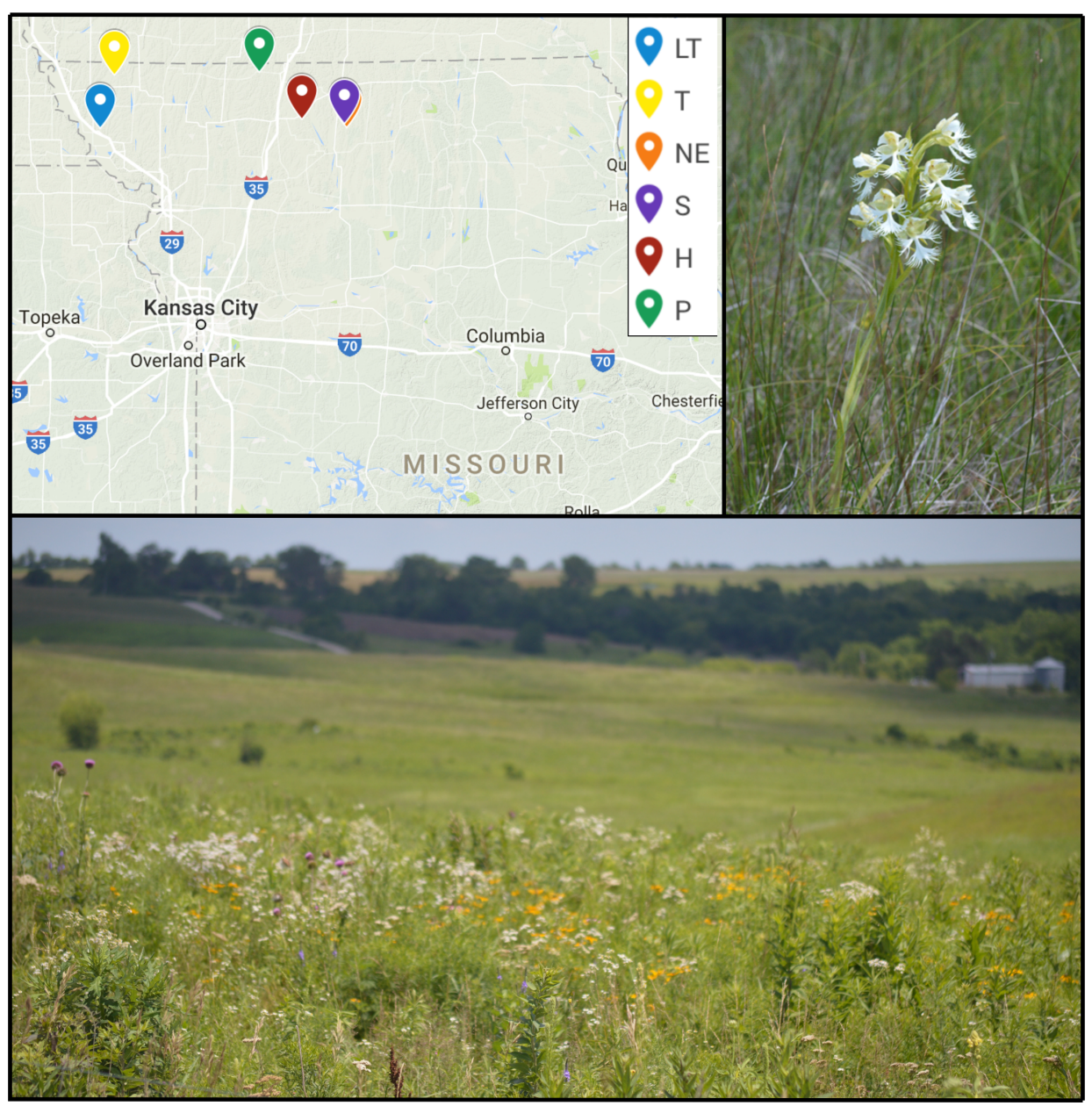

Fig. 1 - a) Map of the sample sites in the northwest region of Missouri, USA.

b) Photo of Platanthera praeclara. c) Photo of landscape and prairie in the sampling area 


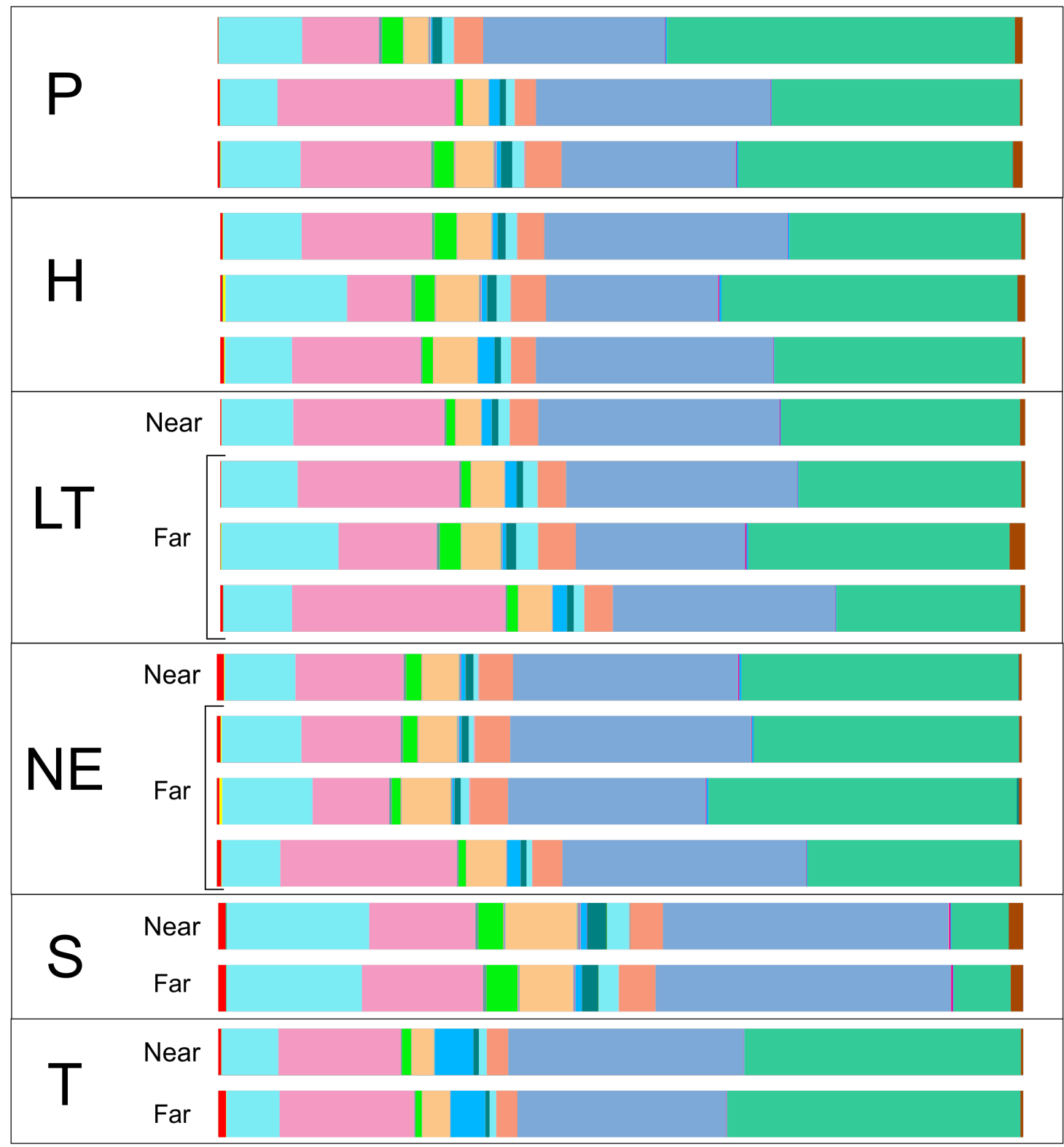

1. Fig. 2 Taxonomic composition at the phylum level.

Color in Graph

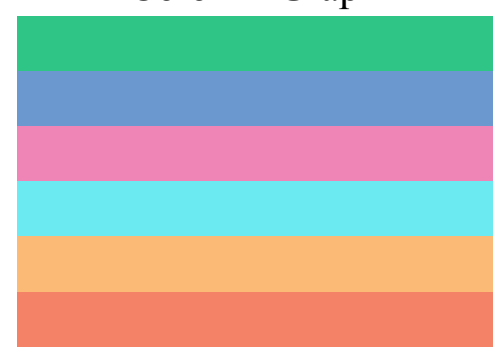

Phylum

Verrucomicrobia

Proteobacteria

Actinobacteria

Acidobacteria

Chloroflexi

Planctomycetes

Legend for Figure 2 depicting six most abundant taxa 

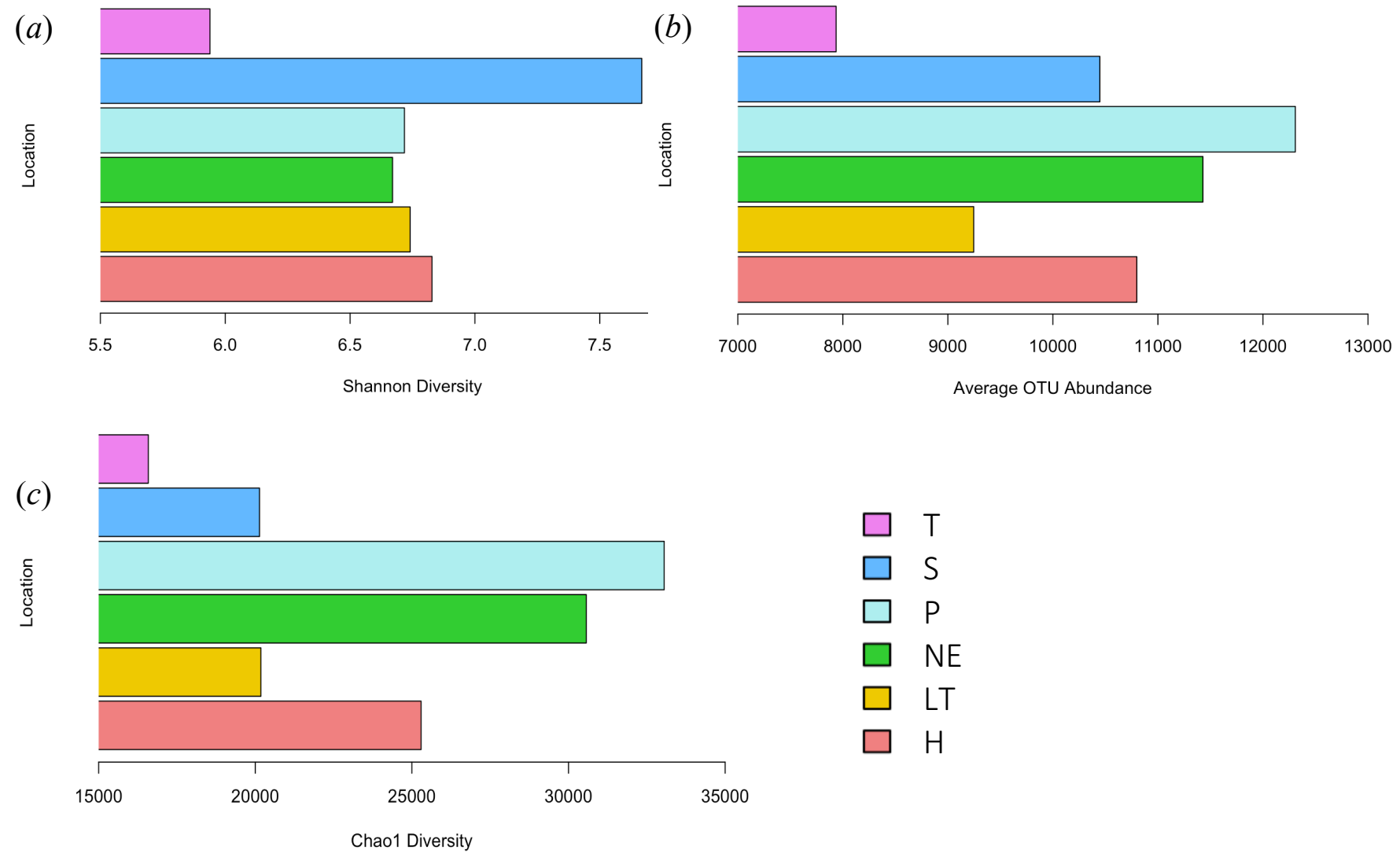

Fig. 3 Average Shannon diversity (a), average OTU abundance (b), and average Chao1 diversity $(c)$ for each sampling location 


\begin{tabular}{|c|c|c|c|}
\hline Location Comparison & Shannon & Chaol & $\begin{array}{c}\text { Observed } \\
\text { oTUs }\end{array}$ \\
\hline $\mathbf{T}--\mathbf{H}$ & $\begin{array}{l}t=-3.72400 \\
p=0.01592\end{array}$ & -- & -- \\
\hline NE-- LT & -- & $\begin{array}{l}t=3.53200 \\
p=0.02362\end{array}$ & -- \\
\hline P -- LT & -- & $\begin{array}{l}t=3.41700 \\
p=0.02996\end{array}$ & -- \\
\hline $\mathbf{S}-\mathbf{L T}$ & $\begin{array}{l}t=3.79100 \\
p=0.01399\end{array}$ & -- & -- \\
\hline $\mathbf{T}$-- LT & $\begin{array}{l}t=-3.75400 \\
p=0.01486\end{array}$ & -- & -- \\
\hline S -- NE & $\begin{array}{l}t=4.31700 \\
p=0.00451\end{array}$ & -- & -- \\
\hline $\mathbf{T} \mathbf{N F}$ & $t=-3.69300$ & $t=-4.00300$ & $t=-3.61400$ \\
\hline ב 10 & $p=0.01707$ & $p=0.00887$ & $p=0.01990$ \\
\hline S-- P & $\begin{array}{l}t=3.56000 \\
p=0.02233\end{array}$ & -- & -- \\
\hline & $t=-3.26100$ & $t=-3.90900$ & $t=-3.7510$ \\
\hline $1-1$ & $p=0.04110$ & $p=0.01071$ & $p=0.01500$ \\
\hline $\mathbf{T}-\mathbf{S}$ & $\begin{array}{c}t=-6.47800 \\
p<0.00100\end{array}$ & -- & -- \\
\hline
\end{tabular}

Table 1 Pairwise comparisons of Shannon diversity, chaol diversity, and raw OTU abundance between sampling locations. Individual indices and OTU abundances were compared using one-way ANOVAs; the resulting t-values and associated p-values are shown for all possible groups of locations. For clarity, comparisons with nonsignificant pvalues were omitted and replaced with dashes. 


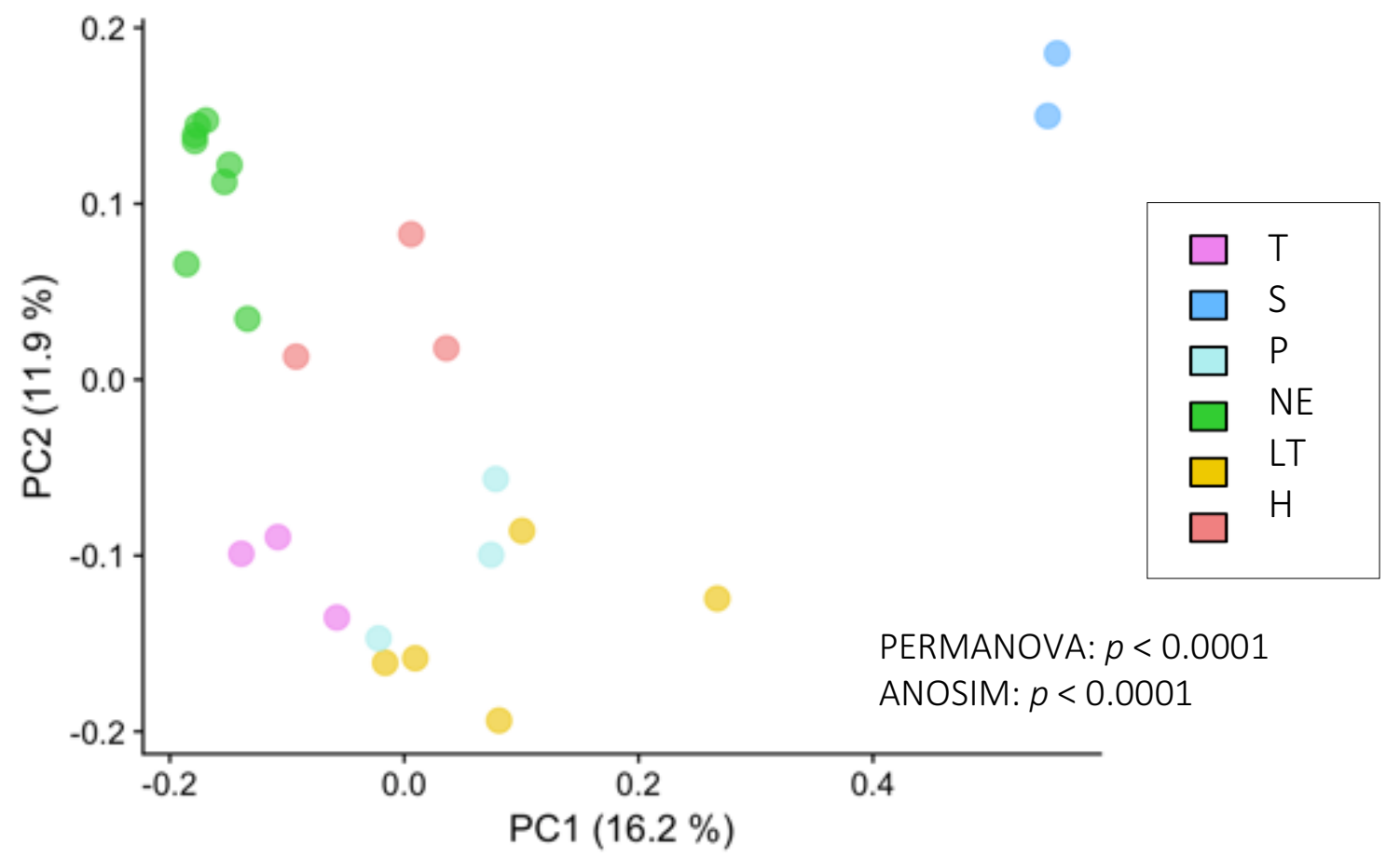

Fig. 4 Principal coordinate analysis (PCoA) based on community dissimilarity between sampling locations. Axes 1 and 2 represent the proportion of variation in the data accounted for in principal components 1 and 2. PERMANOVA and Analysis of Similarity (ANOSIM), each conducted with 9999 permutations, indicate significant differences in community composition among locations. 


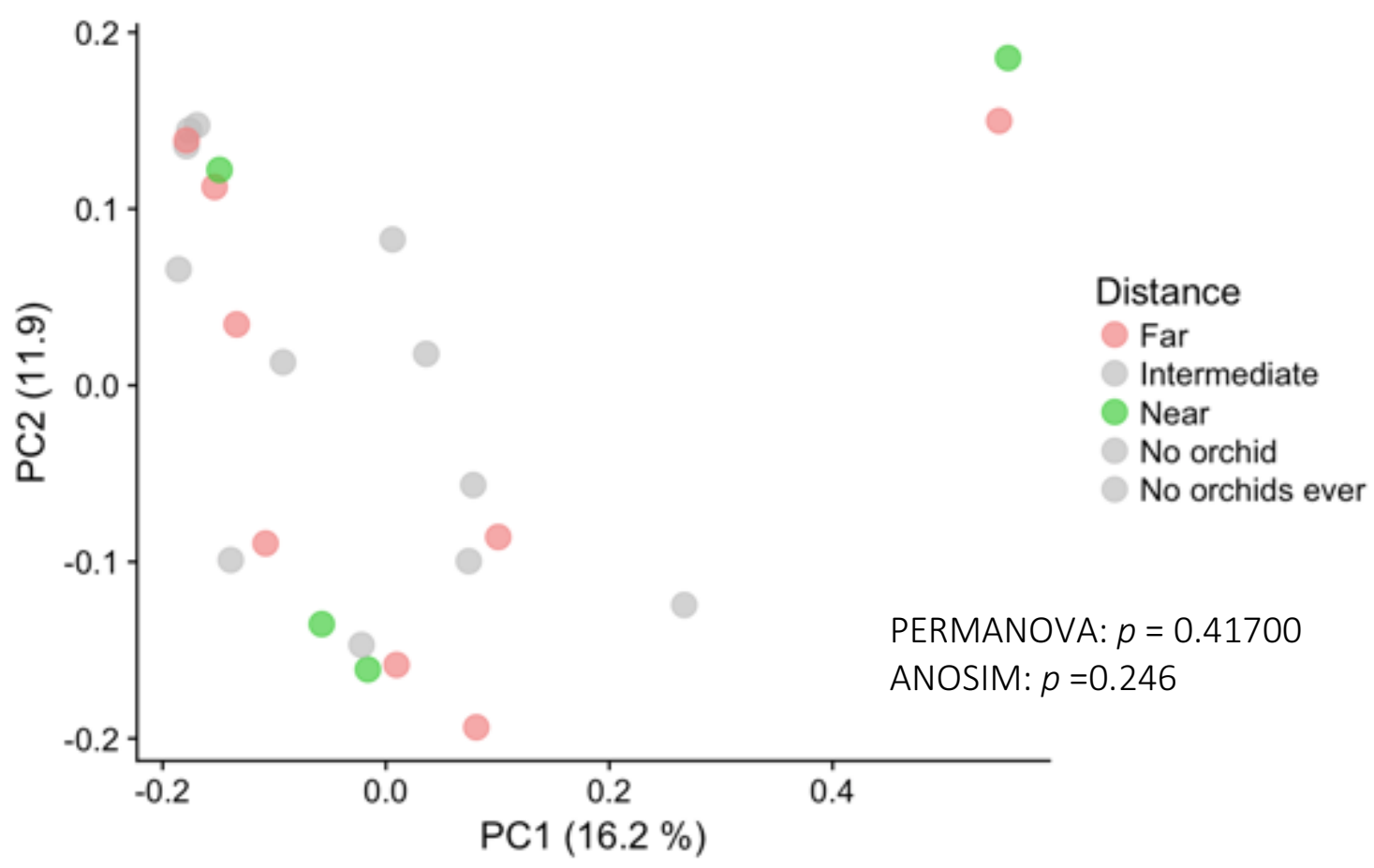

Fig. 5 Principal coordinate analysis (PCoA) based on community dissimilarity between sampling distances. To emphasize the relationship between distances "near" and "far" from a host orchid species, only samples designated as near and far have been shown in color; all other sampling distance groups have been faded in greyscale. Axes 1 and 2 represent the proportion of variation in the data accounted for in principal components 1 and 2. PERMANOVA and Analysis of Similarity (ANOSIM), each conducted with 9999 permutations, indicate no significant differences in community composition among distances away from a host orchid. 


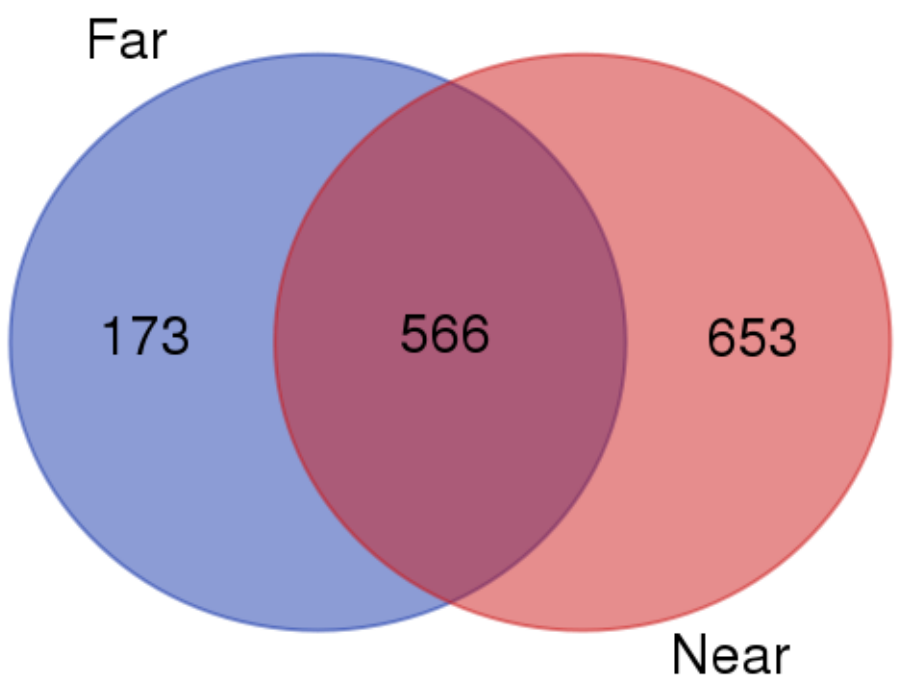

Fig. 6 Venn diagram for OTUs belonging to the core microbiome (90\% occurrence of samples) 


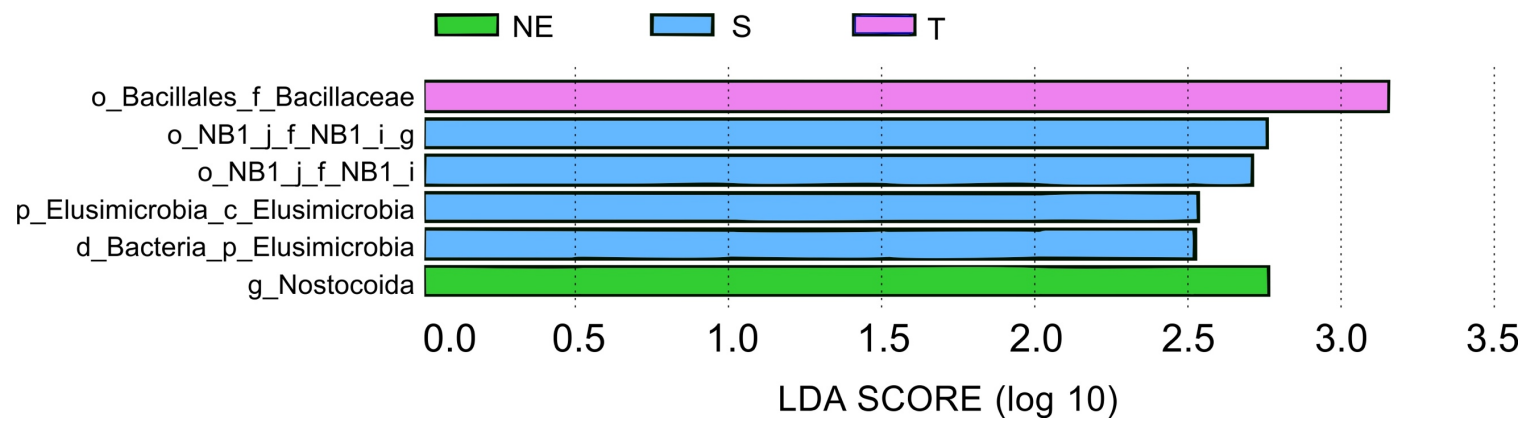

Fig. 7 Linear Discriminant Analysis using LEfSe algorithm. These taxa were shown to be biomarkers and differentially abundant in their locations 


\title{
CHAPTER 2
}

\section{Taxonomical and Functional Characteristics of Microbial Communities Associated to Endangered Terrestrial Orchids using Shotgun Metagenomics}

\begin{abstract}
Metagenomic studies focus on the collection of genomes of all the microbial organisms found in a particular environment or sample. Shotgun metagenomics has become the standard approach for sequencing samples to look at the functional characteristics of microbial communities as well as taxonomic information. Microbial communities impact, through multiple channels, the organisms with which they are in direct contact. They affect the availability of nutrients, release toxins, antimicrobial compounds and growthpromoting substances. Plants are especially susceptible to the effects of the surrounding microbial community. Their inability to easily change environments requires that they deal with these microbial interactions in situ. Orchids are intrinsically dependent on specific members of the microbiota. They require mycorrhizal fungi for seed germination and this reflects the potential consequences that a change in the microbiome might have on their successful establishment. We studied the soil microbiome associated with two species of endangered prairie orchids, Platanthera praeclara and P. leucophaea. The most abundant phylum was Proteobacteria and Bradyrhizobium was the most abundant of the bacterial genera. We found evidence of functional redundancy relative to taxonomic composition. There were no sequence hits for the fungal orders Cantharellales or Sebacinales to which most orchid mycorrhizae belong. Finally, a lack of distinct environmental differences should inform the level of taxonomic resolution that should be used to analyze and compare samples.
\end{abstract}




\section{INTRODUCTION}

Microbial communities have been known to impact, through multiple channels, the organisms with which they are in direct contact. Microbes can affect the availability of nutrients and they can also release toxins, antimicrobial compounds or growth-promoting substances (Kulmatiski, Beard, Stevens, \& Cobbold, 2008). The organism's responses to these interactions will most likely have implications for its growth and development and overall fitness (van der Heijden, Bardgett, \& van Straalen, 2008). Plants are especially susceptible to the effects of the surrounding microbial community. Their inability to easily change environments requires that they deal with these microbial interactions in situ. For example, the biogeochemical processes carried out by the microbiome can have a considerable impact on plants. These processes influence the availability of nutrients as well as the overall structure and composition of the soil (Chen, Mothapo, \& Shi, 2015; Inderjit \& Cahill, 2015).

One example of plants' responsiveness to the influence of microorganisms is the nitrogen cycle and the role bacteria play. Through the process of nitrogen fixation, bacteria make atmospheric nitrogen available to plants (Canfield, Glazer, \& Falkowski, 2010). Changing levels of available nitrogen have been shown to impact plant productivity and diversity at local scales (Cleland \& Harpole, 2010; LeBauer \& Treseder, 2008) as well as affect community composition at regional and biogeographical scales (Fierer et al., 2012). The importance of nitrogen in plant growth and development is perhaps most evident when you consider that it has served as a driver of a symbiotic relationship as in the case of legumes and rhizobia (Friesen, 2012). Along with nitrogen, other macronutrients such as phosphorus and potassium, are also made available to plants 
through bacterial activity (Khan, Jilani, Akhtar, Saqlan, \& Rasheed, 2009; Zhang \& Kong, 2014).

In addition to bacteria, fungi are also components of the microbial community that are linked to plant development, productivity and species richness (Bennett \& Bever, 2007; Van Der Heijden et al., 1998; Wagg, Jansa, Schmid, \& van der Heijden, 2011). There is a diverse spectrum of mycorrhizal fungi that establish close relationships with their plant hosts, and can provide improved uptake of nutrients and water (Augé, 2004; Landeweert, Hoffland, Finlay, Kuyper, \& Van Breemen, 2001), and in some cases carbohydrates, as seen in orchid seed germination (Rasmussen, Dixon, Jersáková, \& Těšitelová, 2015a). In addition, mycorrhizae also establish connections between plants and form an underground network with significant implications for plant fitness and communication (Selosse, Richard, He, \& Simard, 2006). The importance of these relationships cannot be overestimated as the mycorrhizae-plant association dates back to the era of land colonization by plants (Bidartondo et al., 2011; Field et al., 2015; Heckman et al., 2001) and over $80 \%$ of terrestrial plant species establish some form of mycorrhizal relationship (Wang \& Qiu, 2006).

All these functions that are carried out by microbes are possible in part, due to the large diversity of microbial taxa that exists. Furthermore, terrestrial plants are in contact with a great portion of this diversity. It's estimated that there are 100,000 to $1,000,000$ microorganisms per gram of soil (Maron, Mougel, \& Ranjard, 2011) and soil is considered to be perhaps the most microbial rich environment. However, not all soils are created equal. There is a gradient of diversity across soils, with those from tropical regions showing a higher richness than from temperate areas. Within the same climate, 
land that has been utilized for agriculture tends to show lower measures of microbial diversity (Fierer \& Jackson, 2006; Lauber, Ramirez, Aanderud, Lennon, \& Fierer, 2013). Traditional methods of studying microbial species required sample collection from the environment and then isolating the strains so they could be cultured in a lab setting. This methodology has many challenges and limitations which has contributed to databases that acutely underrepresent the reality of microbial diversity (Schloss \& Handelsman, 2006; Whitman, Coleman, \& Wiebe, 1998). A more recent approach incorporates the use of metagenomic sampling and high-throughput sequencing technologies.

Metagenomic studies focus on the collection of genomes of all the microbial organisms found in a particular environment or sample (Wooley, Godzik, \& Friedberg, 2010). Many studies have used molecular markers to identify the taxa present in an environmental sample with primers that target the 16S rRNA gene or ITS region, selecting for bacteria and fungi respectively. This type of amplicon sequencing has been useful for obtaining measures of alpha and beta diversity across samples but also has some limitations, particularly when dealing with rare taxa or those that are not selected by the specific primer used (Coats, Pelletreau, \& Rumpho, 2014; Ong et al., 2013). A more recent method, shotgun metagenomic sequencing, has emerged which complements the insights obtained using amplicons.

Shotgun metagenomic sequencing begins with DNA obtained from all the microorganisms present in an environmental sample and then randomly shearing it into very small fragments. These are then sequenced using a high throughput system (e.g. Illumina HiSeq) and the resulting reads aligned against genomes present in reference databases. This can provide not only taxonomic information but also insight on biological 
function as some reads align with coding sequences (Di Bella, Bao, Gloor, Burton, \& Reid, 2013).

Currently, shotgun metagenomics has become the standard approach to sequencing samples to look at the functional characteristics of microbial communities. The ability to not only consider which organisms are present but also what their functional role might be is perhaps a better tool to use as a comparison across environments or treatments. A difference in taxa represented in a sample might not necessarily equate to a change in the general functioning of a community (Ong et al., 2013). Microbial dormancy and functional redundancy can make inferring microbiome functioning from taxonomic profiles a difficult task (Fierer, 2017; Lennon \& Jones, 2011).

The use of shotgun metagenomics in studies of the environment has increased substantially since some of the first papers describing it appeared (Simon \& Daniel, 2011; Tringe, 2005). Applications have ranged from evaluating the gut microbiome of termites to the impact of gut microbes on human health (Ellison et al., 2014; Flight, 2013; Ley, Lozupone, Hamady, Knight, \& Gordon, 2008). Natural environments such as soil, oceans and even the atmosphere have been studied as well. This broad spectrum of applications has provided some general insights on the characteristics of microbial communities across the planet (Fierer et al., 2012; Morgan \& Huttenhower, 2012; Tringe, 2005). Despite the increase in application of shotgun metagenomics to the study of the microbial communities of different environments, there have not been many studies that focus on the microbiome of plant species of conservation concern. One group of plants that has many species that are considered threatened or endangered, is the orchid family (Orchidaceae) (Swarts \& Dixon, 2009). Orchids are intrinsically dependent on specific 
members of the microbiota. Due to their requirement of the presence of mycorrhizal fungi for seed germination, they are uniquely positioned to reflect the potential consequences that a change in the surrounding microbiome might have on their successful establishment (Rasmussen, Dixon, Jersáková, \& Těšitelová, 2015b).

With this in mind, I conducted a shotgun metagenomic study of the soil microbiome associated with two species of endangered prairie orchids, Platanthera praeclara and P. leucophaea. Like most orchids, they have very small seeds that are wind dispersed over great distances. Despite this, these species have not been able to reestablish naturally in habitat that could be considered of acceptable quality. One possible explanation is that there has been a fundamental change in the function of the microbial community in the soils of these once-modified habitats. Using shotgun sequencing, I hope to determine if the presence or absence of these orchids can be connected to characteristics of the prairie microbiome.

\section{MATERIALS AND METHODS}

\section{Study species and study area}

The sister species pair Platanthera praeclara (western prairie fringed orchid) and $P$. leucophaea (eastern prairie fringed orchid) were historically found throughout the prairies of North America (Sheviak \& Bowles, 1986; Wallace, 2003). With the cultivation and fragmentation of the tallgrass prairies, their populations started to decline and both species are currently federally listed as threatened (U.S. Fish and Wildlife Service, 1996, 2001, 2009). In the northwest portion of the state of Missouri, there are three known populations of $P$. praeclara and one population of $P$. leucophaea. 
The samples used for this study were taken from a subset of samples from another study which looked exclusively at the bacterial community associated with these orchids by using a 16S rRNA primer and amplicon sequencing (Ravelo et al., in prep).

\section{Soil collection and processing}

Sampling took place in 2014 during the flowering season of the orchids (July) to facilitate finding individuals in the tall vegetation of the prairies. The sampling locations used for this study were the following: "NE", "S", "LT", which all had orchid populations and "P" which did not have an orchid population (due to the protected status of these species, initials representing the locations are used instead of complete names). The soil collection strategy included obtaining soil samples close to an orchid $(0.25 \mathrm{~m})$ and samples at a distance of at least $5 \mathrm{~m}$ or more away from the orchid. These were chosen at random using a grid and random number generator. One orchid site $(N E)$ was selected for a more intensive sampling effort with soil taken at $0.25 \mathrm{~m}$ intervals from the orchid until $1 \mathrm{~m}$. Soil cores were collected using a soil probe to $15 \mathrm{~cm}$ deep, forming a circle around the plant. A total of 5 to 8 cores were taken for each sample and then combined to form one composite sample. The probes were cleaned with distilled water and then sanitized with $75 \%$ EtOH between samples. These samples were placed in a cooler with ice while in the field and then frozen that same day. Long-term storage is at $-20 \mathrm{C}$.

For this study, the samples were selected to give a point of comparison between samples taken close to the orchid (NE01, S01, LTO1); intermediate distances to an orchid (NEO2, NE03, NE04); distances of $5 \mathrm{~m}$ or more from an orchid (NE06, NE07, NE08, LT02, LT03, LT04); and within a site that does not have orchids despite appearing to provide high- 
quality habitat $(P 01, P 02, P 03)$. Soil processing included soil homogenization and sub sampling by use of a $2 \mathrm{~mm}$ sieve.

\section{DNA extraction and whole genome shotgun sequencing}

DNA was extracted using the DNeasy Powerlyzer Powersoil kit (MoBio, USA). Libraries were constructed with the TruSeq Nano DNA kit (Illumina, USA) and library concentration was measured with Qubit dsDNA HS Assay Kit (Thermo Fisher Scientific, USA). The samples were then pooled in equimolar concentrations and diluted to $10 \mathrm{nM}$. The library pools were sequenced on two lanes of HiSeq (Illumina, USA) 2 x $150 \mathrm{bp}$. One lane contained three samples (NE01, LTO1, S01), all taken from close $(0.25 \mathrm{~m})$ to an established orchid plant. Another lane was run with 12 samples, which originated from different sites as well as different distances from the orchid plants (NE02, NE03, NE04, NE06, NE07, NE08, LT02, LT03, LT04, P01, P02, P03).

The limited number of samples on one lane was done with the objective of deep sequencing with high coverage of the metagenomic reads per sample. This would allow for a more in-depth characterization of the microbiome. This deep sequencing is particularly important when working with very diverse environments such as soil. The second lane of 12 samples had a main objective of providing comparative metagenomic information. This broad sampling strategy would provide an overview of the microbial communities from many different locations and distances to an orchid. This would provide a "big picture" comparison versus a more in-depth and detailed look of the communities provided by the 3 -sample lane. 


\section{Bioinformatic processing}

Metagenomic analyses were run using the Metagenomics Rapid Annotation (MG-RAST) server and analyzed using the pipeline version 4.0.2. (Aziz et al., 2008; Meyer et al., 2008), which is an open source system for annotation and comparative analyses of metagenomes. This provides not only phylogenetic but also functional summaries of the sequences recovered from the soil samples. The program accesses protein and nucleotide databases for subsequent annotation and comparison allowing an overview of the metabolic functions that are taking place in that community. The FASTQ files were uploaded to the MG-RAST server and processed with the default parameters of quality control (QC) filtering of raw reads, including removal of low quality reads and dereplication (removal of artificial sequences produced by sequencing artifacts). Determining rarefaction, taxonomic composition and functional profiles of annotated species was performed within MG-RAST by applying the Best Hit Classification option using the M5NR and SEED Subsystems databases (Overbeek et al., 2005, 2014; Wilke et al., 2016). As a reference to identify hits, BlastX was used with a minimum alignment length of $15 \mathrm{bp}$ and an $E$-value cut-off of $E<1 \times 10^{-5}$. For each metagenome, a frequency of hits table for each taxon or subsystem was generated, which was then normalized to remove bias due to differences in read lengths and sequencing efforts. The tables generated were used for statistical analyses in STAMP (Statistical Analysis of Metagenomic Profiles) (Parks et al., 2014). Depending on the analysis, $P$-values were calculated using the two-sided Welch's $t$ test or a two-sided G-test (w/Yates') + Fisher's applying a Bonferroni correction (Welch, 1947). 


\section{RESULTS}

Shotgun metagenome characteristics

The 15 metagenomes produced a total of 47.3 billion bp contained in 313.7 million reads (Table S1). Mean lengths of the sequences ranged from 151 to $232 \mathrm{bp}$. The sequences are deposited in MG-RAST under the project title "Platanthera praeclara and P. leucophaea soil microbiome study using shotgun metagenomics".

\section{Microbial community composition}

Most of the metagenomics reads were derived from the taxonomic domain Bacteria (range of 95.3- 98.6\% hits to the M5NR database with a mean of 97.8\%), followed by Eukaryota (range of $0.49-1.71 \%$ with a mean of $0.72 \%$ ), Viruses (range of $0.16-2.38 \%$ with a mean of $0.64 \%$ ) and Archaea (range of $0.39-1.04 \%$ with a mean of $0.49 \%$ ) (Figure 1). The Bacteria domain was represented by 28 phyla and one category of unclassified reads derived from Bacteria (Figure 2). Across all samples, the Proteobacteria and Actinobacteria phyla represented the highest and second highest percentages of matches to the M5NR database with total relative abundances of $48 \%$ and $21 \%$ respectively. These two phyla comprised $69 \%$ of all reads within the domain. Following in relative abundance were the phyla Acidobacteria (5.6\%), Firmicutes (5.3\%) and Verrucomicrobia (4.1\%) which collectively comprised $15 \%$ of reads.

Within Eukaryotes, Ascomycota was the most abundant with a mean of $30.5 \%$ relative abundance across samples. This fungal phylum is commonly known as sac fungi and although there are many economically and biologically important species, there are few mycorrhizal fungi that belong to this group. Another fungal phylum, Basidiomycota, to which many orchid mycorrhizae belong, was the $5^{\text {th }}$ most abundant with a mean relative 
abundance of $6.3 \%$ (Figure 3). Within the Basidiomycota, $60 \%$ of reads corresponded to the Class Agaricomycetes, which is the most common taxonomic class of orchid mycorrhizal fungi (Figure 4). Further analysis revealed that within the Agaricomycetes, only two orders, the Agaricales and Polyporales were represented (Figure 5). The Agaricales are often ectomycorrhizal fungi which have been shown to sometimes associate with orchids, especially the mycoheterotrophs.

Three samples (NE01, LT02, LT03) had a much higher relative abundance of reads of Viruses than the other samples $(1.02-1.29 \%$ for these 3 samples vs. an average of $0.12 \%$ for all other samples) (Figure 1). This taxonomic abundance correlated with an increased proportion of Phages, Prophages, Transposable elements, Plasmids category within the SEED subsystem (Appendix Figure S1). However, these samples also had much lower overall reads than any of the other samples in the study (see Appendix Table S1 and Figure S2). Despite the numbers of reads being normalized across all samples for these analyses, the correlation between an increased proportion of Viruses that was found only in samples that had abnormally low reads is problematic. This would presumably indicate that this result could be an artifact of sequencing and not due to a biological cause.

\section{Microbial Communities based on location}

To compare microbial communities based on location, we focused on a two-way comparison of the bacterial communities' taxonomic composition between samples from the high-quality prairie site that does not have orchids ("P") and samples from all the other sites with orchids ("NE", "LT", "S"). We examined the differences between 
taxonomic bacterial families and conducted a two-sided Welch's t-test to test for significant differences (Figure 6). We found 38 families were statistically significant.

For an in-depth look at the microbial community found near orchids, we compared the relative abundance of bacterial genera of two samples ("LT" and "S") which were taken close to an orchid. We used a two-sided G-test (w/Yates') + Fisher's applying a Bonferroni correction. There were a total of 515 genera that showed significant differences. Figure 7 highlights the 50 genera with highest relative abundance that were significantly different between sites. The two most abundant genera found in the "LT" sample were Bradyrhizobium and Streptomycetes. These are commonly known for their nitrogen-fixing and antibiotic-producing traits respectively. Two genera from the "S" sample which were in significantly higher abundance than in sample "LT" included Candidatus solibacter and Geobacter. These bacteria are capable of degrading plant cell wall polysaccharides and anaerobic respiration and capable of oxidizing metals, respectively.

\section{Microbial functional profile}

A comparison between site "P" and "All other locations" was carried out using two-sided Welch's t-test. We found 7 of the possible 28 metabolic processes were statistically significant (Figure 8). The top 2 categories with the largest differences between sites were Sulfur Metabolism and Cofactors, Vitamins, Prosthetic Groups, Pigments. To understand the metabolic traits of the microbial communities found near an orchid we analyzed the functional characteristics of the communities from samples "LT01" and "S01". We used the sequences with hits to the SEED Subsystems database and conducted 
a two-sided G-test (w/Yates') + Fisher's applying a Bonferroni correction. Results show that 27 of the 28 Level 1 cellular processes categorized in the SEED database were statistically significant between the two samples (Figure 9). The top three categories with the largest differences were, Carbohydrates; Protein Metabolism; and Amino Acids and Derivatives.

\section{DISCUSSION}

Shotgun metagenomics is starting to become the standard approach used for studies interested in assessing all the microbial organisms present in an environment. There are definite benefits to capturing a snapshot of the entire microbiome versus detecting only specific microbes by way of primers and amplicon sequencing (Di Bella et al., 2013). A constraint that affects the widespread use of this methodology, however, is cost. Although the cost of high-throughput sequencing has decreased substantially and at quite a rapid pace, the need for deep sequencing to achieve sufficient read coverage, limits the number of samples that can be sequenced at a time on one lane (multiplexing). This is especially relevant in highly diverse environments such as soil (Howe et al., 2014). As a

result, studies which have ecological questions that require extensive sampling might find this metagenomics approach cost-prohibitive or that they need to reframe their approach to limit the number of samples analyzed.

As discussed in other studies (Fierer et al., 2013; Mendes et al., 2015), we also found Bacteria to be the most abundant members of the microbial community. This was true across all samples. This high proportion of reads that are assigned to bacteria might affect the discoverability of other, less abundant taxa (Fierer, 2017). This is especially important to keep in mind when designing a sampling and sequencing regime when 
working with highly diverse environments such as soil (Mocali \& Benedetti, 2010). This is also relevant when one is interested in taxa other than bacteria, as was the case in our study, where fungi such as orchid mycorrhizal fungi, have an impact on our study species.

Comparison of the bacterial phyla across sites showed a consistent dominance of certain taxa in regards to their overall relative abundance. The most abundant phylum by far was Proteobacteria, accounting for $69 \%$ of all total reads within the Bacteria domain. Proteobacteria are known for including nitrogen-fixing bacteria that tend to associate with legumes such as Rhizobium and Bradyrhizobium (Traveset \& Richardson, 2014). In addition, Bradyrhizobium was the most abundant of the bacterial genera when we compared samples taken close to an orchid, especially for our sample site "LT" (see Figure 7). Due to the high abundance of this taxa of nitrogen-fixing bacteria we expected to find an equally high representation of reads for metabolic functions related to Nitrogen Metabolism. However, in effect, this functional process was not a predominant characteristic of the microbial community. Furthermore, sample site "LT" had fewer reads than site "S" for nitrogen metabolism (Figure 9).

Since orchids are obligate symbionts of orchid mycorrhizae for seed germination we expected to find some taxa of known orchid mycorrhizal fungi in our samples. Although there were taxa corresponding to the Class Agaricomycetes (Phylum Basidiomycetes) to which most orchid mycorrhizae belong, there were no sequence hits for the orders Cantharellales or Sebacinales. These taxa are where the majority of mycorrhiza that associate with terrestrial orchids are found (Bonnardeaux et al., 2007). 
This result could indicate insufficient read coverage for the discovery of less abundant taxa such as orchid mycorrhizae. It is also possible that the databases used for identification and binning of sequences in the metagenomic bioinformatics pipeline are lacking representatives of these orchid mycorrhizal species. Within the MG-RAST pipeline, representative sequences are used in a BLAT search against the M5nr and M5rna databases (Wilke et al., 2012) . The M5rna database integrates other commonly used databases such as SILVA, Greengenes and RDP (Plummer et al., 2015). However, it does not access the fungal sequence database UNITE (Kõljalg et al., 2013) which has many mycorrhizal fungi, including orchid mycorrhizae (Tedersoo et al., 2011). The absence of a fungal specific database within the MG-RAST pipeline could bias the results regarding the taxonomic composition of the microbial community and should be taken into consideration when interpreting shotgun metagenomics data.

Despite the absence of specific orchid mycorrhizal fungi, there were reads representing the order Agaricales which includes many taxa of ectomycorrhizal fungi, which have been shown to sometimes associate with orchids, especially the mycoheterotrophs (Tedersoo et al., 2014).

One of the objectives for this study was to compare the microbiome between sites which had orchid populations ("NE", "S" and "LT") and a site without populations ("P") of our study species. We considered both the taxonomic characteristics as well as functional characteristics of the microbiomes. We compared Bacteria families and found 38 families showed significant differences between these locations (Figure 6). When we analyzed the 
functional characteristics of the microbiomes we found only 7 subsystems out of a possible 28 to be statistically significant (Figure 8). This discrepancy in significance when comparing taxa versus function is often considered to be due to redundancy within the microbiome (O’Brien et al., 2016). Usually more than one taxa will have similar functional attributes and carry out overlapping metabolic processes

We also evaluated the characteristics of the microbiome closely associated to orchids and compared samples taken from two different orchids at different sites (LT01 and S01). Because we were comparing two samples, we increased our taxonomic resolution to the genus taxonomic level. We found 515 genera showed significant differences in relative abundances between the microbiomes of the samples, of which the top 50 are shown in Figure 7.

When we looked at the functional attributes corresponding to these microbiomes, 27 of the 28 possible metabolic processes were significantly different. This result contrasted starkly with our previous comparison where only 7 of the 28 subsystems were statistically significant. We surmise that this is due to the increased taxonomic resolution which was used in our comparison and the fact that it was between two samples instead of groups of samples, resulting in less microbial heterogeneity to add noise to the statistical analysis.

Increasing the taxonomic resolution to look at bacterial genus and doing pairwise sample comparisons showed differences that could go undetected if analyzed at too broad of a scale.

An additional consideration is that many studies that have looked at functional traits in microbiomes compare quite different ecosystems, for example, agriculture vs. natural 
vegetation or forest vs. prairie (Dinsdale et al., 2013; Taş et al., 2014), while in this study, we compared sites of similar habitat located over a relatively limited geographic area. A lack of distinct environmental differences should also inform the level of taxonomic resolution that should be used to analyze and compare samples.

In conclusion, we found that statistical differences were dependent on the taxonomic resolution used in the analyses. We also found evidence of functional redundancy relative to taxonomic composition and finally, sequencing depth is highly important when searching for less abundant taxa in microbial rich environments such as soil. 


\section{LITERATURE CITED}

Augé, R. M. (2004). Arbuscular mycorrhizae and soil/plant water relations. Canadian Journal of Soil Science, 84(4), 373-381. https://doi.org/10.4141/S04-002

Aziz, R. K., Bartels, D., Best, A., DeJongh, M., Disz, T., Edwards, R. A., ... Zagnitko, O. (2008). The RAST Server: Rapid annotations using subsystems technology. BMC Genomics, 9. https://doi.org/10.1186/1471-2164-9-75

Bennett, A. E., \& Bever, J. D. (2007). Mycorrhizal species differentially alter plant growth and response to herbivory. Ecology, 88(1), 210-218. https://doi.org/10.1890/0012-9658(2007)88[210:MSDAPG]2.0.CO;2

Bidartondo, M. I., Read, D. J., Trappe, J. M., Merckx, V., Ligrone, R., \& Duckett, J. G. (2011). The dawn of symbiosis between plants and fungi. Biology Letters, 7(4), 574-577. https://doi.org/10.1098/rsbl.2010.1203

Bonnardeaux, Y., Brundrett, M., Batty, A., Dixon, K., Koch, J., \& Sivasithamparam, K. (2007). Diversity of mycorrhizal fungi of terrestrial orchids: compatibility webs, brief encounters, lasting relationships and alien invasions. Mycological Research, 111(1), 51-61. https://doi.org/10.1016/j.mycres.2006.11.006

Canfield, D. E., Glazer, A. N., \& Falkowski, P. G. (2010). The Evolution and Future of Earth's Nitrogen Cycle. Science. American Association for the Advancement of Science. https://doi.org/10.2307/40931809

Chen, H., Mothapo, N. V., \& Shi, W. (2015). Soil Moisture and pH Control Relative Contributions of Fungi and Bacteria to N2O Production. Microbial Ecology, 69(1), 180-191. https://doi.org/10.1007/s00248-014-0488-0

Cleland, E. E., \& Harpole, W. S. (2010). Nitrogen enrichment and plant communities. 
Annals of the New York Academy of Sciences, 1195(1), 46-61.

https://doi.org/10.1111/j.1749-6632.2010.05458.x

Coats, V. C., Pelletreau, K. N., \& Rumpho, M. E. (2014). Amplicon pyrosequencing reveals the soil microbial diversity associated with invasive Japanese barberry (DC.). Molecular Ecology, 23(6), 1318-1332. https://doi.org/10.1111/mec.12544

Di Bella, J. M., Bao, Y., Gloor, G. B., Burton, J. P., \& Reid, G. (2013). High throughput sequencing methods and analysis for microbiome research. Journal of Microbiological Methods, 95(3), 401-14. https://doi.org/10.1016/j.mimet.2013.08.011

Dinsdale, E. A., Edwards, R. A., Bailey, B. A., Tuba, I., Akhter, S., McNair, K., ... Ponomarenko, V. (2013). Multivariate analysis of functional metagenomes. Frontiers in Genetics, 4, 41. https://doi.org/10.3389/fgene.2013.00041

Ellison, M. J., Conant, G. C., Cockrum, R. R., Austin, K. J., Truong, H., Becchi, M., ... Cammack, K. M. (2014). Diet alters both the structure and taxonomy of the ovine gut microbial ecosystem. DNA Research : An International Journal for Rapid Publication of Reports on Genes and Genomes, 21(2), 115-25. https://doi.org/10.1093/dnares/dst044

Field, K. J., Rimington, W. R., Bidartondo, M. I., Allinson, K. E., Beerling, D. J., Cameron, D. D., ... Pressel, S. (2015). First evidence of mutualism between ancient plant lineages (Haplomitriopsida liverworts) and Mucoromycotina fungi and its response to simulated Palaeozoic changes in atmospheric CO. New Phytologist, 205(2), 743-756. https://doi.org/10.1111/nph.13024

Fierer, N. (2017). Embracing the unknown: disentangling the complexities of the soil 
microbiome. Nature Reviews Microbiology, 15(10), 579-590.

https://doi.org/10.1038/nrmicro.2017.87

Fierer, N., \& Jackson, R. B. (2006). The diversity and biogeography of soil bacterial communities. Proceedings of the National Academy of Sciences of the United States of America, 103(3), 626-31. https://doi.org/10.1073/pnas.0507535103

Fierer, N., Ladau, J., Clemente, J. C., Leff, J. W., Owens, S. M., Pollard, K. S., ... McCulley, R. L. (2013). Reconstructing the Microbial Diversity and Function of Pre-Agricultural Tallgrass Prairie Soils in the United States. Science (AAAS), 342(6158), 621-624. https://doi.org/10.1126/science.1243768

Fierer, N., Lauber, C. L., Ramirez, K. S., Zaneveld, J., Bradford, M. A., \& Knight, R. (2012). Comparative metagenomic, phylogenetic and physiological analyses of soil microbial communities across nitrogen gradients. The ISME Journal, 6(5), 1007-17. https://doi.org/10.1038/ismej.2011.159

Flight, M. H. (2013). Neurodevelopmental disorders: The gut-microbiome-brain connection. Nature Publishing Group, 15(FEBRUARY 2014), 3669. https://doi.org/10.1038/nrn3669

Friesen, M. L. (2012). Widespread fitness alignment in the legume-rhizobium symbiosis. New Phytologist, 194(4), 1096-1111. https://doi.org/10.1111/j.14698137.2012.04099.x

Heckman, D. S., Geiser, D. M., Eidell, B. R., Stauffer, R. L., Kardos, N. L., \& Hedges, S. B. (2001). Molecular evidence for the early colonization of land by fungi and plants. Science, 293(5532), 1129-1133. https://doi.org/10.1126/science.1061457

Howe, A. C., Jansson, J. K., Malfatti, S. A., Tringe, S. G., Tiedje, J. M., \& Brown, C. T. 
(2014). Tackling soil diversity with the assembly of large, complex metagenomes. Proceedings of the National Academy of Sciences of the United States of America, 111(13), 4904-9. https://doi.org/10.1073/pnas.1402564111

Inderjit, \& Cahill, J. F. (2015). Linkages of plant-soil feedbacks and underlying invasion mechanisms. AoB Plants, 7(0), plv022-. https://doi.org/10.1093/aobpla/plv022

Khan, A. A., Jilani, G., Akhtar, M. S., Saqlan, S. M., \& Rasheed, M. (2009). Phosphorus Solubilizing Bacteria: Occurrence, Mechanisms and their Role in Crop Production. Journal of Agriculture and Biological Sciences, 1(1), 48-58. https://doi.org/10.5923/j.re.20120201.10

Kõljalg, U., Nilsson, R. H., Abarenkov, K., Tedersoo, L., Taylor, A. F. S., Bahram, M., ... Larsson, K.-H. (2013). Towards a unified paradigm for sequence-based identification of fungi. Molecular Ecology, 22(21), 5271-5277. https://doi.org/10.1111/mec.12481

Kulmatiski, A., Beard, K. H., Stevens, J. R., \& Cobbold, S. M. (2008). Plant-soil feedbacks: a meta-analytical review. Ecology Letters, 11(9), 980-92. https://doi.org/10.1111/j.1461-0248.2008.01209.x

Landeweert, R., Hoffland, E., Finlay, R. D., Kuyper, T. W., \& Van Breemen, N. (2001). Linking plants to rocks: Ectomycorrhizal fungi mobilize nutrients from minerals. Trends in Ecology and Evolution. https://doi.org/10.1016/S0169-5347(01)02122-X

Lauber, C. L., Ramirez, K. S., Aanderud, Z., Lennon, J., \& Fierer, N. (2013). Temporal variability in soil microbial communities across land-use types. The ISME Journal, 7(8), 1641-50. https://doi.org/10.1038/ismej.2013.50

LeBauer, D. S., \& Treseder, K. K. (2008). Nitrogen limitation of net primary productivity 
in terrestrial ecosystems is globally distributed. Ecology, 89(2), 371-379. https://doi.org/10.1890/06-2057.1

Lennon, J. T., \& Jones, S. E. (2011). Microbial seed banks: The ecological and evolutionary implications of dormancy. Nature Reviews Microbiology. https://doi.org/10.1038/nrmicro2504

Ley, R. E., Lozupone, C. A., Hamady, M., Knight, R., \& Gordon, J. I. (2008). Worlds within worlds: evolution of the vertebrate gut microbiota. Nature Reviews. Microbiology, 6(10), 776-88. https://doi.org/10.1038/nrmicro1978

Maron, P.-A., Mougel, C., \& Ranjard, L. (2011). Soil microbial diversity: Methodological strategy, spatial overview and functional interest. Comptes Rendus Biologies, 334(5-6), 403-11. https://doi.org/10.1016/j.crvi.2010.12.003

Mendes, L. W., Tsai, S. M., Navarrete, A. A., de Hollander, M., van Veen, J. A., \& Kuramae, E. E. (2015). Soil-Borne Microbiome: Linking Diversity to Function. Microbial Ecology, 70(1), 255-265. https://doi.org/10.1007/s00248-014-0559-2

Meyer, F., Paarmann, D., D’Souza, M., Olson, R., Glass, E. M., Kubal, M., ... Edwards, R. A. (2008). The metagenomics RAST server - a public resource for the automatic phylogenetic and functional analysis of metagenomes. BMC Bioinformatics, 9, 386. https://doi.org/10.1186/1471-2105-9-386

Mocali, S., \& Benedetti, A. (2010). Exploring research frontiers in microbiology: the challenge of metagenomics in soil microbiology. Research in Microbiology, 161(6), 497-505. https://doi.org/10.1016/j.resmic.2010.04.010

Morgan, X. C., \& Huttenhower, C. (2012). Chapter 12: Human microbiome analysis. PLoS Computational Biology, 8(12), e1002808. 
https://doi.org/10.1371/journal.pcbi.1002808

O’Brien, S. L., Gibbons, S. M., Owens, S. M., Hampton-Marcell, J., Johnston, E. R., Jastrow, J. D., ... Antonopoulos, D. A. (2016). Spatial scale drives patterns in soil bacterial diversity. Environmental Microbiology, 18(6), 2039-51. https://doi.org/10.1111/1462-2920.13231

Ong, S. H., Kukkillaya, V. U., Wilm, A., Lay, C., Ho, E. X. P., Low, L., ... Nagarajan, N. (2013). Species identification and profiling of complex microbial communities using shotgun Illumina sequencing of $16 \mathrm{~S}$ rRNA amplicon sequences. PloS One, 8(4), e60811. https://doi.org/10.1371/journal.pone.0060811

Overbeek, R., Begley, T., Butler, R. M., Choudhuri, J. V, Chuang, H.-Y., Cohoon, M., ... Vonstein, V. (2005). The subsystems approach to genome annotation and its use in the project to annotate 1000 genomes. Nucleic Acids Research, 33(17), 5691-702. https://doi.org/10.1093/nar/gki866

Overbeek, R., Olson, R., Pusch, G. D., Olsen, G. J., Davis, J. J., Disz, T., ... Stevens, R. (2014). The SEED and the Rapid Annotation of microbial genomes using Subsystems Technology (RAST). Nucleic Acids Research, 42(Database issue), D206-14. https://doi.org/10.1093/nar/gkt1226

Plummer, E., Twin, J., Bulach, D. M., Garland, S. M., \& Tabrizi, S. N. (2015). A Comparison of Three Bioinformatics Pipelines for the Analysis of Preterm Gut Microbiota using 16S rRNA Gene Sequencing Data. J Proteomics Bioinform Citation, 8(12), 283-291. https://doi.org/10.4172/jpb.1000381

Rasmussen, H. N., Dixon, K. W., Jersáková, J., \& Těšitelová, T. (2015a). Germination and seedling establishment in orchids: A complex of requirements. Annals of 
Botany. https://doi.org/10.1093/aob/mcv087

Rasmussen, H. N., Dixon, K. W., Jersáková, J., \& Těšitelová, T. (2015b). Germination and seedling establishment in orchids: a complex of requirements. Annals of Botany, mcv087-. https://doi.org/10.1093/aob/mcv087

Schloss, P. D., \& Handelsman, J. (2006). Toward a census of bacteria in soil. PLoS Computational Biology, 2(7), e92. https://doi.org/10.1371/journal.pcbi.0020092

Selosse, M. A., Richard, F., He, X., \& Simard, S. W. (2006). Mycorrhizal networks: des liaisons dangereuses? Trends in Ecology and Evolution. https://doi.org/10.1016/j.tree.2006.07.003

Sheviak, C. J., \& Bowles, M. L. (1986). The prairie fringed orchids: a pollinator-isolated species pair. Rhodora, 88, 267-290.

Simon, C., \& Daniel, R. (2011). Metagenomic analyses: past and future trends. Applied and Environmental Microbiology, 77(4), 1153-61. https://doi.org/10.1128/AEM.02345-10

Swarts, N. D., \& Dixon, K. W. (2009). Terrestrial orchid conservation in the age of extinction. Annals of Botany, 104(3), 543-56. https://doi.org/10.1093/aob/mcp025

Taş, N., Prestat, E., McFarland, J. W., Wickland, K. P., Knight, R., Berhe, A. A., ... Jansson, J. K. (2014). Impact of fire on active layer and permafrost microbial communities and metagenomes in an upland Alaskan boreal forest. The ISME Journal, 8(9), 1904-19. https://doi.org/10.1038/ismej.2014.36

Tedersoo, L., Abarenkov, K., Nilsson, R. H., Schüssler, A., Grelet, G.-A., Kohout, P., ... Kõljalg, U. (2011). Tidying Up International Nucleotide Sequence Databases: Ecological, Geographical and Sequence Quality Annotation of ITS Sequences of 
Mycorrhizal Fungi. PLoS ONE, 6(9), e24940.

https://doi.org/10.1371/journal.pone.0024940

Tedersoo, L., Bahram, M., Polme, S., Koljalg, U., Yorou, N. S., Wijesundera, R., ... Abarenkov, K. (2014). Global diversity and geography of soil fungi. Science, 346(6213), 1256688-1256688. https://doi.org/10.1126/science.1256688

Traveset, A., \& Richardson, D. M. (2014). Mutualistic Interactions and Biological Invasions. Annual Review of Ecology, Evolution, and Systematics, 45(1), 140924162923008-. https://doi.org/10.1146/annurev-ecolsys-120213-091857

Tringe, S. G. (2005). Comparative Metagenomics of Microbial Communities. Science (AAAS), 308(5721), 554-557. https://doi.org/10.1126/science.1107851

U.S. Fish and Wildlife Service. (1996). Platanthera praeclara (western prairie fringed orchid) recovery plan. Ft. Snelling, MN.

U.S. Fish and Wildlife Service. (2001). Eastern prairie fringed orchid, Platanthera leucophaea (Nuttall) Lindley recovery plan. Fort Snelling, Minnesota.

U.S. Fish and Wildlife Service. (2009). Western Prairie Fringed Orchid (Platanthera praeclara) 5-year Review: Summary and Evaluation. Bloomington, Minnesota.

van der Heijden, M. G. A., Bardgett, R. D., \& van Straalen, N. M. (2008). The unseen majority: soil microbes as drivers of plant diversity and productivity in terrestrial ecosystems. Ecology Letters, 11(3), 296-310. https://doi.org/10.1111/j.14610248.2007.01139.x

Van Der Heijden, M. G. A., Klironomos, J. N., Ursic, M., Moutoglis, P., StreitwolfEngel, R., Boller, T., ... Sanders, I. R. (1998). Mycorrhizal fungal diversity determines plant biodiversity, ecosystem variability and productivity. Nature, 
396(6706), 69-72. https://doi.org/10.1038/23932

Wagg, C., Jansa, J., Schmid, B., \& van der Heijden, M. G. A. (2011). Belowground biodiversity effects of plant symbionts support aboveground productivity. Ecology Letters, 14(10), 1001-1009. https://doi.org/10.1111/j.1461-0248.2011.01666.x

Wallace, L. E. (2003). The cost of inbreeding in Platanthera leucophaea (Orchidaceae). American Journal of Botany, 90(2), 235-242. https://doi.org/10.3732/ajb.90.2.235

Wang, B., \& Qiu, Y.-L. (2006). Phylogenetic distribution and evolution of mycorrhizas in land plants. Mycorrhiza, 16(5), 299-363. https://doi.org/10.1007/s00572-0050033-6

Welch, B. L. (1947). The generalisation of student's problems when several different population variances are involved. Biometrika, 34(1-2), 28-35. https://doi.org/10.1093/biomet/34.1-2.28

Whitman, W. B., Coleman, D. C., \& Wiebe, W. J. (1998). Prokaryotes: The unseen majority. Proceedings of the National Academy of Sciences, 95(12), 6578-6583. https://doi.org/10.1073/pnas.95.12.6578

Wilke, A., Bischof, J., Gerlach, W., Glass, E., Harrison, T., Keegan, K. P., ... Meyer, F. (2016). The MG-RAST metagenomics database and portal in 2015. Nucleic Acids Research, 44(D1), D590-D594. https://doi.org/10.1093/nar/gkv1322

Wilke, A., Harrison, T., Wilkening, J., Field, D., Glass, E. M., Kyrpides, N., ... Meyer, F. (2012). The M5nr: a novel non-redundant database containing protein sequences and annotations from multiple sources and associated tools. BMC Bioinformatics, 13(1), 141. https://doi.org/10.1186/1471-2105-13-141

Wooley, J. C., Godzik, A., \& Friedberg, I. (2010). A primer on metagenomics. PLoS 
Computational Biology, 6(2), e1000667.

https://doi.org/10.1371/journal.pcbi.1000667

Zhang, C., \& Kong, F. (2014). Isolation and identification of potassium-solubilizing bacteria from tobacco rhizospheric soil and their effect on tobacco plants. Applied Soil Ecology, 82, 18-25. https://doi.org/10.1016/j.apsoil.2014.05.002 
FIGURES

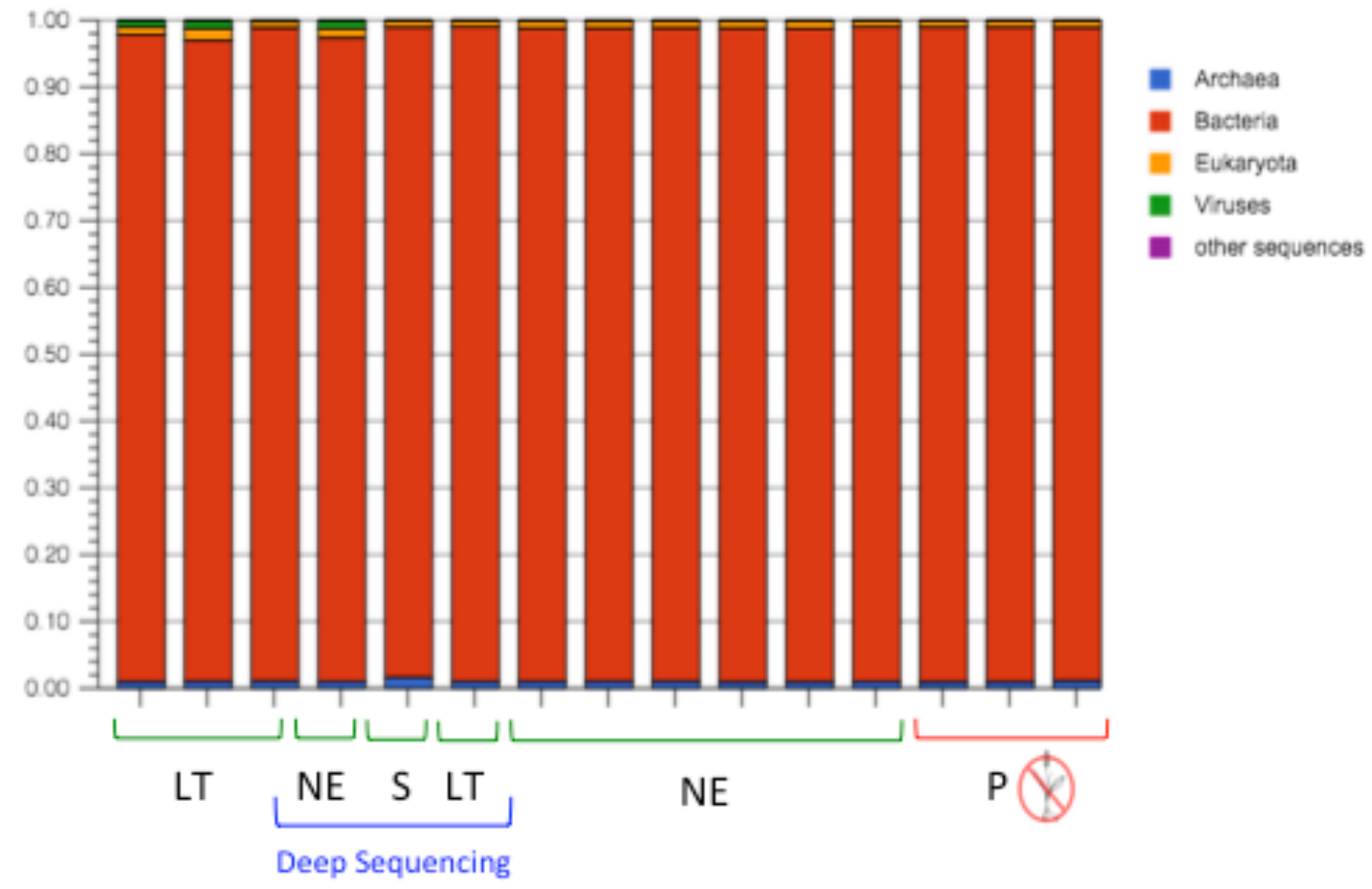

Figure 1. Taxonomic composition of samples at the Domain level Reads have been normalized. 


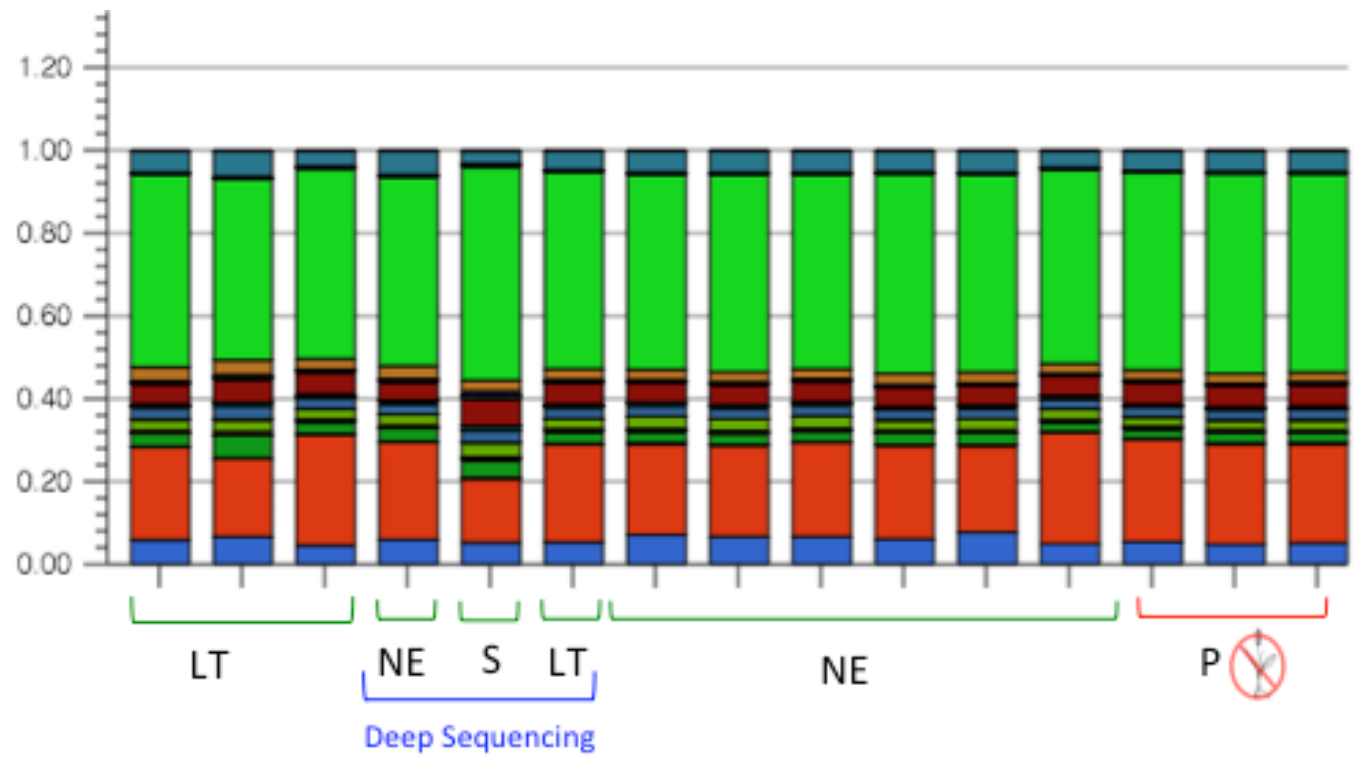

Figure 2. Taxonomic composition of samples by phylum within Bacteria domain. Reads have been normalized.

- Acidobacteria

- Actinobacteria

Aquificae

- Bacteroidetes

- Candidatus Poribacteria

- Chlamydiae

- Chlorobi

Chloroflex

- Chrysiogenetes

- Cyanobacteria

Deferribacteres

- Deinococcus-Thermus

- Dictyoglomi

- Elusimicrobia

- Fibrobacteres

- Firmicutes

- Fusobacteria

- Gemmatimonadetes

- Lentisphaerae

- Nitrospirae

- Planctomycetes

- Proteobacteria

- Spirochaetes

- Synergistetes

- Tenericutes

[1] Thermotogae

- Verrucomicrobia

- unclassified (derived from Bacteria) 


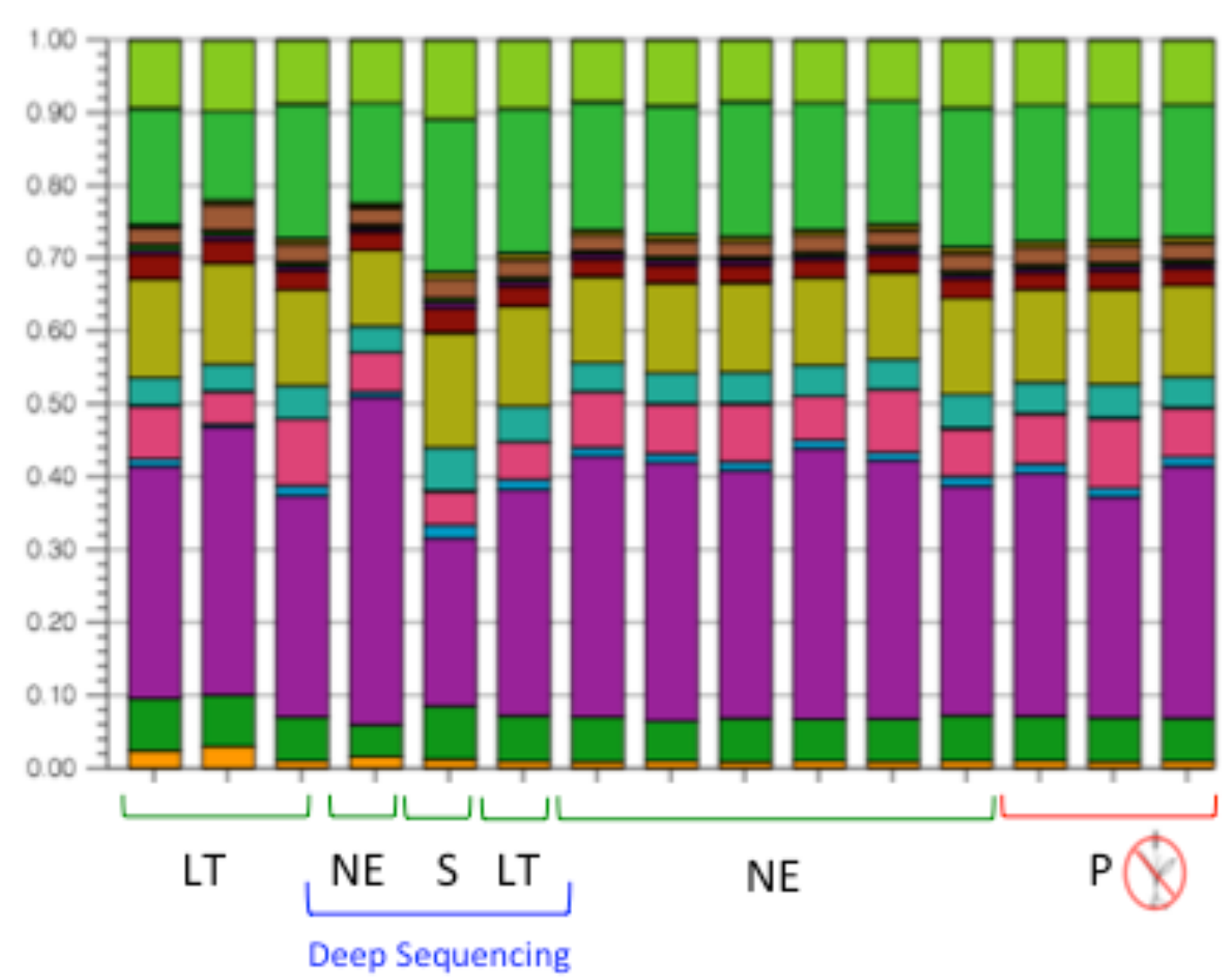

Figure 3. Taxonomic composition of samples by phylum within Eukaryota domain. Reads have been normalized. Five most abundant phyla have been highlighted in red in the legend.

- Chytridiomycota

- Cnidaria

- Echinodermata

- Echiura

- Entoprocta

- Euglenida

- Glomeromycota

- Hemichordata

- Microsporidia

- Mollusca

- Nematoda

[1 Nemertea

- Onychophora

- Phaeophyceae

- Placozoa

- Platyhelminthes

- Porifera

- Priapulida

- Rotifera

- Sipuncula

- Streptophyta

- Tardigrada

- Xanthophyceae

- Xenoturbellida

_ unclassified (derived from Eukaryota)

- unclassified (derived from Fungi) 


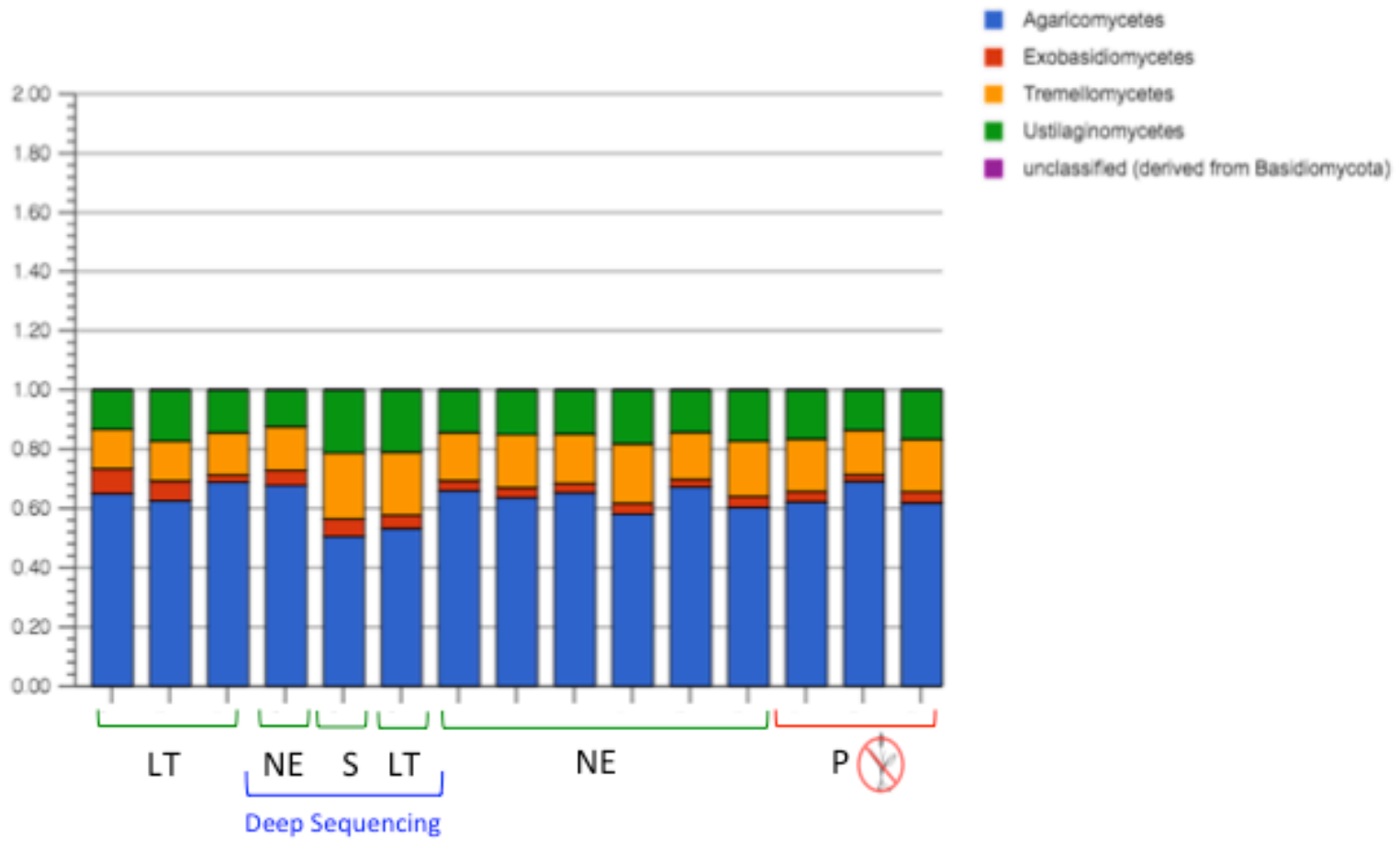

Figure 4. Taxonomic composition of samples by Class within the Basidiomycota phylum. Reads have been normalized. 


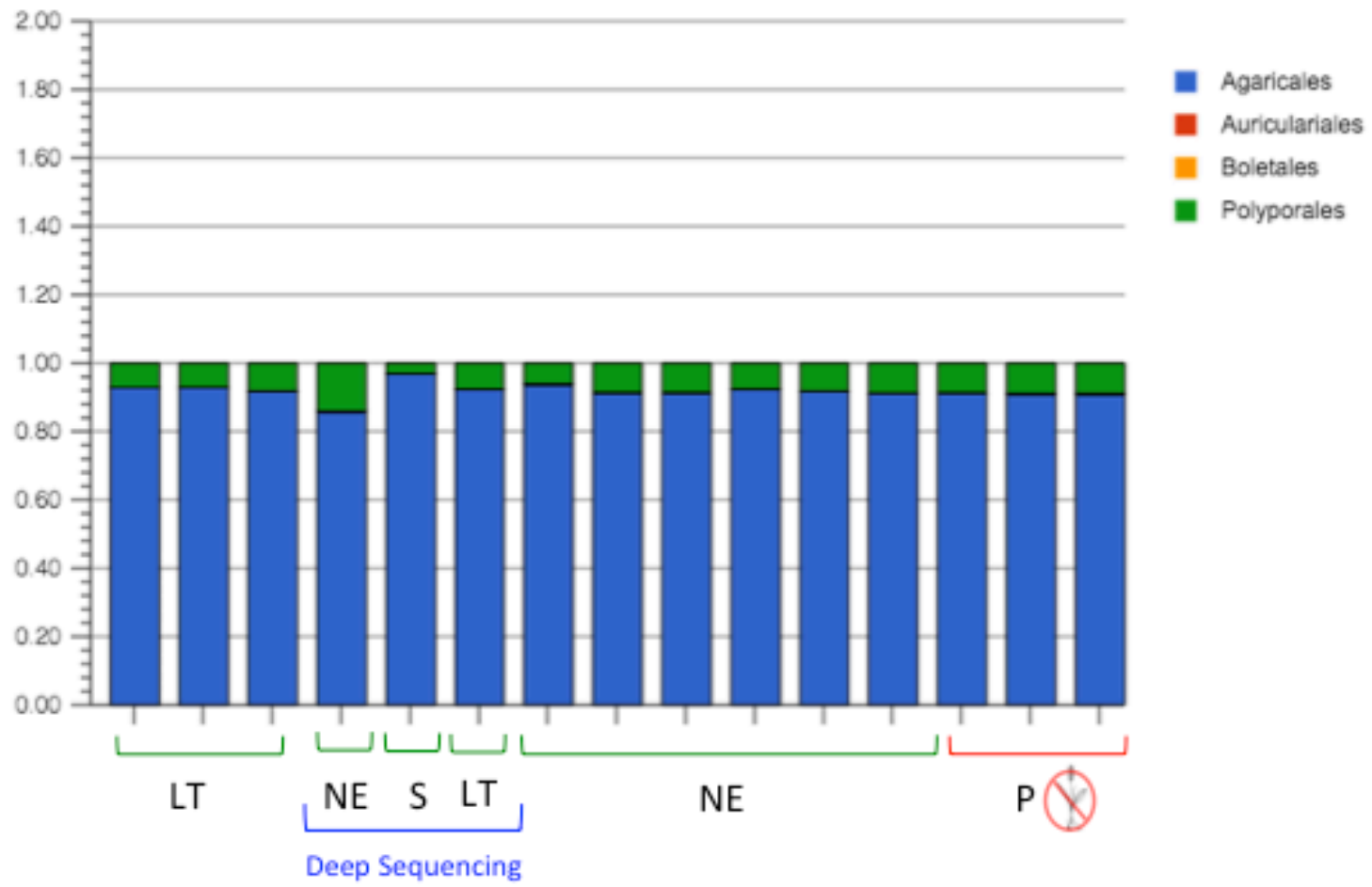

Figure 5. Taxonomic composition of samples by order within Agaricomycetes Class. Reads have been normalized. 


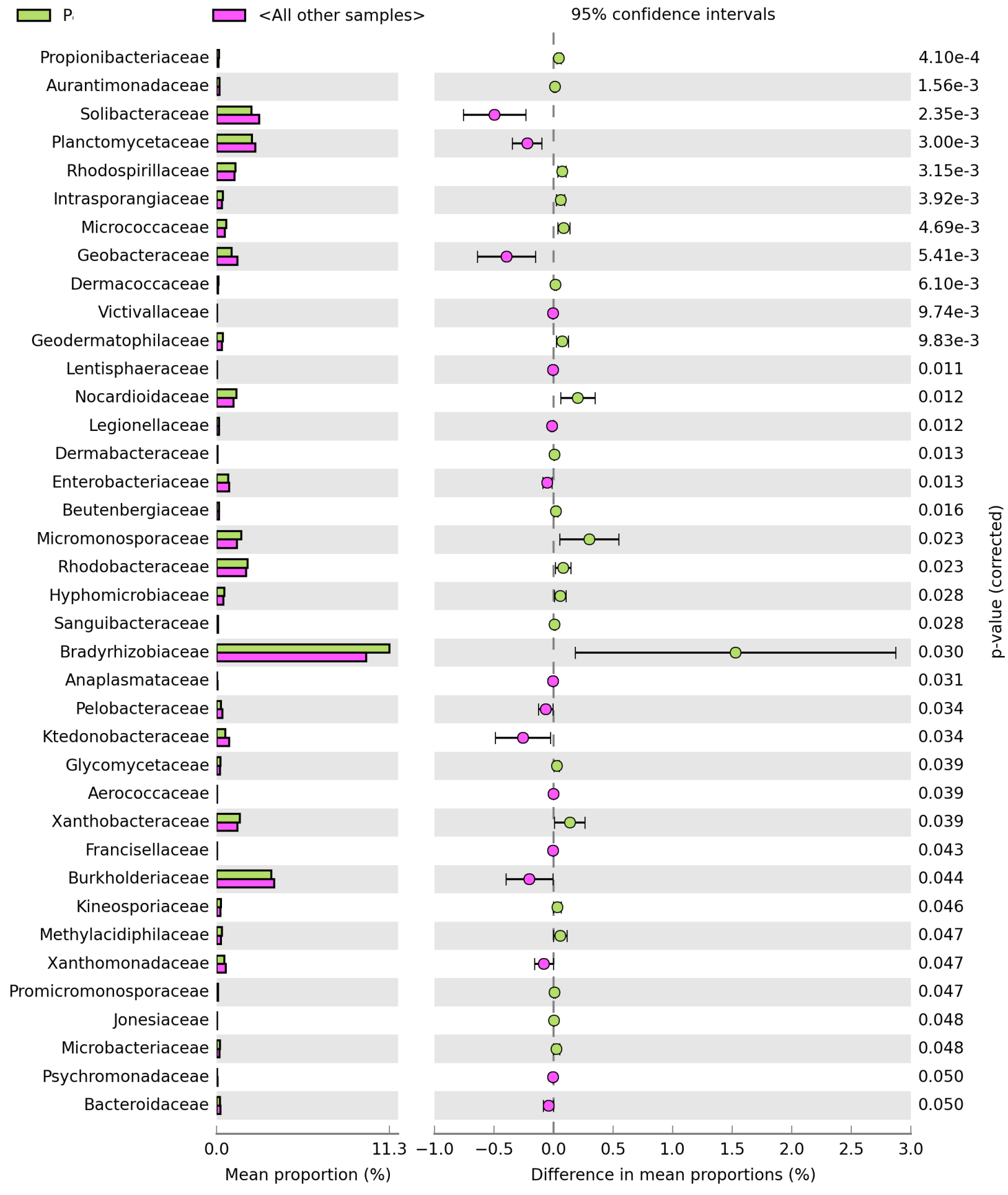

Figure 6. Comparison of Bacteria families

These families show significant differences between site " $\mathrm{P}$ " (no orchids) and all the other sample sites (with orchids). Reads have been normalized. 


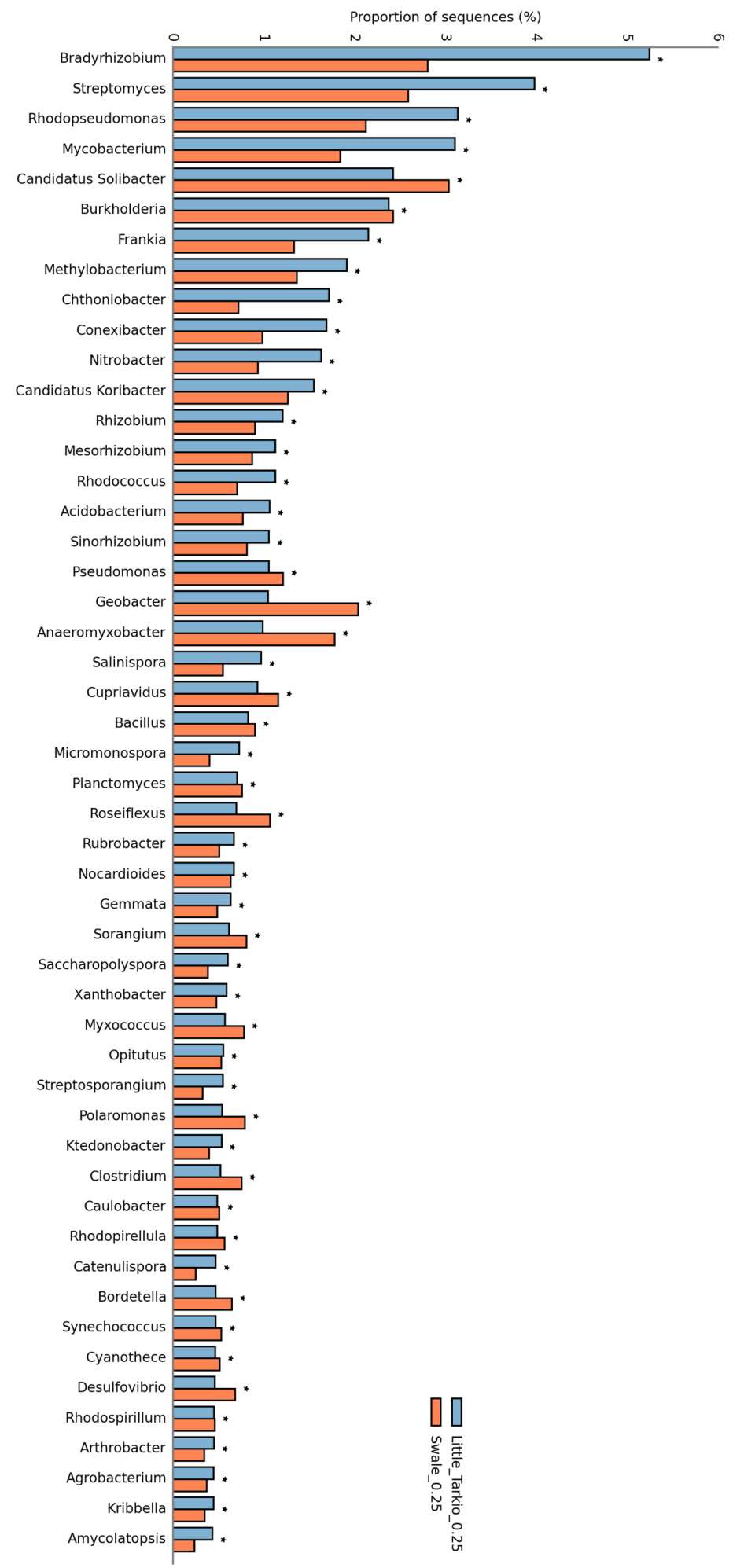

Figure 7. Bacteria genera comparison between " $\mathrm{S}$ " (Swale) and "LT" (Little Tarkio). These samples were taken at close to an orchid. This figure shows the top 50 most abundant genera that were statistically significant. 


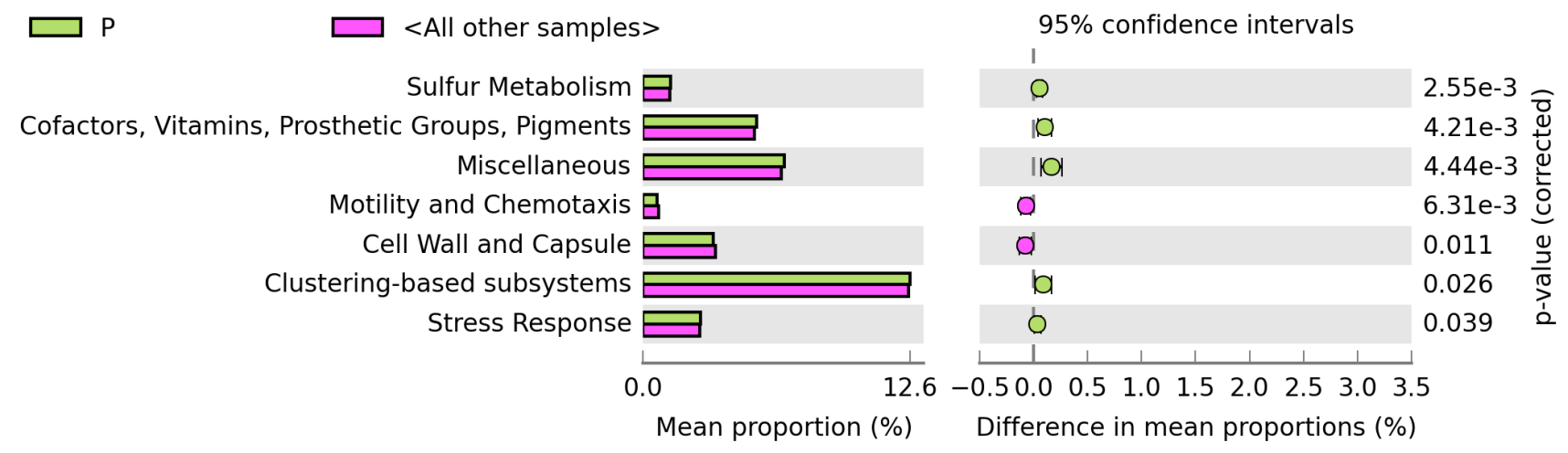

Figure 8. Comparison of functional profiles with SEED subsystems between site "P" (no orchids) and "All other sites". 


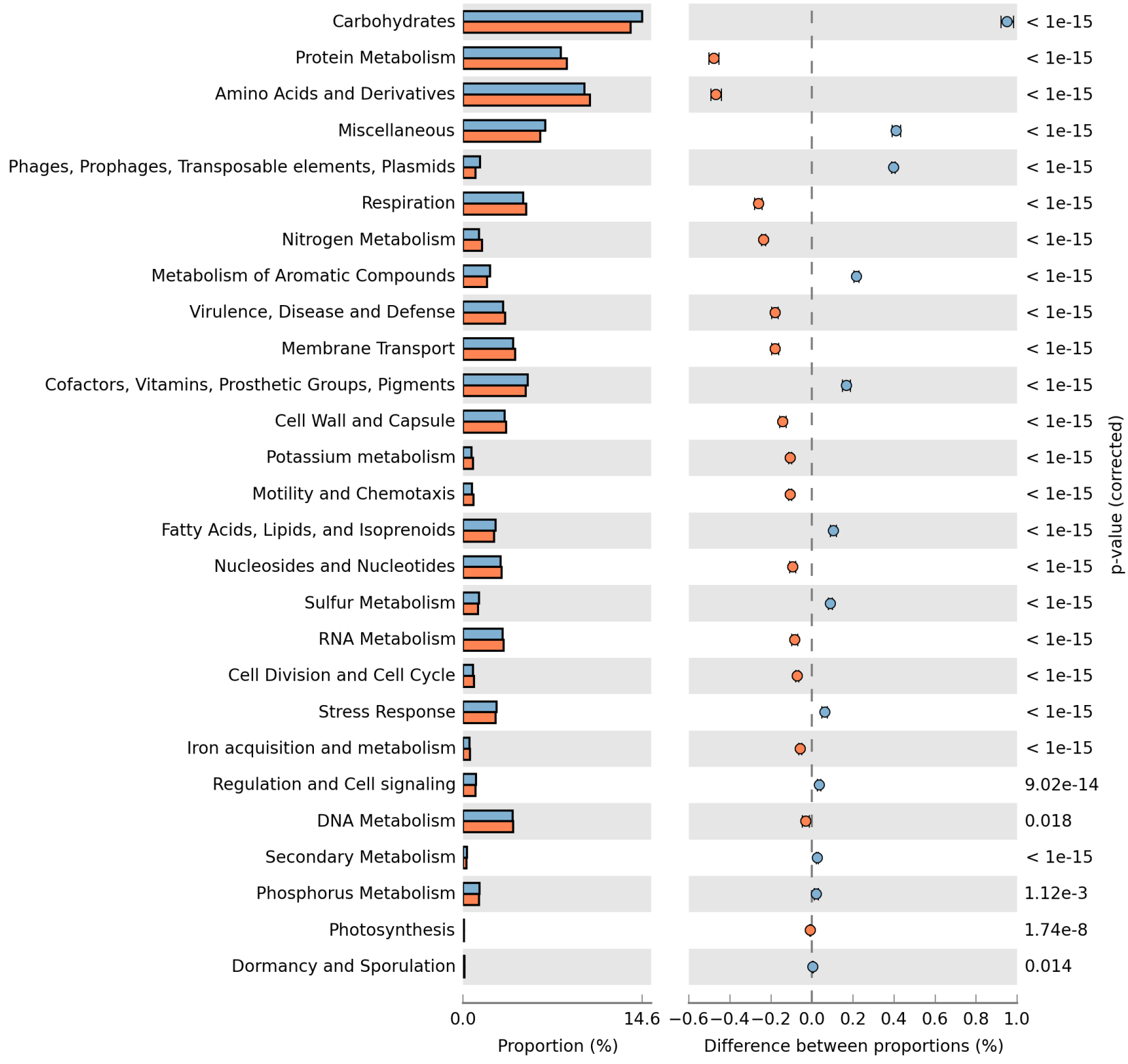

Figure 9. Comparison of functional microbiome using Subsystems (SEED) for samples "S" and "LT". These samples were taken at a close distance to an orchid $(0.25 \mathrm{~cm})$. 


\begin{tabular}{|c|c|c|c|c|c|c|c|c|c|}
\hline $\begin{array}{l}\text { MG-RAST } \\
\text { SAMPLE ID }\end{array}$ & $\begin{array}{l}\text { Sample } \\
\text { Name }\end{array}$ & Location & Proximity & bp Count & $\begin{array}{c}\text { Sequence } \\
\text { Count }\end{array}$ & $\begin{array}{c}\text { mean } \\
\text { bp }\end{array}$ & $\begin{array}{l}\% \\
\text { known } \\
\text { protein }\end{array}$ & $\begin{array}{l}\% \\
\text { unknown } \\
\text { protein }\end{array}$ & $\begin{array}{l}\text { \% Total } \\
\text { predicted } \\
\text { protein }\end{array}$ \\
\hline 1_CGATGT_L001_R & NE01 & North Evans & Near & $106,751,778$ & 463,400 & 230 & 42.6 & 57.2 & 99.8 \\
\hline 2_CAGATC_L001_R & S01 & Swale & Near & $12,767,097,930$ & $84,775,282$ & 151 & 34.4 & 65.5 & 99.9 \\
\hline 3_GTGAAA_L001_R & LT01 & Little Tarkio & Near & $6,479,871,224$ & $42,957,209$ & 151 & 36.2 & 63.7 & 99.9 \\
\hline 4_CGATGT_LO02_R & NE02 & North Evans & Intermediate & $2,683,689,003$ & $17,790,637$ & 151 & 34.8 & 65.1 & 99.9 \\
\hline 5_TGACCA_L002_R & NE03 & North Evans & Intermediate & $2,606,252,163$ & $17,283,191$ & 151 & 34.6 & 65.3 & 99.9 \\
\hline 6_ACAGTG_L002_R & NE04 & North Evans & Intermediate & $3,227,673,351$ & $21,377,144$ & 151 & 35.1 & 64.8 & 99.9 \\
\hline 7_GCCAAT_L002_R & NE06 & North Evans & Far & $3,049,794,336$ & $20,210,278$ & 151 & 35.1 & 64.8 & 99.9 \\
\hline 8_CAGATC_L002_R & NE07 & North Evans & Far & $2,985,878,617$ & $19,780,938$ & 151 & 34.7 & 65.2 & 99.9 \\
\hline 9_CTTGTA_L002_R & NE08 & North Evans & Far & $2,727,376,701$ & $18,096,573$ & 151 & 35.9 & 64 & 99.9 \\
\hline 10_AGTCAA_L002_R & P01 & $\begin{array}{l}\text { Pawnee } \\
\text { Prairie }\end{array}$ & No orchids & $2,793,544,076$ & $18,524,186$ & 151 & 36.9 & 62.9 & 99.8 \\
\hline 11_AGTTCC_L002_R & $\mathrm{P} 02$ & $\begin{array}{l}\text { Pawnee } \\
\text { Prairie }\end{array}$ & No orchids & $2,815,776,048$ & $18,674,226$ & 151 & 36.6 & 63.3 & 99.9 \\
\hline 12_ATGTCA_L002_R & P03 & $\begin{array}{l}\text { Pawnee } \\
\text { Prairie }\end{array}$ & No orchids & $2,867,599,871$ & $19,002,498$ & 151 & 36.1 & 63.8 & 99.9 \\
\hline 13_CCGTCC_L002_R & LT02 & Little Tarkio & Far & $48,692,119$ & 211,069 & 231 & 42.9 & 56.9 & 99.8 \\
\hline 14_GTCCGC_L002_R & LT03 & Little Tarkio & Far & $47,155,059$ & 203,010 & 232 & 41.1 & 58.7 & 99.8 \\
\hline 15_GTGAAA_L002_R & LT04 & Little Tarkio & Far & $2,171,565,526$ & $14,391,268$ & 151 & 35.2 & 64.7 & 99.9 \\
\hline
\end{tabular}

Table S1. Sequencing information for the 15 sample metagenomes 
Phages, Prophages, Transposable elements, Plasmids

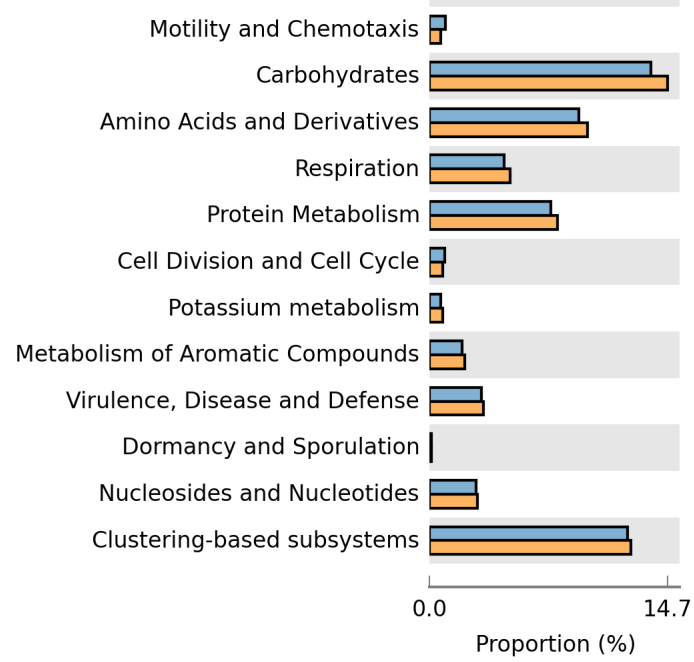

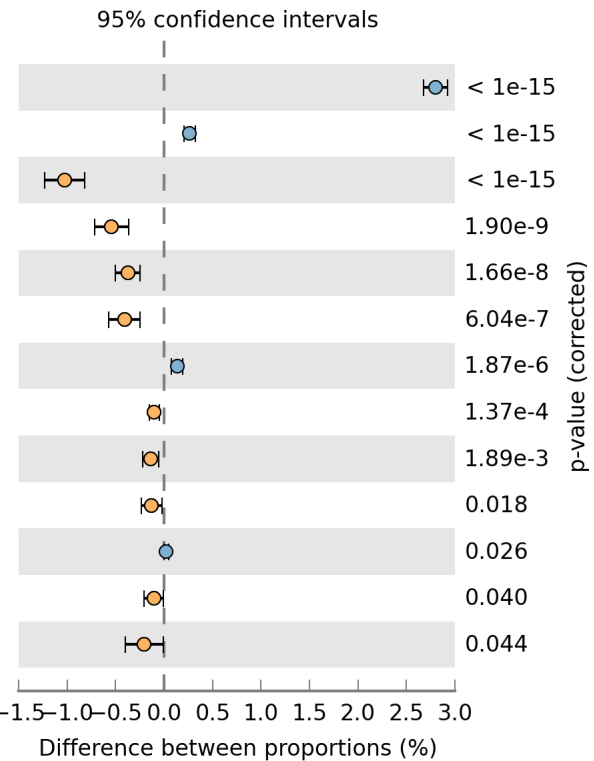

Appendix. Figure S1. Comparison of sample "N01" which had much lower reads than sample "N02". Sample N01 had a high relative abundance of Viruses as seen in Figure 1.

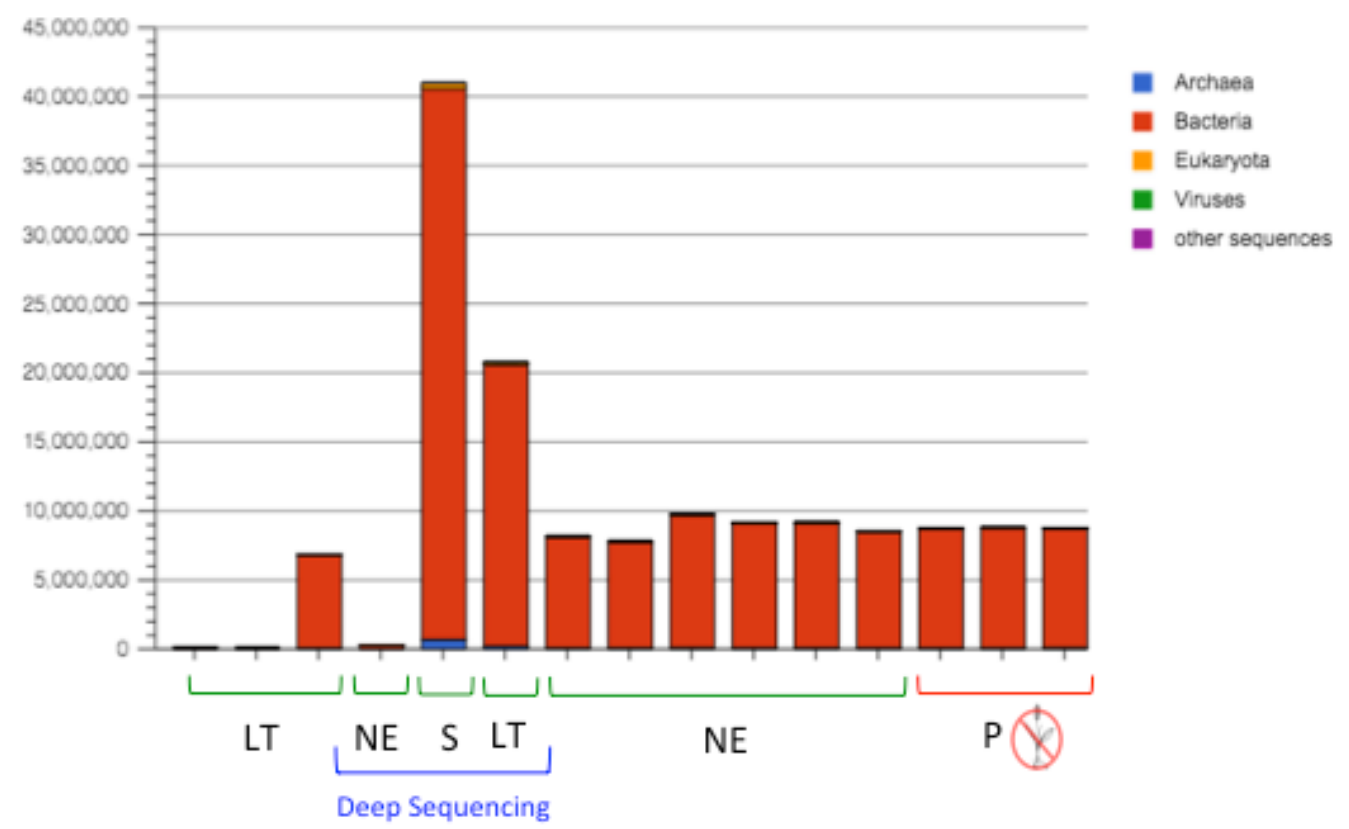

Appendix. Figure S2. Non-normalized taxonomic distribution 


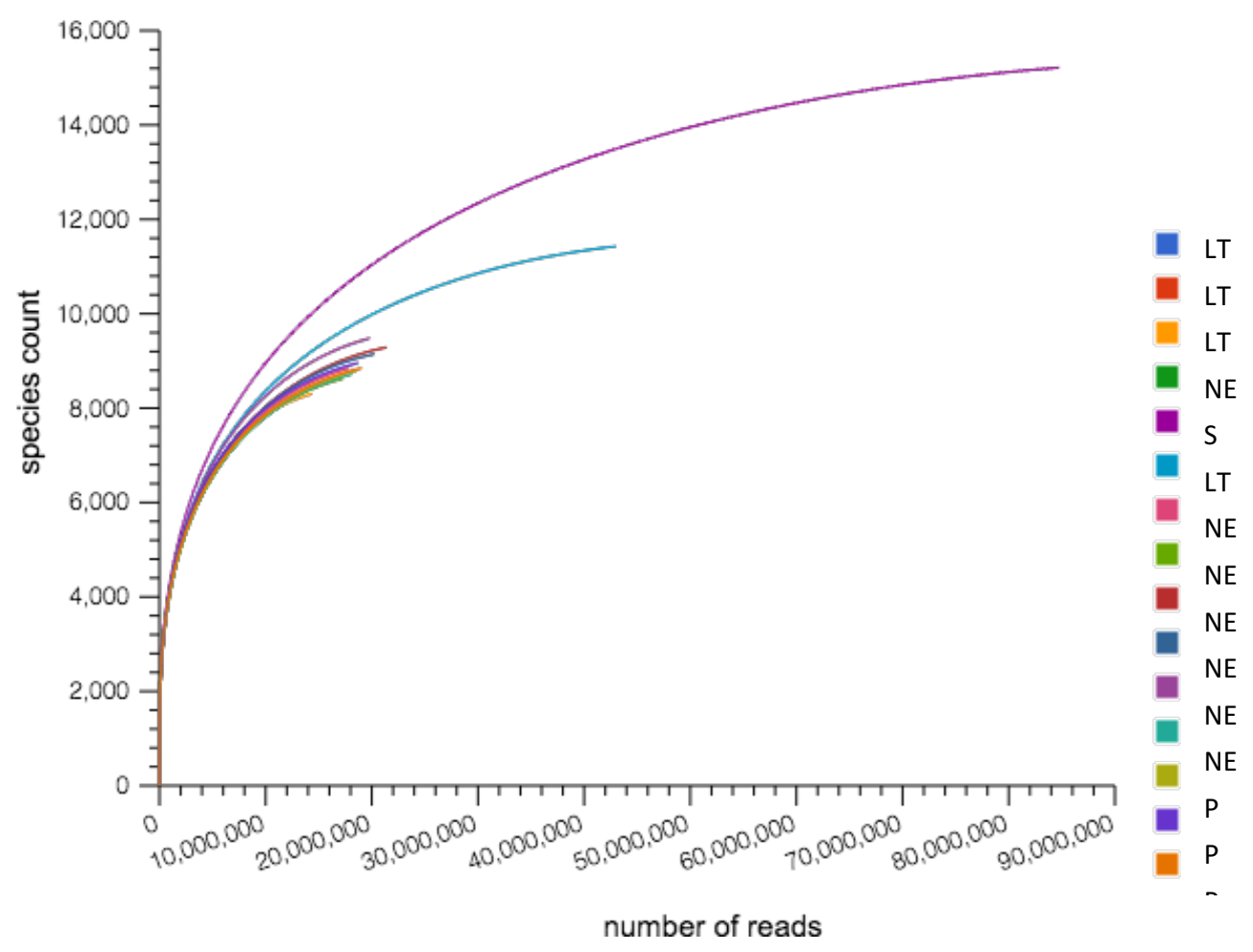

Appendix Figure S3. Alpha rarefaction curves 


\title{
CHAPTER 3
}

\section{Bacterial Influence on the Symbiotic Germination of Orchid Seeds}

\author{
ABSTRACT \\ Orchid mycorrhizal fungi play a special role in the germination of orchid seeds, as they \\ invade the embryo and form a mass of orchid and fungal tissue called a protocorm. The \\ mycorrhiza functions as the sole provider of carbon compounds at this stage in the plant's \\ development. An additional element impacting the orchid-mycorrhizal symbiosis, is the \\ effect bacteria have on the mycorrhizal role of seed germination. Some bacteria help \\ establish and support the mycorrhizal relationship with the plant. We isolated bacteria \\ from an adult orchid and tested the influence of these bacterial cultures on the \\ germination of orchid seeds, which were symbiotically germinated with a mycorrhizal \\ fungus. We isolated and identified three bacteria strains: Paraburkholderia sediminicola, \\ Variovorax boronicumulans and Sphingomonas sp. strain BPM3 and used seeds from \\ Prosthechea boothiana (dollar orchid) and a strain of Tulasnella, an orchid mycorrhizal \\ fungus. \\ At 30 and 45 days after inoculation we counted germination stages. There were \\ significant differences between the treatments and control only at stage 4 of protocorm \\ development but not for earlier stages. There were also significant differences between \\ the seed sowing batches for developmental stages $0-3$. These results highlight the need \\ for broader surveys of orchid associated bacteria in germination studies as well as the \\ importance of determining an optimum pretreatment germination protocol for \\ Prosthechea boothiana.
}




\section{INTRODUCTION}

The relationship between orchids and their mycorrhizal fungal symbionts has been a topic of study ever since the discovery of the relationship by Noel Bernard in 1899 (MarcAndré Selosse, Boullard, \& Richardson, 2011).

Orchid mycorrhizal fungi play a special role in the germination of orchid seeds. These mycorrhizal fungi invade the embryo and form a mass of orchid and fungal tissue called a protocorm (Smith \& Read, 2008). Due to the lack of endosperm in the seed, which facilitates the development of the embryo into a seedling, the mycorrhiza functions as the sole provider of carbon compounds at this stage in the plant's development (Rasmussen, Dixon, Jersáková, \& Těšitelová, 2015). The protocorm continues to grow until it forms a seedling with a shoot and true leaf. Once the seedling is able to photosynthesize, the association with the fungus is less crucial, however, there is some evidence that the relationship is maintained even as the orchid develops into an adult plant (Cameron, Leake, \& Read, 2006; Stöckel, Těšitelová, Jersáková, Bidartondo, \& Gebauer, 2014). Symbiotic germination studies of orchids with mycorrhizal fungi often focus on determining which fungi are able to germinate the seeds and once germinated, if the protocorms are able to continue their growth and develop into seedlings. These fungi are usually isolated from root tissues of orchids and then cultivated in the lab. Fungal plugs from these cultures are then used to inoculate plates with growth media and orchid seeds to induce germination (Dearnaley, 2007; Fracchia, Aranda-Rickert, Flachsland, Terada, \& Sede, 2014; Zettler, Stewart, Bowles, \& Karel, 2001). There are some orchid mycorrhizal fungi that are able to produce germination in several orchid species. However, there are different degrees of specificity in the orchid 
myccorrhizal relationship and some orchids require a specific fungal symbiont (Pandey, Sharma, Taylor, \& Yadon, 2013; Sharma, Zettler, Van Sambeek, Ellersieck, \& Starbuck, 2003). There is also evidence that different fungal species will associate with a species of orchid at different times in the plant's life cycle. This assemblage of fungi can vary temporally or they can co-occur simultaneously (Dearnaley, 2007; Jacquemyn et al., 2014).

Despite being an active field of study, and considering the importance this symbiotic relationship has for orchids, there are still many unknowns (Marc-Andre Selosse, 2014). An additional element impacting the orchid-mycorrhizal symbiosis, is the effect bacteria have on the mycorrhizal role of seed germination. This topic has received some attention but is still an emerging area of research (Shekhovtsova, Marakaev, Pervushina, \& Osipov, 2013; Wilkinson, Dixon, \& Sivasithamparam, 1989).

Bacteria are abundant and widespread members of the microbial community, which are known to affect plants in a myriad of ways due to their roles as nutrient cyclers, pathogens and also growth promoters (Buée, de Boer, Martin, van Overbeek, \& Jurkevitch, 2009; Glick, 2012). Some bacteria can directly impact the relationship between plants and mycorrhiza and are known as Myccorhizal Helper Bacteria (Deveau \& Labbé, 2016). They, amongst other functions, help establish and support the mycorrhizal relationship with the plant.

Research that used to limit itself to the study of the plant and mycorrhizal fungus is now starting to incorporate the role of bacteria. As we learn more about the microbial community and its interactions, a clearer picture of the tri-partite relationship between plants, mycorrizal fungi and bacteria is starting to emerge (Bonfante \& Anca, 2009). 
Within orchid research, a handful of studies have started to incorporate the role of bacteria as well. In one of the first studies of this kind, Wilkinson et al. (1989) isolated and evaluated the bacteria associated with Australian terrestrial orchids. They tested 7 strains of bacteria on the germination of Pterostylis vittata seeds and found some strains promoted germination while others suppressed seedling development. Other studies have looked at the influence of auxin producing bacteria on epiphytic orchids (Tsavkelova, Cherdyntseva, \& Netrusov, 2005; Tsavkelova, Cherdyntseva, Botina, \& Netrusov, 2007) as well as growth promoting bacteria (Pavlova et al., 2017). A study that specifically looked at seed germination of Dendrobium nobile orchids in co-occurrence with bacteria also found mixed results in terms of germination success depending on the bacterial strain (Tsavkelova et al., 2016). However, the study used a nutrient rich media instead of a mycorrhizal fungus to induce germination.

For our study we were interested in isolating bacteria from an adult orchid and testing the influence of these bacterial cultures on the germination of orchid seeds, which were symbiotically germinated with a mycorrhizal fungus. We used a minimal media (M9 $+\mathrm{ACC})$ to act as an initial screen in an attempt to isolate auxin-producing bacteria that could promote seed germination. Identifying bacterial cultures that positively impact symbiotically germinated orchid seeds could improve reintroduction efforts of rare or endangered orchids as there is evidence that orchids grown in symbiotic conditions are more resilient than those which have been reproduced through tissue culture or germinated non-symbiotically on nutrient-rich media (Teixeira da Silva et al., 2015).

\section{MATERIALS AND METHODS}




\section{Pilot study}

Initial trials of this study were conducted to determine which orchid and fungus combination would be used in the germination experiment with bacteria. Three species of orchids were used: Platanthera ciliaris (yellow fringed orchid), Prosthechea boothiana (dollar orchid), and Encyclia tampensis (butterfly orchid). The Platanthera seeds originated from an orchid nursery located in Belleville, Michigan (Great Lakes Orchids, MI, USA). The Prosthechea seeds were collected in Naples, Florida and the Encyclia seeds were from the Florida Panther National Wildlife Refuge, in Florida. The Prosthechea and Encyclia seeds are from a collection housed at Illinois College, which have been collected and stored by Dr. Larry Zettler and his lab. The Platanthera seeds were purchased from the nursery.

The fungal isolate was also sourced from the Zettler lab. The genus used was Tulasnella (fungal isolate ID 427). This fungus was originally isolated from orchid roots and now forms part of the Zettler lab's extensive orchid mycorrhizae collection. This particular isolate was selected due to its ability to facilitate germination in a wide variety of orchid species.

Each fungal-orchid pair was sown in Modified Oatmeal Agar with at least 3 replicates in June of 2017. They were then covered in aluminum foil for 3 weeks and stored at room temperature. An initial visual observation showed that the petri dishes containing the Platanthera seeds had signs of contamination and had to be removed from the trial. 142 days after sowing there were clear differences in the success in germination of each fungal-orchid pair. Prosthechea seeds showed a much higher germination rate and subsequent seedling development compared to Encyclia seeds. Based on this result we 
selected the combination of the Tulasnella fungus and Prosthechea boothiana orchid for subsequent use in the bacteria-fungi-orchid germination study.

Orchid seeds

The seeds from the orchid species selected for this study are from the epiphytic orchid Prosthechea boothiana (dollar orchid). The seeds were collected by Dr. Larry Zettler, cleaned, and stored at $-7 \mathrm{C}$. The dollar orchid is a small epiphytic plant that grows on small trees in southern Florida. It's known for its numerous discoid-shaped pseudobulbs, which inspired its common name.

Mycorrhizal fungus

The fungal genus Tulasnella belongs to the order Cantharellales within the division Basidiomycota. It is a widespread saprotrophic fungal genus that often forms a mycorrhizal relationship with orchids (Linde et al., 2017) . There are approximately 50 accepted species in the genus.

\section{Bacteria}

The bacteria used for this study were isolated from the root system of two 3-year old terrestrial orchids of the species Platantera ciliaris (yellow fringed orchid). The plants were purchased from a native orchid nursery in Michigan, U.S.A (Great Lakes Orchids

LLC.). These plants were grown in bog-like conditions, similar to their preferred natural habitat.

To prepare the plants for bacteria isolation, the roots were rinsed with sterile DI water to remove the soil. The roots were then cut from the plant and ground with a mortar and pestle (Figure 1). We added $562 \mathrm{mg}$ of ground root tissue to $562 \mathrm{ul}$ of phosphate-buffered 
saline (PBS) to prepare an initial suspension, which was used for ten-fold dilutions. An aliquot of $0.1 \mathrm{ml}$ was plated onto two different media: M9+ ACC minimal media and Tryptic Soy Agar (TSA). The M9+ACC media was used to select for isolates that could potentially have growth-promoting properties. Plant associated bacteria are often enriched for the gene encoding the enzyme 1-aminocyclopropane-1-carboxylate (ACC) deaminase $(a c d S)$. This gene is involved in the cleaving of plant-produced ACC, which is a precursor of ethylene, a stress hormone which affects the plants response to infection (Checcucci et al., 2017). In the M9+ ACC media, ACC was the only source of nitrogen, therefore acting as a screening element for bacteria enriched with the $a c d S$ gene. The plates were incubated at $28 \mathrm{C}$ until single colonies could be detected.

\section{Experimental design}

Three bacterial isolates were selected for sowing in petri dishes with an orchid mycorrhizal fungus and orchid seeds. Each isolate was sown at 3 different concentrations $\left(10^{-1}, 10^{-3}, 10^{-5}\right)$ after ten-fold dilutions were performed to standardize concentrations across isolates. This resulted in 9 treatments with 6 replicates each and 6 plates as controls, which did not have bacteria, for a total of 60 plates.

\section{Seed sowing}

Petri dishes with Modified Oatmeal Agar were prepared for seed sowing. For seed sterilization, $2.5 \mathrm{ml}$ of $5.25 \% \mathrm{NaClO}$ (bleach) was combined with $2.5 \mathrm{ml}$ of $95 \%$ Ethanol and mixed together with a small quantity of orchid seeds. This mixture was then left to rest for 3-4 minutes and then the liquid was removed. The seed pellet left over was rinsed twice with sterile DI water and a final $3 \mathrm{ml}$ of water was added to the seeds for sowing. Each plate was sowed with 10 drops of the seed + water solution. Once all the solution 
was used, another batch of sterilized seeds was prepared. This was repeated 5 times until all 60 plates were sowed. Each batch was identified with a label. The first batch of seeds to be sowed was S222, then S222dot, S222X, S222Smile and finally S222Star. Plates were sealed with parafilm, covered in aluminum foil and stored overnight at room temperature $(25 \mathrm{C})$.

\section{Fungal Inoculation}

24 hours after seed sowing, fungal plugs were added to the petri dishes with orchid seeds. The fungal isolates were cut from fungal cultures that had been sown on plates with Potato Dextrose Agar one month prior. Each plug measured approximately $1 \mathrm{~cm}$ by $1 \mathrm{~cm}$. Plates were sealed with parafilm, covered with aluminum foil and stored at room temperature.

\section{Bacterial inoculation}

5 days after fungal inoculation, bacteria were sown onto the plates. Each bacterial culture had been incubated for 24 hours prior in liquid culture (LB) at $28 \mathrm{C}$ on a shaker. We measured the optical density of each culture at A600 on a Spectrophotometer Nanodrop 2000C. This measurement was used to calculate and standardize the dilutions across bacterial cultures. Three dilutions were used to achieve 3 different concentrations for each bacterial isolate: $10^{-1}, 10^{-3}$ and $10^{-5}$.

Each plate received $25 \mathrm{ul}$ (3-4 drops) of one of the bacterial cultures at a specific concentration. The 6 control plates did not receive a bacterial inoculation. The plates were gently swirled to distribute and spread out the bacterial inoculant. Plates were sealed with parafilm and stored in the dark at room temperature. 


\section{Orchid-Fungus-Bacteria Incubation period}

5 days after bacterial inoculation, the plates were visually inspected to check on their status and to look for signs of germination. At this time, 3 plates showed contamination and were removed from the study ( 1 control plate, 1 plate with M9-18 of concentration $10^{-1}$, and 1 plate with M9-18 of concentration $10^{-3}$ ). Plates continued to be stored in the dark at room temperature.

15 days after bacterial inoculation, all plates were observed under a Leica Stereoscope and seeds were counted and categorized into Viable and Non-Viable. Viable Seeds had a visible embryo while Non-Viable Seeds did not have a visible embryo or had one that was very reduced and of a shriveled appearance (Figure 1). At this time, plates were left exposed to ambient light and room temperature.

30 days after bacterial inoculation, all plates were once again observed with a stereoscope and seeds were counted and if germination had occurred, the stage of germination was recorded. The germination process was divided into stages $0-5$, according to characteristics detailed in Stewart and Zettler, 2002.

45 days after bacterial inoculation, plates were once again counted and the germination stage for the seeds recorded.

\section{Statistical Analysis}

The data collected was analyzed with JMP Software, Version 14.0.1 by SAS Institute Inc., Cary, NC. One-way ANOVAs were performed with the germination counts by Bacteria culture and also by Seed batch. A post hoc Tukey HSD test was used for a pairwise comparison of means for the groups. 


\section{RESULTS}

\section{Bacteria isolation and identification}

Different colonies were selected for isolation and cultivation based on characteristics such as color, size and shape. We selected 10 colonies from the M9 media and 5 from the TSA media. Colonies were incubated in tubes at $28 \mathrm{C}$ in Lysogeny Broth (LB) on a shaker. Freezer stocks were created with $85 \%$ bacterial culture and $15 \%$ Dimethyl Sulfoxide (DMSO) and stored at -80 C. PCR was performed and the samples with the best results were sent for Sanger sequencing using the 16S rRNA gene primer at the University of Missouri-DNA core. Ultimately, 3 bacterial isolates were selected to be used in the study based on their BLAST matches: Isolate M9-13 (Paraburkholderia sedminicola); M9-18 (Variovorax boronicumulans); and M9-19 (Sphingomonas sp. strain BPM3).

\section{Orchid seed germination}

The first observation of the plates under the stereoscope was at 15 days after inoculation. After differentiating and counting seeds that had a healthy embryo, we calculated the percentage of seed viability for the Prosthechea boothiana seeds used in this study. The overall viability of the seeds was $61.2 \%$. We also calculated the range and median for the number of viable seeds sowed per plate across the 57 plates. The Minimum number of viable seeds counted on a plate was 40, while the Maximum was 449. The Median was calculated at 184 viable seeds per plate.

At 30 days after inoculation we could see germination occurring in most of the plates. We counted the number of seeds in each stage of germination and protocorm development using as a guideline the stages described in Stewart \& Zettler, 2002. Figure 2 depicts 
some of the stages found. We calculated the mean for each germination stage for each bacteria culture and its corresponding dilution. The results are shown in Figure 3. At 45 days after inoculation, we repeated the process and the results are shown in Figure 4. To standardize the number of viable seeds across all plates, we normalized the seed count values on a scale of 0 to 1 , We then graphed the normalized seed counts at 45 days and grouped them by Bacterial Culture, Dilution and Seed Sowing Batch (Figure 5). A One-Way Analysis of Variance (ANOVA) was performed on the normalized counts of germination stages by Bacterial Culture to determine if the different bacterial species had effects on the rates of germination. There was a significant effect of bacterial culture on stage 4 seed germination at $\mathrm{p}<0.05,[\mathrm{~F}(3,53)=3.4207, \mathrm{p}=0.0237]$. A Post hoc comparison using the Tukey HSD test indicated that the control was significantly different than all of the bacterial cultures (M9-13, M9-18, M9-19) (Figure 6). However, none of the bacterial cultures significantly differed from each other. This indicates that only the number of seeds in an advanced stage of germination (stage 4) was different amongst treatments and this was due to the control plates and not because of differences between bacterial cultures.

In addition, an ANOVA was conducted comparing the germination stages to the Seed Sowing Batch used for each plate. There was a significant effect at $p<0.05$ of the Seed Sowing Batch on stage 0 of germination $[F(4,52)=4.2218$, $p<.0001]$; stage $1[F(4,52)=$ $2.1135, \mathrm{p}<.0001]$; stage $2 \mathrm{~F}(4,52)=0.2093, \mathrm{p}<.0001]$; and stage $3 \mathrm{~F}(4,52)=0.0143$, $\mathrm{p}<.00412]$. There were no significant differences at stage 4 based on the Seed Sowing Batch (Figure 7). 
We conducted a post hoc comparison using the Tukey HSD test for each of the significant results. For stage 0 of germination, batches S222X and S222Star, as well as S222Smile and S222dot were not significantly different to each other. For stage 1, the pairs S222dot and S222smile were not significantly different; the same as S222Star and S222X. The batch S222 was significantly different to all the others. For stage 2, seed batches S222Star, S222X and S222 were not significantly different to each other. The pair S222smile and S222dot were also not significantly different. For stage 3 germination, only the seed batch S222Smile was significantly different to batch S222. These results indicate that for the beginning stages of germination (stages 0-3), the seed batch that was used to sow the orchid seeds had a significant impact on the rate of germination while the bacterial cultures did not. Once germination advanced to stage 4, then the absence of a bacterial culture had a significant effect while seed batch origin did not. The control plates had a significantly higher number of stage 4 seeds compared to the plates with bacterial culture, regardless of the bacterial isolate (M9-13, M9-18, M9-19).

\section{DISCUSSION}

This study did not find that any of the three bacterial cultures used, Paraburkholderia sedminicola (M9-13); Variovorax boronicumulans (M9-18); and Sphingomonas sp. strain BPM3 (M9-19), promoted the germination of Prosthechea boothiana seeds. However, the controls had significantly better germination results only at an advanced stage of germination, stage 4. Otherwise, there were no significant differences between the bacteria treatments and the controls.

In studies that looked at orchid seed germination, be it symbiotically with a fungus or non-symbiotically on nutrient-rich media, the addition of bacteria produced mixed 
results. Some taxa had a negative effect despite being identified as growth promoting bacteria due to the substantial amount of extracellular mucus produced in each plate (Tsavkelova et al., 2016). A study by Wilkinson et al. (1994) found that auxin (IAA) stimulated germination, whereas other hormones had negative effects.

Due to the variable results obtained by previous studies when adding bacteria, and the lack of significant differences in this study, we believe it would be beneficial to have a broader selection of bacterial isolates to use as treatments for future orchid germination experiments.

We also found that the seed-sowing batch had an important effect on the germination stages found on each plate at 45 days after inoculation (see Figure 5). The first batch of seeds to be sowed was labeled S222 and had the lowest number of germinated seeds of all the plates. Very few seeds from those plates germinated and advanced to later stages of protocorm development. These differences were statistically significant and dependent on the stage of germination. These results were unexpected as the process used to sow the seeds was standardized and consistent across all batches. We surmise that there may have been a small difference in the time allotted for seed sterilization with the $\mathrm{NaClO}$ (bleach) and ethanol mix, which may have resulted in the differences observed. The standard time used to sterilize these seeds was 3-4 minutes. However, there is a wide variation in times used depending on the study species as well as sterilization technique (Rasmussen et al., 2015). Some studies have shown ranges from 5 min to longer than 8 hours to achieve optimum germination rates (Rasmussen, 1995; Yeung, 2017). Despite this broad variation in surface sterilization times used in different studies, it would appear, based on our results, that a change in 1-2 minutes could have impacted germination rates. An 
additional benefit to the surface sterilization treatment with a solution of $\mathrm{NaClO}$ and ethanol, is that it produces scarification of the seed coat, which has been shown to increase germination (Rasmussen, 1995). An insufficient period of soaking of the orchid seeds in the sterilizing solution could have impeded proper scarification and therefore reduced germination rates for that batch of seeds. It would be important to consider this implication in future studies.

In conclusion, we were able to successfully isolate bacterial cultures from orchid roots and conduct a symbiotic germination experiment with mycorrhizal fungi and endophytic root bacteria. To find beneficial bacteria that stimulate orchid seed germination and can be used to improve orchid reintroduction efforts, a broader survey of bacteria is necessary. This will increase the likelihood of finding plant growth promoting bacteria and mycorrhizal helper bacteria that can positively impact orchid seed germination. 


\section{LITERATURE CITED}

Bonfante, P., \& Anca, I.-A. (2009). Plants, mycorrhizal fungi, and bacteria: a network of interactions. Annual Review of Microbiology, 63, 363-83. http://doi.org/10.1146/annurev.micro.091208.073504

Buée, M., de Boer, W., Martin, F., van Overbeek, L., \& Jurkevitch, E. (2009). The rhizosphere zoo: An overview of plant-associated communities of microorganisms, including phages, bacteria, archaea, and fungi, and of some of their structuring factors. Plant and Soil, 321(1-2), 189-212. http://doi.org/10.1007/s11104-009-9991-3

Cameron, D. D., Leake, J. R., \& Read, D. J. (2006). Mutualistic mycorrhiza in orchids: evidence from plant-fungus carbon and nitrogen transfers in the green-leaved terrestrial orchid Goodyera repens. The New Phytologist, 171(2), 405-16. http://doi.org/10.1111/j.1469-8137.2006.01767.x

Checcucci, A., Azzarello, E., Bazzicalupo, M., Carlo, A. De, Emiliani, G., Mancuso, S., ... Mengoni, A. (2017). Role and regulation of ACC deaminase gene in Sinorhizobium melilotr: Is it a symbiotic, rhizospheric or endophytic gene? Frontiers in Genetics. http://doi.org/10.3389/fgene.2017.00006

Dearnaley, J. D. W. (2007). Further advances in orchid mycorrhizal research. Mycorrhiza, 17(6), 475-486. http://doi.org/10.1007/s00572-007-0138-1

Deveau, A., \& Labbé, J. (2016). Mycorrhiza helper bacteria. In Molecular Mycorrhizal Symbiosis (pp. 437-450). http://doi.org/10.1002/9781118951446.ch24

Fracchia, S., Aranda-Rickert, A., Flachsland, E., Terada, G., \& Sede, S. (2014). Mycorrhizal compatibility and symbiotic reproduction of Gavilea australis, an endangered terrestrial orchid from south Patagonia. Mycorrhiza, 24(8), 627634. http://doi.org/10.1007/s00572-014-0579-2

Glick, B. R. (2012). Plant Growth-Promoting Bacteria: Mechanisms and Applications. Scientifica, 2012, 1-15. http://doi.org/10.6064/2012/963401

Jacquemyn, H., Brys, R., Merckx, V. S. F. T., Waud, M., Lievens, B., \& Wiegand, T. 
(2014). Coexisting orchid species have distinct mycorrhizal communities and display strong spatial segregation. New Phytologist, 202(2), 616-627. http://doi.org/10.1111/nph.12640

Linde, C. C., May, T. W., Phillips, R. D., Ruibal, M., Smith, L. M., \& Peakall, R. (2017). New species of Tulasnella associated with terrestrial orchids in Australia. IMA Fungus. http://doi.org/10.5598/imafungus.2017.08.01.03

Pandey, M., Sharma, J., Taylor, D. L., \& Yadon, V. L. (2013). A narrowly endemic photosynthetic orchid is non-specific in its mycorrhizal associations. Molecular Ecology, 22(8), 2341-2354. http://doi.org/10.1111/mec.12249

Pavlova, A. S., Leontieva, M. R., Smirnova, T. A., Kolomeitseva, G. L., Netrusov, A. I., \& Tsavkelova, E. A. (2017). Colonization strategy of the endophytic plant growthpromoting strains of Pseudomonas fluorescens and Klebsiella oxytoca on the seeds, seedlings and roots of the epiphytic orchid, Dendrobium nobile Lindl. Journal of Applied Microbiology, 123(1), 217-232.

http://doi.org/10.1111/jam.13481

Rasmussen, H. N. (1995). Terrestrial orchids from seed to mycotrophic plant. Cambridge University Press. Retrieved from http://eds.b.ebscohost.com.proxy.mul.missouri.edu/eds/detail/detail?vid=5\&s id $=88577216-3$ ddc-405d-81554ddc23442aee\%40sessionmgr104\&bdata=JnNpdGU9ZWRzLWxpdmUmc2Nvc GU9c210ZQ\%3D\%3D\#AN=edshlc.005467097.7\&db=edshlc

Rasmussen, H. N., Dixon, K. W., Jersáková, J., \& Těšitelová, T. (2015). Germination and seedling establishment in orchids: A complex of requirements. Annals of Botany. http://doi.org/10.1093/aob/mcv087

Selosse, M.-A. (2014). The latest news from biological interactions in orchids: in love, head to toe. New Phytologist, 202(2), 337-340.

Selosse, M.-A., Boullard, B., \& Richardson, D. (2011). Noël Bernard (1874-1911): orchids to symbiosis in a dozen years, one century ago. Symbiosis, 54(2), 61-68. http://doi.org/10.1007/s13199-011-0131-5 
Sharma, J., Zettler, L. W., Van Sambeek, J. W., Ellersieck, M. R., \& Starbuck, C. J. (2003). Symbiotic Seed Germination and Mycorrhizae of Federally Threatened Platanthera praeclara (Orchidaceae). The American Midland Naturalist, 149(1), 104-120. http://doi.org/10.1674/00030031(2003)149[0104:SSGAMO]2.0.CO;2

Shekhovtsova, N. V., Marakaev, O. A., Pervushina, K. A., \& Osipov, G. A. (2013). The underground organ microbial complexes of moorland spotted orchid Dactylorhiza maculata (L.) Soó (Orchidaceae). Advances in Bioscience and Biotechnology, 04(07), 35-42. http://doi.org/10.4236/abb.2013.47A2005

Smith, S. E., \& Read, D. (2008). Mycorrhizal Symbiosis. Mycorrhizal Symbiosis. http://doi.org/10.1016/B978-012370526-6.50015-5

Stewart, S. L., \& Zettler, L. W. (2002). Symbiotic germination of three semi-aquatic rein orchids (Habenaria repens, $\mathrm{H}$. quinquiseta, $\mathrm{H}$. macroceratitis) from Florida. Aquatic Botany, 72(1), 25-35. http://doi.org/10.1016/S0304-3770(01)002145

Stöckel, M., Těšitelová, T., Jersáková, J., Bidartondo, M. I., \& Gebauer, G. (2014). Carbon and nitrogen gain during the growth of orchid seedlings in nature. New Phytologist, 202(2), 606-15. http://doi.org/10.1111/nph.12688

Teixeira da Silva, J. A., Tsavkelova, E. A., Zeng, S., Ng, T. B., Parthibhan, S., Dobránszki, J., ... Rao, M. V. (2015). Symbiotic in vitro seed propagation of Dendrobium: fungal and bacterial partners and their influence on plant growth and development. Planta, 242(1), 1-22. http://doi.org/10.1007/s00425-015-23019

Tsavkelova, E. A., Cherdyntseva, T. A., Botina, S. G., \& Netrusov, A. I. (2007). Bacteria associated with orchid roots and microbial production of auxin. Microbiological Research, 162(1), 69-76. http://doi.org/10.1016/j.micres.2006.07.014

Tsavkelova, E. A., Cherdyntseva, T. A., \& Netrusov, A. I. (2005). Auxin production by bacteria associated with orchid roots. Microbiology, 74(1), 46-53. http://doi.org/10.1007/s11021-005-0027-6 
Tsavkelova, E. A., Egorova, M. A., Leontieva, M. R., Malakho, S. G., Kolomeitseva, G. L., \& Netrusov, A. I. (2016). Dendrobium nobile Lindl. seed germination in cocultures with diverse associated bacteria. Plant Growth Regulation, 80(1), 7991. http://doi.org/10.1007/s10725-016-0155-1

Wilkinson, K. G., Dixon, K., \& Sivasithamparam, K. B. (1989). Interaction of soil bacteria, mycorrhizal fungi and orchid seed in relation to germination of Australian orchids. New Phytologist, 112(3), 429-435 EP-. http://doi.org/10.1111/j.1469-8137.1989.tb00334.x

Wilkinson, K. G., Dixon, K. W., Sivasithamparam, K., \& Ghisalberti, E. L. (1994). Effect of IAA on symbiotic germination of an Australian orchid and its production by orchid-associated bacteria. Plant and Soil. http://doi.org/10.1007/BF00009292

Yeung, E. C. (2017). A perspective on orchid seed and protocorm development. Botanical Studies, 58(1), 33. http://doi.org/10.1186/s40529-017-0188-4

Zettler, L. W., Stewart, S. L., Bowles, M. L., \& Karel, A. (2001). Mycorrhizal Fungi and Cold-assisted Symbiotic Germination of the Federally Threatened Eastern Prairie Fringed Orchid, Platanthera leucophaea (Nuttall) Lindley. American Midland Naturalist, 145(1), 168-175. http://doi.org/10.1674/00030031(2001)145[0168:MFACAS]2.0.CO;2 


\section{FIGURES}
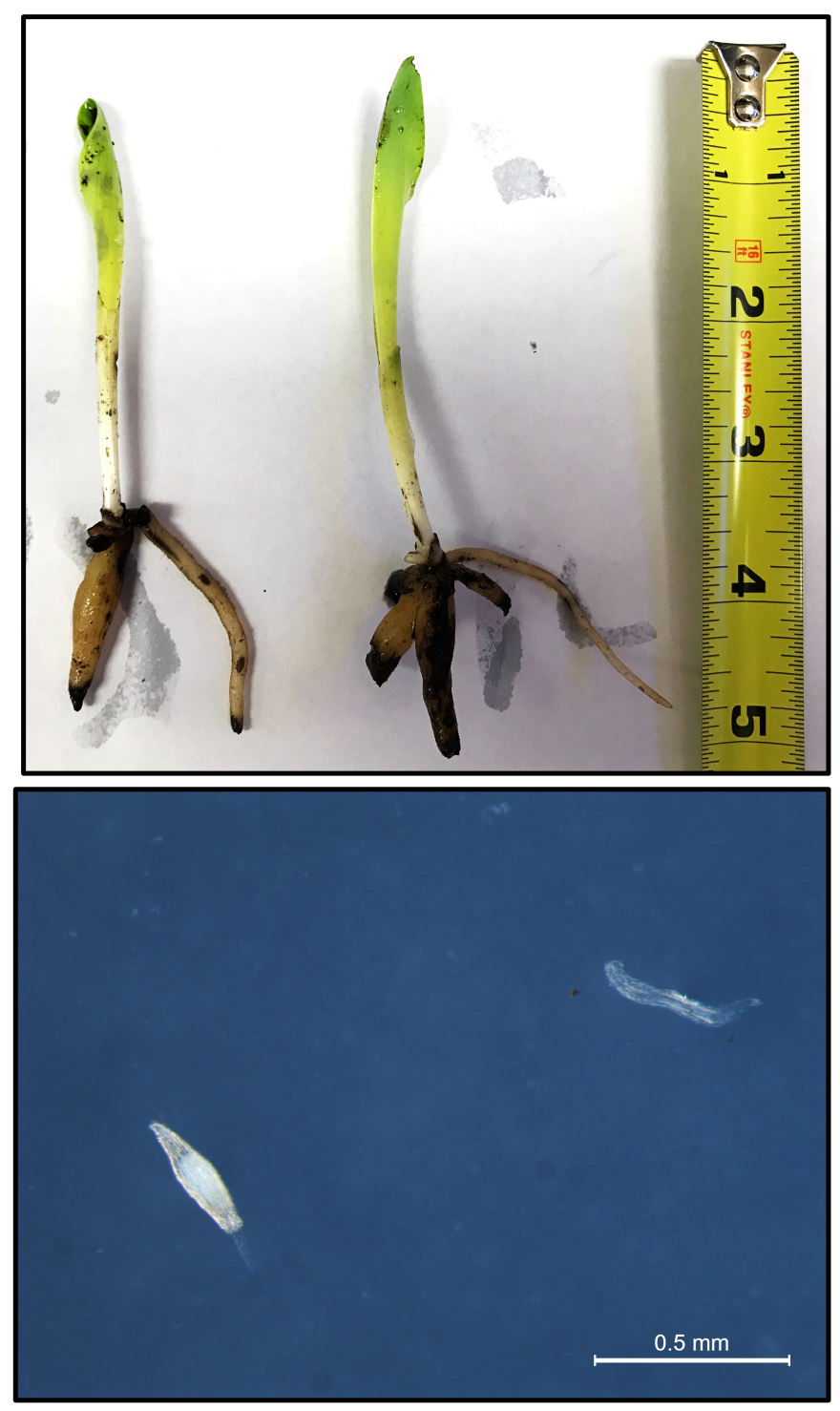

Figure 1. Top- Platanthera ciliaris plants before roots were removed and ground for bacteria isolation.

Bottom- Stereoscope image of a seed with a healthy, viable embryo on the left and a seed without an embryo and therefore, non-viable to the right. 


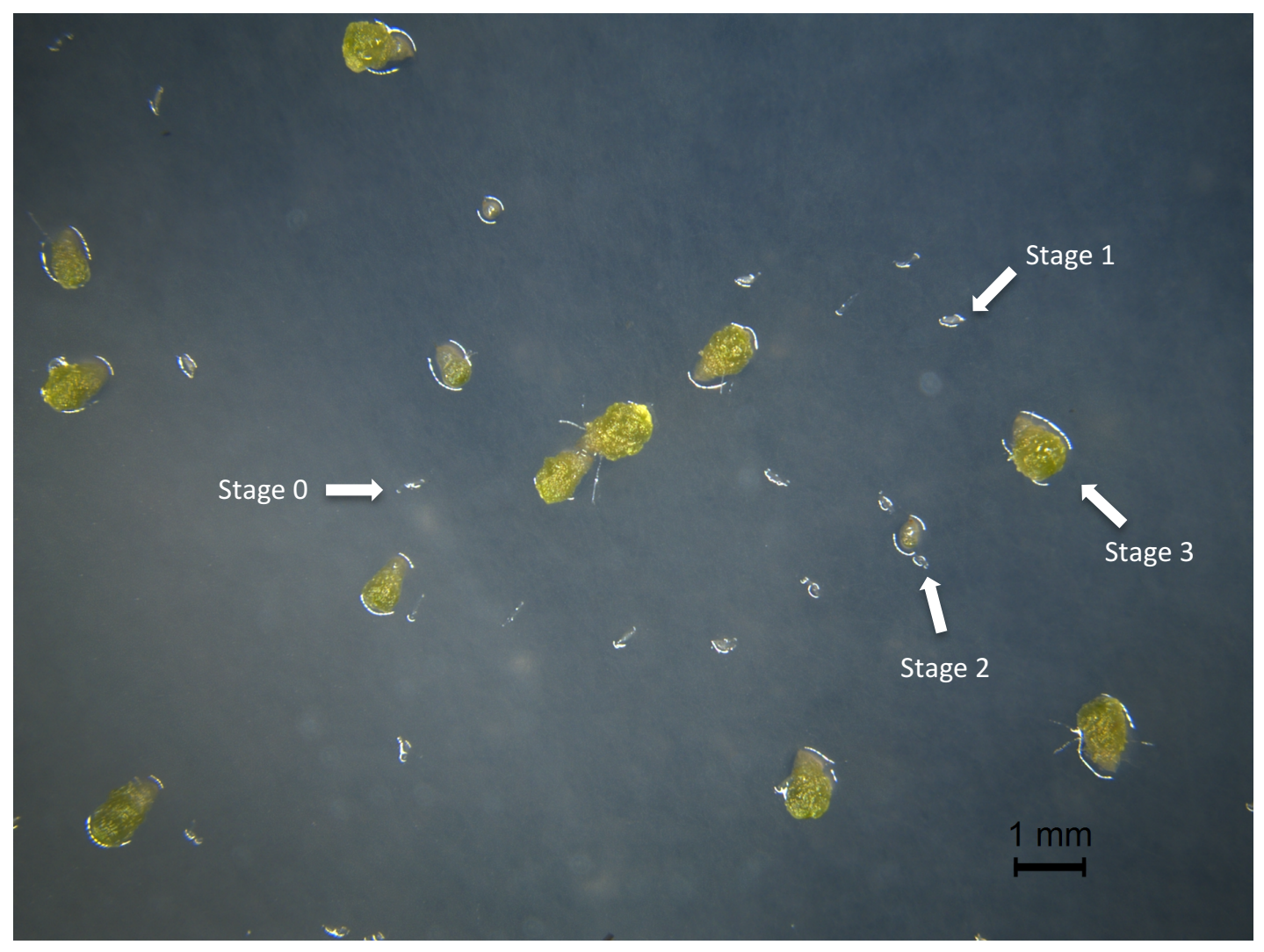

Figure 2. Seed germination and protocorm stages of Prosthechea boothiana. Stage $0=$ no germination; Stage 1= germination; Stage 2= embryo ruptures testa; Stage $3=$ appearance of a protomeristem; Scale bar=1 $\mathrm{mm}$. 


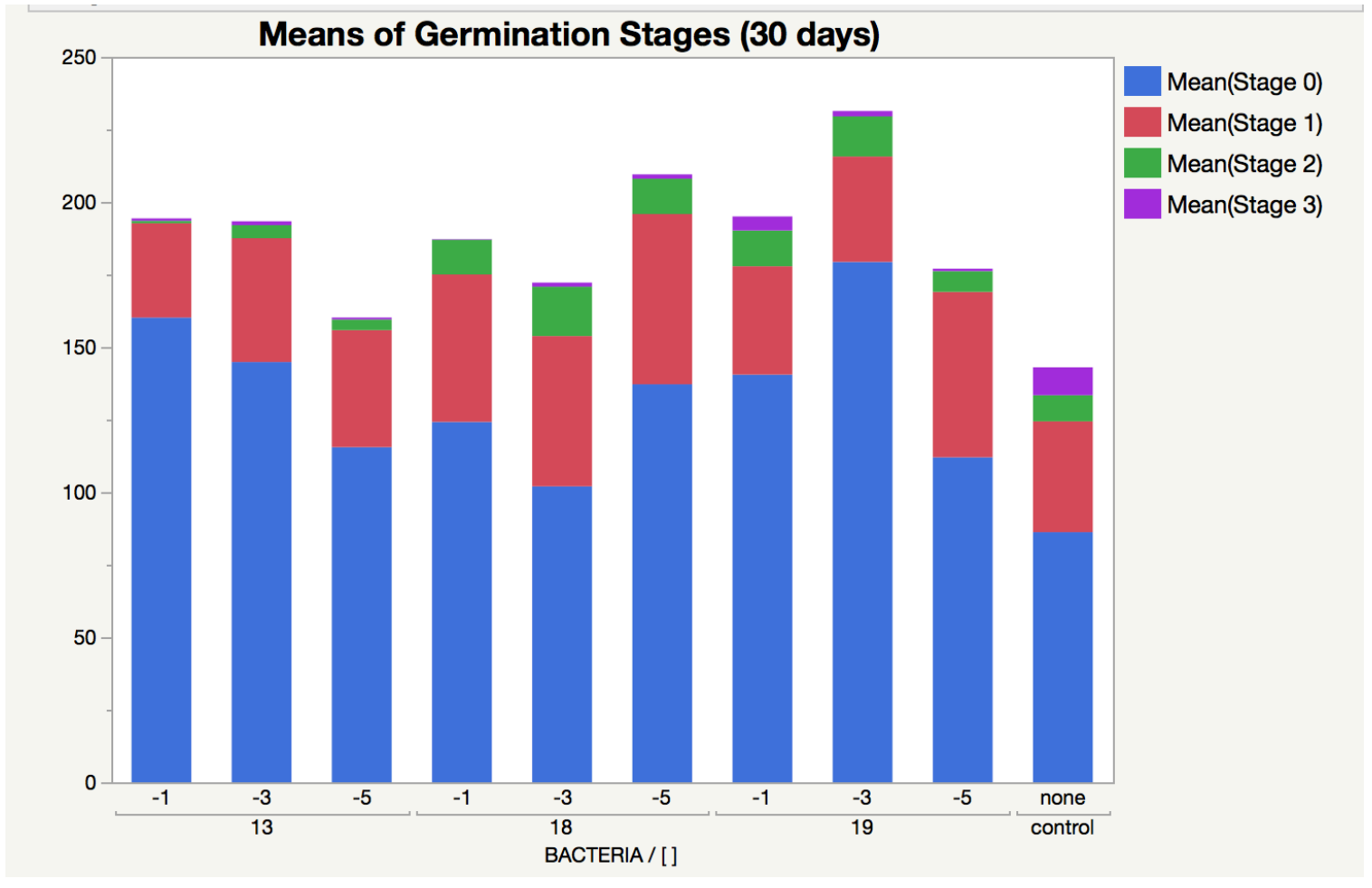

Figure 3. Means of germination stages at 30 days after bacterial inoculation grouped by bacterial isolate and dilution of bacterial inoculant 


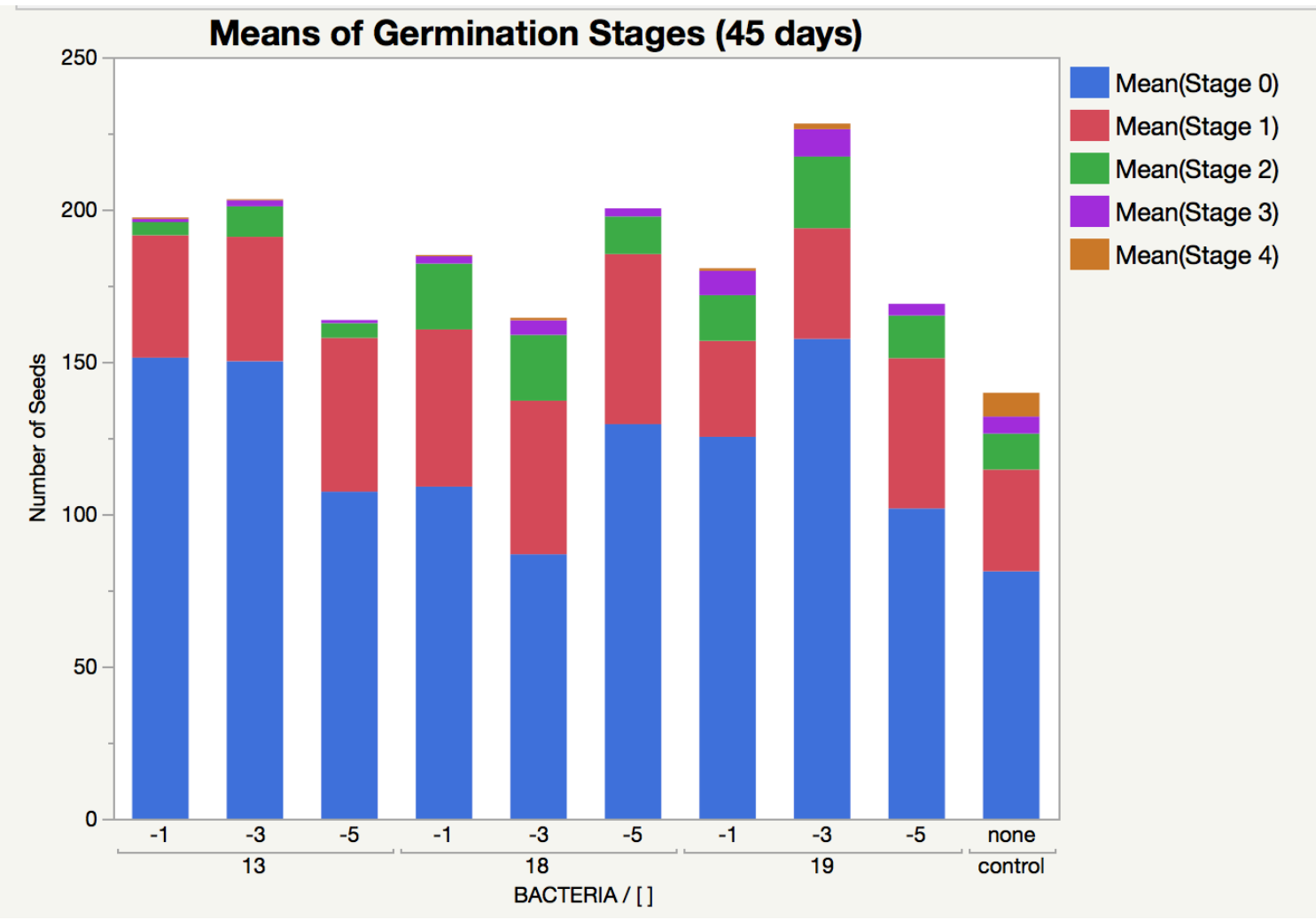

Figure 4. Means of germination stages at 45 days after bacterial inoculation grouped by bacterial isolate and dilution of bacterial inoculant 


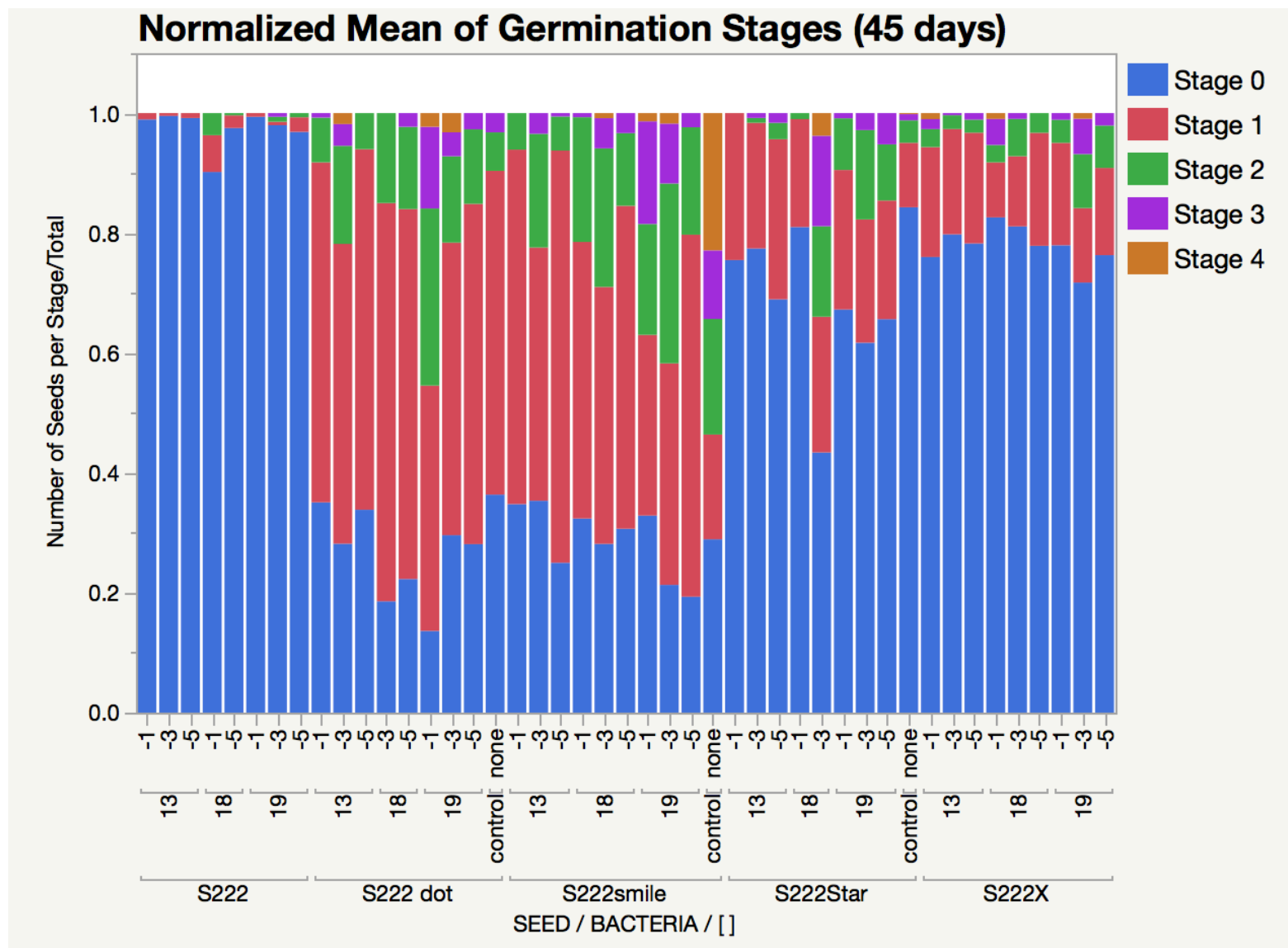

Figure 5. Normalized mean of germination stages grouped by Seed Batch, Bacterial Culture and Dilution of bacterial inoculant 

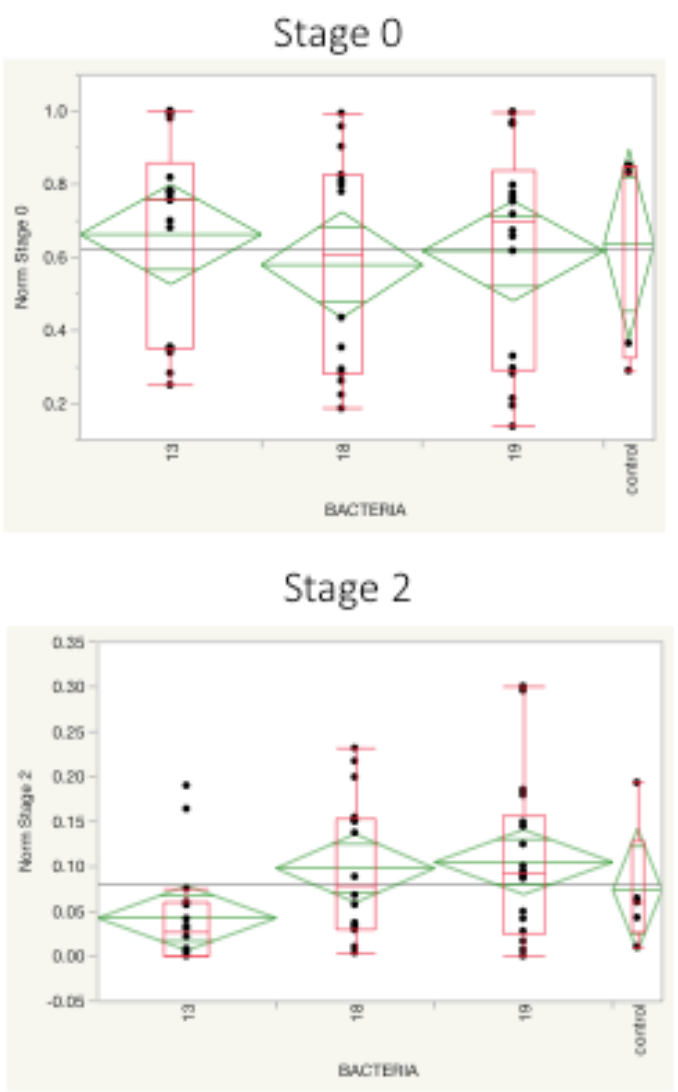

Stage 4

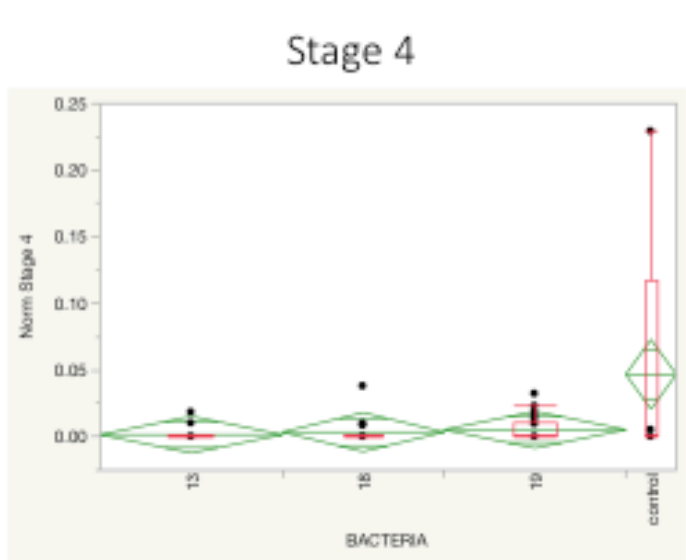

Stage 1

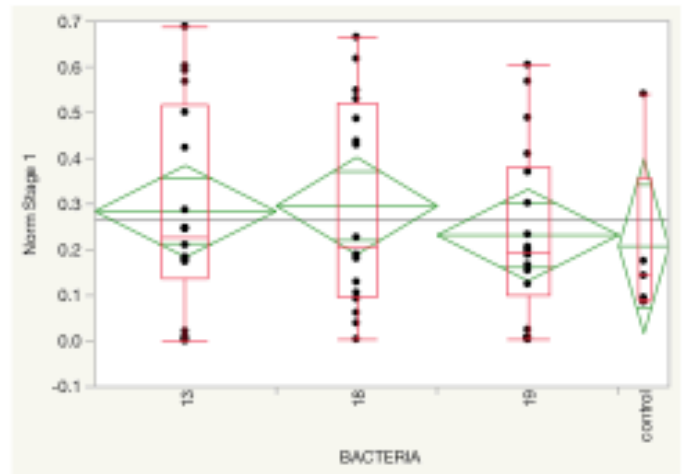

Stage 3

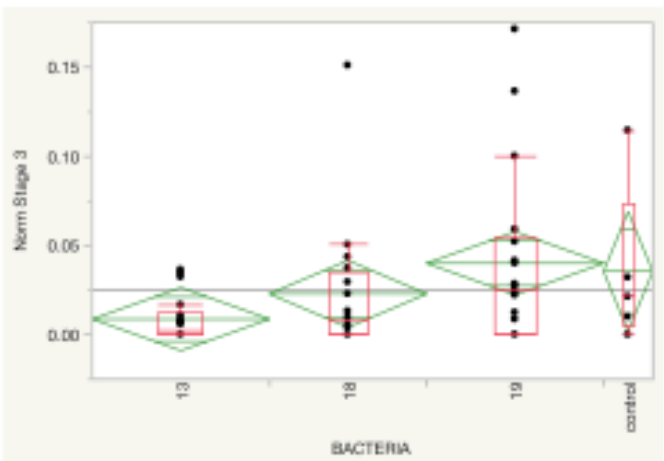

Figure 6. Results of One-way ANOVA by Bacteria Culture 
Stage 0

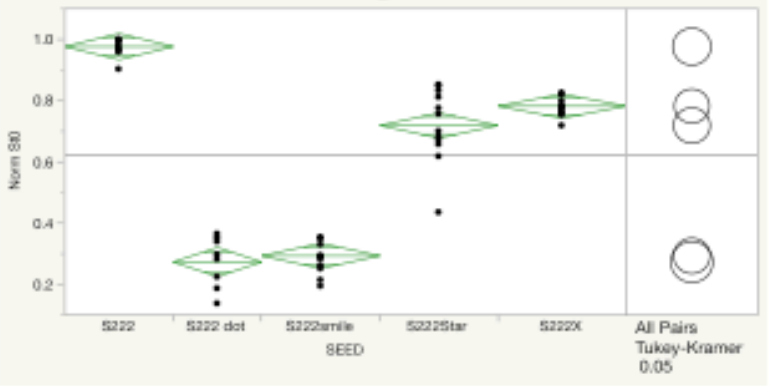

Stage 2

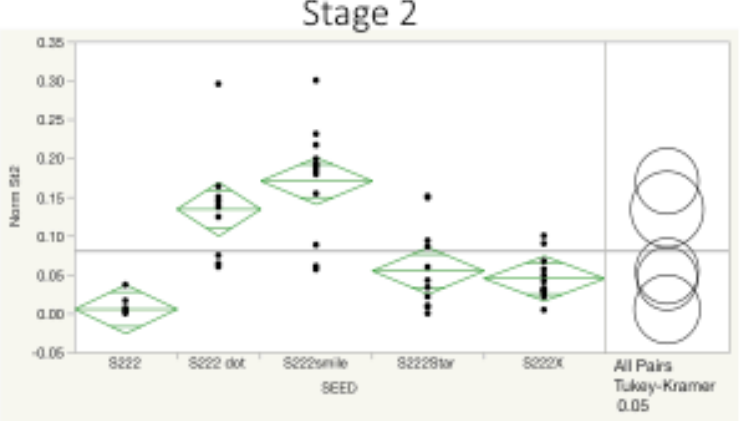

Stage 4

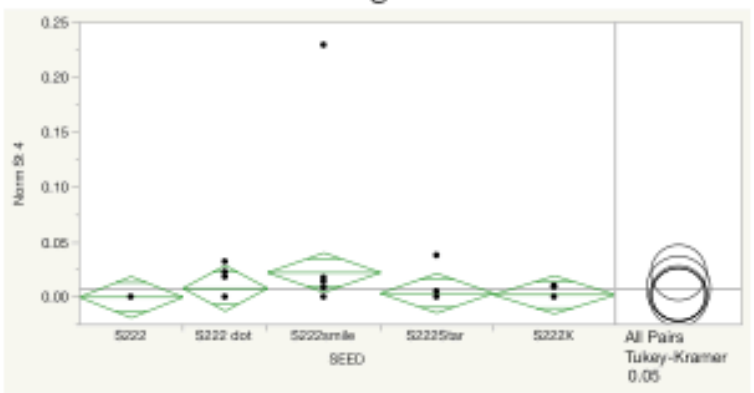

Stage 1

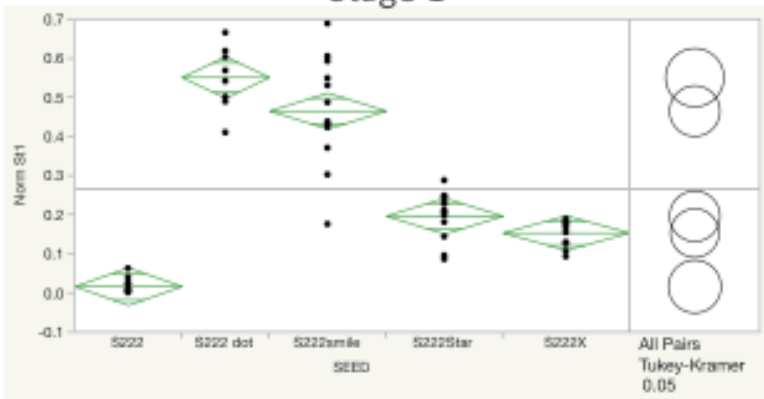

Stage 3

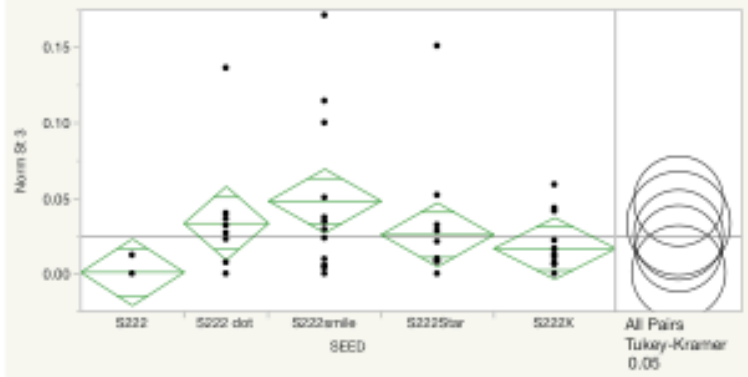

Figure 7. Results of One-way ANOVA by Seed Batch. 


\section{VITA}

Andrea Ravelo was born in Cordoba, Argentina but has lived most of her life in the state of Missouri in the US. She studied Biology at the Universidad Nacional de Cordoba in Argentina for her undergraduate degree. She then continued her studies at the University of MissouriColumbia, obtaining a Master's degree in Curriculum and Instruction with an emphasis in secondary science teaching. She taught for nine years at Fulton High School, where she taught all levels of Spanish as well as several different classes within the Science department. During that time, she completed a second Master's degree in TESOL, also at the University of MissouriColumbia. Andrea left teaching at the high school level to start her PhD in the department of

Biological Sciences. While conducting research for her dissertation, she also was a teaching assistant for the lab section of Bio 1020, Plant Systematics and Botany. Teaching continues to be an interest of hers and she plans to implement her teaching and research skills in the future. 